Portland State University

PDXScholar

\title{
Hydrologic Trends and Spatial Relationships of Stream Temperature and Discharge in Urbanizing Watersheds in the Portland Metropolitan Area of the Pacific Northwest
}

Emma Lee Brenneman

Portland State University

Follow this and additional works at: https://pdxscholar.library.pdx.edu/open_access_etds

Part of the Geography Commons, and the Hydrology Commons Let us know how access to this document benefits you.

\section{Recommended Citation}

Brenneman, Emma Lee, "Hydrologic Trends and Spatial Relationships of Stream Temperature and Discharge in Urbanizing Watersheds in the Portland Metropolitan Area of the Pacific Northwest" (2019). Dissertations and Theses. Paper 5128.

https://doi.org/10.15760/etd.7007

This Thesis is brought to you for free and open access. It has been accepted for inclusion in Dissertations and Theses by an authorized administrator of PDXScholar. Please contact us if we can make this document more accessible: pdxscholar@pdx.edu. 
Hydrologic Trends and Spatial Relationships of Stream Temperature and Discharge in Urbanizing Watersheds in the Portland Metropolitan Area of the Pacific Northwest

by

Emma Lee Brenneman

A thesis submitted in partial fulfillment of the requirements for the degree of

Master of Science

in

Geography

Thesis Committee:

Heejun Chang, Chair

Alida Cantor

Andres Holz

Portland State University

2019 


\begin{abstract}
This study explores various relationships of streamflow and stream temperature over the Portland Metropolitan area in two urbanizing watersheds. Four stream temperature and discharge metrics were derived from USGS stream gauges in the Tualatin River and Johnson Creek watersheds and were analyzed for monotonic trends. Additionally, this study explored the sensitivity of stream temperature to air temperature and streamflow to assess where locations throughout the watershed may be more sensitive to these changes. Relationships among stream temperature, air temperature, and streamflow were assessed using linear and nonlinear bivariate regression for yearly values and summer months. Additionally, this study seeks to explain the spatial variations of thermal sensitivity throughout the Johnson Creek watershed using predictors derived using different weights at the contributing watershed scale and the buffer scale. Results indicate significant increasing trends in stream temperature metrics at various locations throughout the study area. Decreasing baseflow does not appear to coincide with increasing temperature metrics. Significant increasing trends in October and November are present in runoff ratio and TQmean. In both watersheds, air temperature appears to have a greater influence than streamflow on stream temperature, though the addition of discharge generally improves model fit. Increasing thermal sensitivity in Johnson Creek is related to increasing and decreasing standard deviation of slope, increasing mean slope, increasing open water and wetlands, less forest area, increasing standard deviation of NDVI, decreasing restoration area, increasing gray infrastructure density, and increasing upstream flow length. At most, ordinary least squares explained $30 \%$ of the variance in
\end{abstract}


thermal sensitivity when only including stream temperature monitoring locations in the mainstem of the creek. Modelling tributary only stream temperature monitoring locations used a variety of watershed, buffer-scale, areal average and inverse distance weighted variables. The findings of this study highlight the importance of temporal scale and complex hydro-climatic influences along an urban-rural gradient in assessing patterns of discharge and temperature. These results have important implications for watershed managers, local agencies, and stakeholders who have worked to restore Johnson Creek and help to guide future water quality planning throughout the watershed. 


\section{Acknowledgements}

A very big thank you to my advisor, Dr. Heejun Chang, who was always levelheaded and optimistic despite my constant self-deprecating inner monologue. Without his guidance, I would have been lost throughout this process. I have so much gratitude to my colleagues and friends Katelyn Michelson, Benjamin Fahy, Janardan Mainali, Junjie Chen, Daniel Larson, and especially Ashley Baker, for their guidance and laughter, assurance, and with whom I could commiserate. Thank you in addition to my committee members, Dr. Andres Holz and Dr. Alida Cantor for their valuable input.

A very big thank you to my emotional support dog Liza Minelli, I should have gotten you sooner! Additionally, a very sincere thank you to Matthew, who was my primary support system during this process. Your encouragement, reassurance, love and patience were vital to my success. I don't think either of us knew what we were getting into. A very sincere thank you to Michelle, Anders, June, and Raymond for being the best family I could ever hope for. I love you all so much. I also want to give thanks to the memory of Todd Andrew Brenneman. I strive to make you proud every day. I wish we could share this milestone together. I love you.

Thank you to the Urban Resilience to Extremes Sustainability Research Network under National Science Foundation grant AGS-1444755. It has been inspiring to collaborate, travel and network with a wonderful group of friendly, passionate researchers across the globe 
Table of Contents

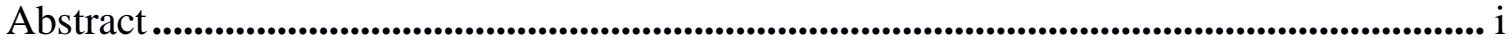

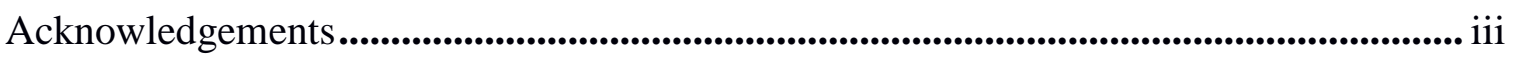

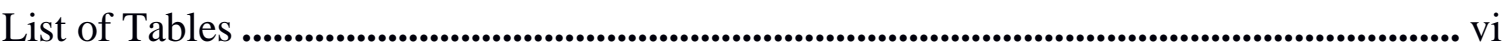

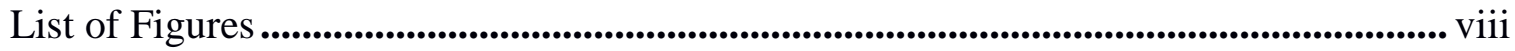

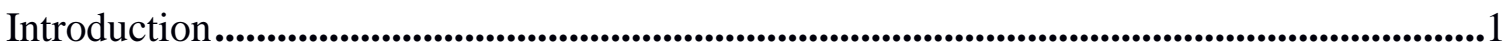

\section{Hydrologic Trends of Discharge and Stream Temperature and Assessment of}

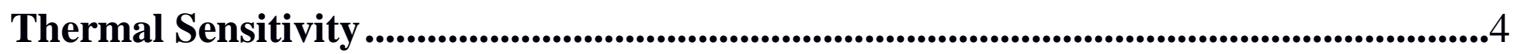

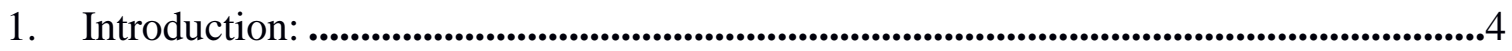

2. Study Area

3. Data and Methods ........................................................................................................13

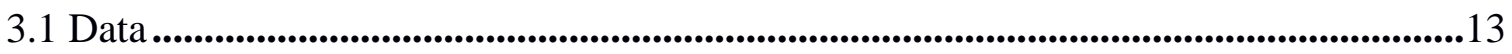

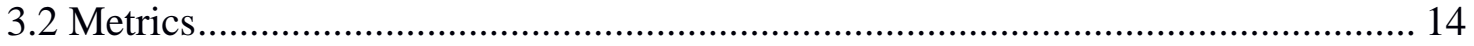

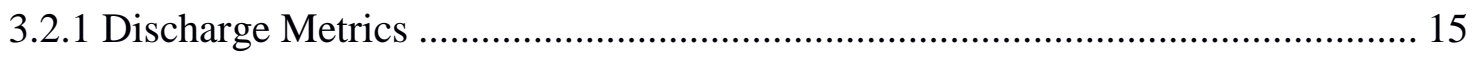

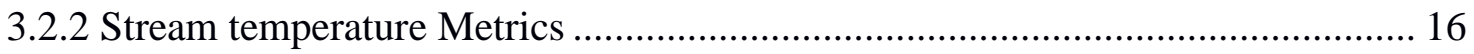

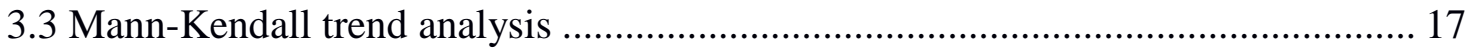

3.4 Quantifying thermal sensitivity with nonlinear regression ................................ 18

4. Results........................................................................................................................23

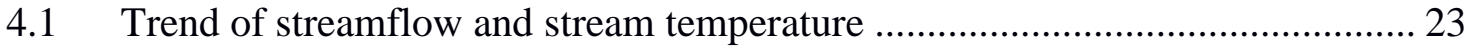

4.2 Thermal sensitivity and nonlinear regression.............................................. 35

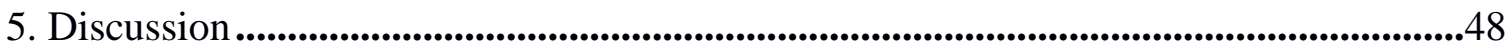

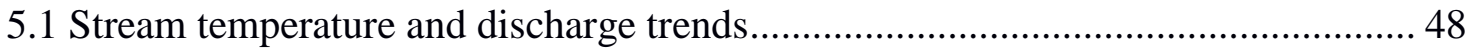

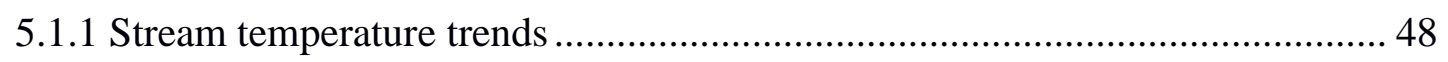

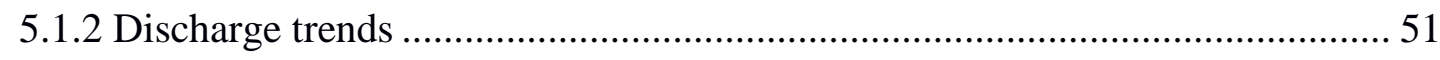

5.2 Relation between stream temperature, air temperature and discharge ................... 53

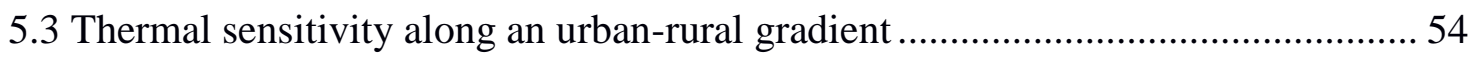

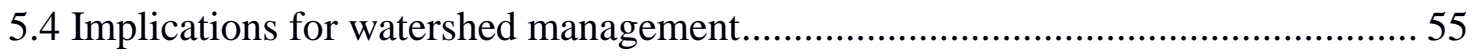

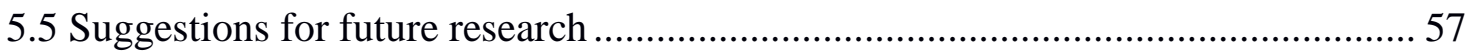

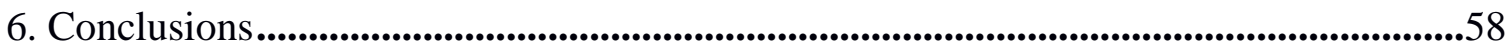

II. Spatial analysis of thermal sensitivity in Johnson Creek Watershed, Oregon .....60 


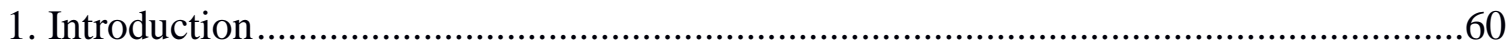

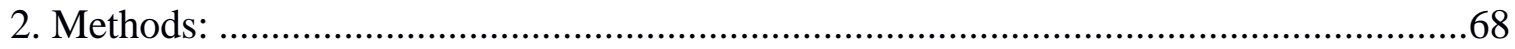

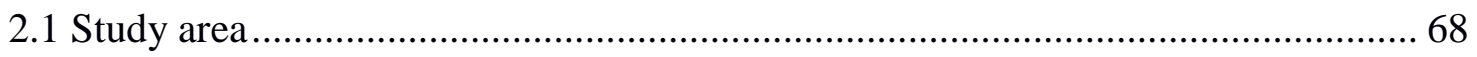

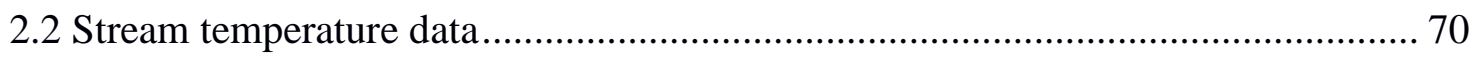

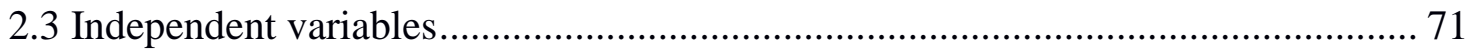

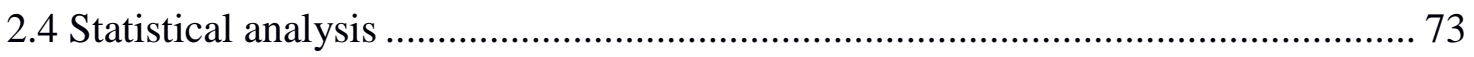

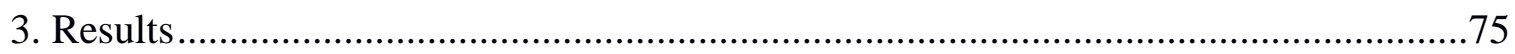

3.1 Spatial variation of mean thermal sensitivity ..................................................... 75

3.2 Correlation between thermal sensitivity and independent variables ........................ 76

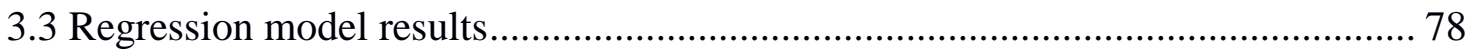

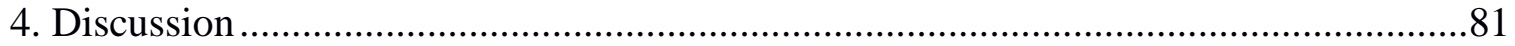

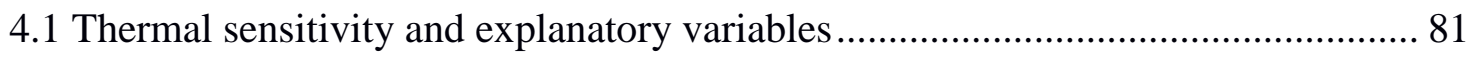

4.1.1 Significant correlations not included in spatial models ...................................... 81

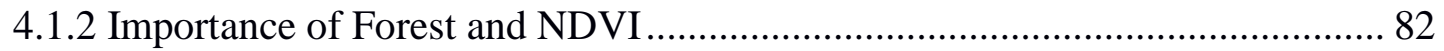

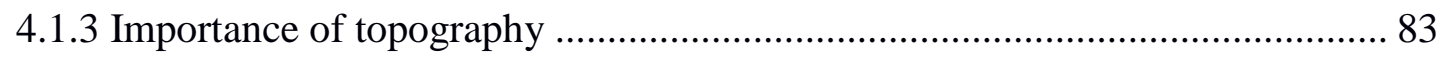

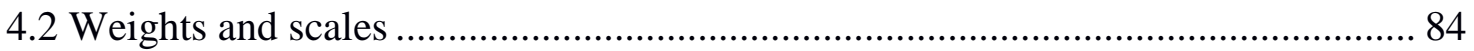

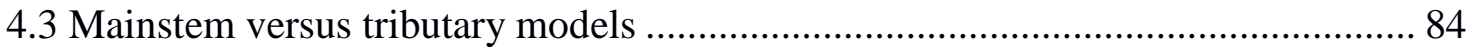

4.4 Importance of best management practices on thermal sensitivity........................... 85

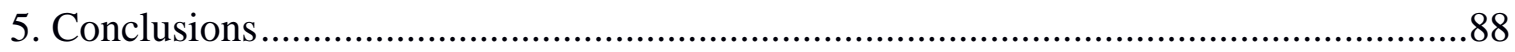

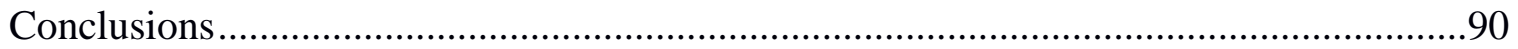

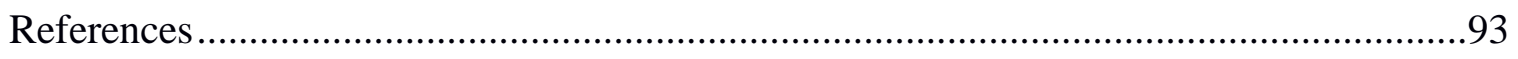

Appendix: Mann-Kendall trend analyses for entire period of record ..............................104 


\section{List of Tables}

Table 1: Land use and watershed characteristics between the Tualatin River and Johnson

Creek study areas. .............................................................................. 12

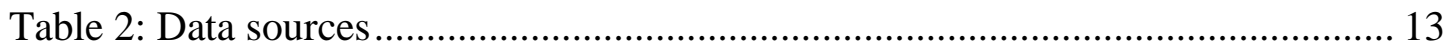

Table 3: Metrics derived from stream temperature, discharge, and precipitation data14

Table 4: Mann-Kendall test results for 7 -day moving average of daily maximum temperature October 2002-September 2018. $\tau$ values in red indicate a significant increasing trend and values in blue indicate a significant decreasing trend. $\mathrm{p}$ is significance level where values are significant at $* 0.10, * * 0.05, * * * 0.01$. Stations are listed from highest to lowest in each watershed 24

Table 5: Mann-Kendall test results for 7 -day moving average of daily minimum temperature October 2002-September 2018. $\tau$ values in red indicate a significant increasing trend and values in blue indicate a significant decreasing trend. $\mathrm{p}$ is significance level where values are significant at $* 0.10, * * 0.05, * * * 0.01 \ldots .25$

Table 6: Mann-Kendall test results for the total number of days above 17.8C October 2002- September 2018. $\tau$ values in red indicate a significant increasing trend and values in blue indicate a significant decreasing trend. $\mathrm{p}$ is significance level where values are significant at $* 0.10, * * 0.05, * * * 0.01$ 26

Table 7: Mann-Kendall test results for thermal flashiness October 2002- September 2018. $\tau$ values in red indicate a significant increasing trend and values in blue indicate a significant decreasing trend. $\mathrm{p}$ is significance level where values are significant at $* 0.10, * * 0.05, * * * 0.01$

Table 8: Mann-Kendall test results for baseflow index October 2002-September 2018. $\tau$ values in red indicate a significant increasing trend and values in blue indicate a significant decreasing trend. $\mathrm{p}$ is significance level where values are significant at $* 0.10, * * 0.05, * * * 0.01$ 28

Table 9: Mann-Kendall test results for the Richards-Baker flashiness index October 2002- September 2018. $\tau$ values in red indicate a significant increasing trend and values in blue indicate a significant decreasing trend. $\mathrm{p}$ is significance level where values are significant at $* 0.10, * * 0.05, * * * 0.01$

Table 10: Mann-Kendall test results for runoff ratio October 2002- September 2018. $\tau$ values in red indicate a significant increasing trend and values in blue indicate a significant decreasing trend. $\mathrm{p}$ is significance level where values are significant at $* 0.10, * * 0.05, * * * 0.01$

Table 11: Mann-Kendall test results for TQmean October 2002- September 2018. $\tau$ values in red indicate a significant increasing trend and values in blue indicate a significant decreasing trend. $\mathrm{p}$ is significance level where values are significant at $* 0.10, * * 0.05, * * * 0.01$

Table 12: Mann-Kendall test results for precipitation and air temperature at Portland International AirportOctober 2002- September 2018. $\tau$ values in red indicate a 
significant increasing trend and values in blue indicate a significant decreasing trend. $\mathrm{p}$ is significance level where values are significant at $* 0.10, * * 0.05$, $* * * 0.01$

Table 13: Root mean square error for each model for each station. Values in bold indicate the lowest RMSE stream temperature models including only air temperature or including both air temperature and discharge, for yearly and summer data. Values with * indicate the overall, lowest RMSE for each station. LM: linear model, NLS: Nonlinear model, 7Avg: seven day moving average data. 42

Table 14: Thermal sensitivity values for each station. The highest thermal sensitivity value is in bold for each station for all models. LM: linear model, NLS: Nonlinear model, 7Avg: seven day moving average data

Table 15: Results of linear models with $\mathrm{R}^{2}$ values and standardized coefficients with significance level (***p-value 0.01). LM A - 7Avg: Linear model with 7 day moving average of air temperature. LM Q - 7Avg: Linear model with 7 day moving average of air temperature and discharge. LM A - Daily: Linear model with raw daily values of air temperature. LM Q - Daily: Linear model with raw daily values of air temperature and discharge. 44

Table 16: Relevant literature review and relation to research ..................................6 64

Table 17: Explanatory variables used in analysis

Table 18: Correlations between thermal sensitivity and explanatory variables. P-value $* * *=0.01, * *=0.05, *=0.1, \wedge$ Mean Air Temp at site. 76

Table 19: Regression model results top: Watershed areal average, watershed inverse distance weighted versus stream buffer areal average and stream buffer IDW models. Bottom: Models comparing mainstem stations only versus tributary stations only. 


\section{List of Figures}

Figure 1: Conceptual diagram of major processes and systems of water in urban

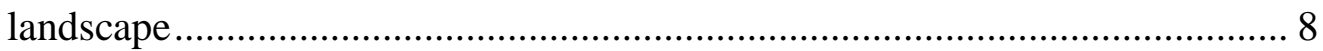

Figure 2: Study site of Tualatin River Watershed and Johnson Creek Watershed..... 11

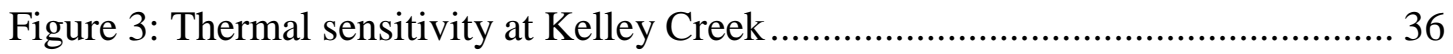

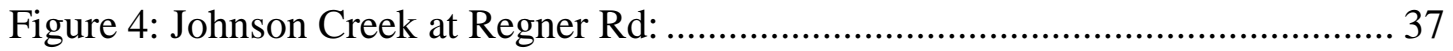

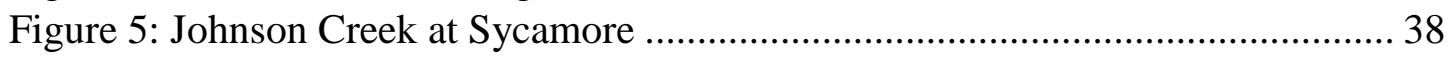

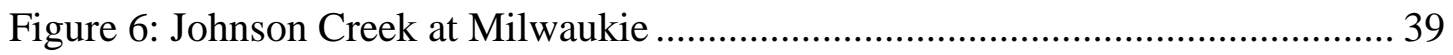

Figure 7: Fanno Creek at Durham .................................................................. 40

Figure 8: Tualatin River at Oswego Dam ............................................................ 41

Figure 9: Study area of Johnson Creek watershed with a simplified base map of 2011

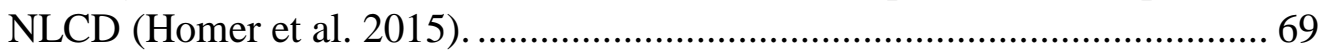

Figure 10: Thermal sensitivity values with subwatersheds and stream buffers throughout

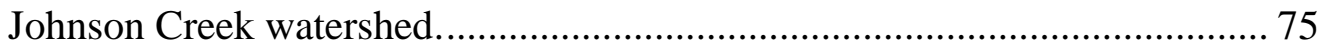

Figure 11: Thermal sensitivity values between mainstem locations $(n=29)$ and tributary locations $(n=59)$. Since the notches of two plots, or confidence intervals, do not overlap this is strong evidence that the two medians are significantly different (Chambers et al. 1983; R Core Team 2018). 76 


\section{Introduction}

Urbanization is an unavoidable phenomenon as human environments expand, shift and globalize. With increasing growth of urban areas at a rapid rate, the expansion of urban areas continues to threaten the natural environment in terms of resources and quality (Grimm et al. 2008, McGrane 2016, United Nations 2018). Urbanization can affect many facets of the physical environment, such as soils, geomorphology, weather, ecology, and water. The evolution of pervious surfaces to impervious fundamentally alters meteorological and hydrological systems, mutating these urbanized environments towards a new homeostasis of urban hydrology. What was once a simple water cycle has now reformed to include a complex dynamic of natural and engineered networks with known and unknown consequences for urban life alike (Kaushal and Belt 2012; Bhaskar

et al. 2016). Urban hydrology, as a relatively new field (McGrane 2016) still has many opportunities for further research and discovery.

This thesis particularly focuses on exploring the impacts of urbanization, land use, and climate on stream temperature and discharge in two watersheds in the Portland Metropolitan area in Oregon, USA. Water temperatures in urban streams and ponds are typically higher than in rural waterbodies. Of course, water temperatures can vary naturally due to unique groundwater characteristics, changing of the seasons, and snow melt, but it is the variation of stream temperatures caused by anthropogenic changes that are of concern. For example, stream temperatures in urban areas can warm due to a decrease in riparian shading, thermal pollution from industry, heated runoff from impervious surfaces and stormwater piping, climate change, and reduced baseflow 
(Morrill, Conklin and Bales 2005; Caissie 2006; Nelson and Palmer 2007; Seekell and Pace 2011, Somers et al. 2013; Johnson and Wilby 2015; Chen et al. 2016a; McGrane 2016; Chang, Watson and Strecker 2017; Arora et al. 2018; Brans et al. 2018). Discharge is also affected by urbanization, which increases runoff response time and flood magnitude and frequency and alters baseflow regimes and groundwater recharge by reduced infiltration (Rose and Peters 2001; Jennings and Jarnagin 2002; Baker et al. 2004; Konrad, Booth and Burges 2005; Chang et al 2007; Sahoo and Smith 2009; Ogden et al. 2011; Price 2011; Velpuri and Senay 2013; Valipour 2015; Bhasker et al. 2016; Pennino et al 2016; Aulenbach et al. 2017; Ferreira et al. 2018). These interactions are complex, and there still remains a large amount of uncertainty in how these impairments are manifested across the urban and natural environment.

It is important to analyze trends of stream temperature and discharge as well as the sensitivity of stream temperature to changes in air temperature for urban streams, or thermal sensitivity. Thermal sensitivity is imperative to quantify to be able to understand the major drivers for stream temperature. If thermal sensitivity is higher in a particular area of the watershed, you can expect that under a warming climate, these locations will be a greater risk for impaired water quality, while areas of lower thermal sensitivity may serve as thermal refugia and be more resilient over time. Having an intimate understanding of the complex dynamics of your managed watershed has real life implications for how and where resources are spent, and if they are mitigating negative effects of urbanization as intended. Temporal and spatial scale analyses work in tandem to better illuminate and interpret complex relationships among the land, the climate, and 
water quality. By looking temporally, we can see how stream temperature and discharge have improved or degraded overtime. By looking spatially at thermal sensitivity across an urban-rural gradient in a small mixed-use watershed, these high-resolution explorations better pinpoint the complex interactions that land use, imperviousness, vegetation, engineered grey and green infrastructure, restoration, topography, and the relative weights and scales of these factors influence stream temperature. As such, the first chapter of this thesis focuses on the temporal dynamics of changing discharge and air temperature on stream temperature, while the second chapter further delves into the spatial relationships of stream temperature. 


\section{Hydrologic Trends of Discharge and Stream Temperature and Assessment of Thermal Sensitivity}

\section{Introduction:}

It is understood that urban areas are continuing to develop, with more than $2 / 3$ of the world's population projected to live in cities by 2050 (United Nations 2018). This dense and highly fragmented landscape has many implications for urban ecology (Pickett et al. 2001, Grimm et al. 2008). The effect of urbanization on stream ecology can be best summarized as the 'urban stream syndrome' (Walsh et al. 2005), which can alter many aspects of aquatic and riparian environments; most notably flashier runoff, decreased baseflow, high concentrations of nutrients, pesticides, and heavy metals, decreased biodiversity of native species, high stream temperatures, and altered geomorphology (Paul and Meyer 2001, Walsh et al. 2005, Caissie 2006; Elga, Jan and Okke 2015; McGrane 2016; Redfern et al. 2016).

Urbanizing and natural streams can easily be distinguished by their differing hydrographic characteristics. Many studies seek to examine the effect of urban hydrology and fluvial geomorphology. Rose and Peters (2001) cited Shaw (1994) as they identified five major effects of urbanization on streamflow: higher runoff, shorter lag time between precipitation and runoff, higher peak flows, less low flows and reduced groundwater recharge, and degraded water quality. Kaushal and Belt (2012) argued through an urban watershed continuum framework that engineered stormwater systems act as artificial headwaters that effectively increases water hyper connectivity while recognizing 'the urban karst' of leaky pipes, sewage, and septic systems common in urban hydrology. 
Konrad et al. (2005) determined that the fraction of time that daily streamflow exceeds mean annual streamflow in the Puget Lowland, Washington was less than $30 \%$ in urbanized streams while greater than 30\% in rural streams. Levell and Chang (2008) found a restored stream reach in Johnson Creek, Portland to be more stable than an impacted reach, but still showed signs of sedimentation and aggradation compared to a reference reach. In contrast, in their study of urban versus rural streams in Vancouver, B.C. Finkenbine et al. (2000) claimed that urbanization had led to improved spawning conditions for fish in stream that are 20 years post development citing little new fine sediment input, though they identify lower baseflow and less large woody debris in these urban streams. Ogden et al. (2011) recognized the contradictory conclusions found in research regarding storm and flood runoff and found that imperviousness and urbanization significantly affects flood peaks for both moderately extreme and extreme rainfall events. Ferreira et al. (2018) found that in an urban environment, $17 \%-29 \%$ of rainfall becomes storm runoff, whereas in a peri-urban environment, $9-13 \%$ of rainfall becomes storm runoff. Aulenbach et al. (2017) found that increases in storm hydrologic metrics (peak streamflow, stormwater yield, storm runoff) were related to increases in effective impervious surface, while decreases in the same metrics were related to increases in best management practice (BMP) implementation. They found that for every $1 \%$ increase in watershed effective impervious drainage area (EIA), it would take approximately a 2.6, 1.1, and $1.5 \%$ increase in EIA treated by BMPs to mitigate the effects of additional EIAs (on peak streamflow, stormwater yield, and storm runoff, respectively). Bhaskar et al. (2016) found that predicting what will happen to baseflow is 
dependent on the city in question - in certain circumstances urbanization can increase baseflow or decrease baseflow dependent on sewershed, water table height, climate and geology. The effects of urbanization on streams are numerous and sometimes contradictory (Redfern et al. 2016). Thus, further research on these metrics can help to pinpoint statistically significant relationships of discharge characteristics in an urban setting.

Water temperatures in urban areas can be significantly higher than their rural counterparts. Water temperatures in streams are cyclic in nature, increasing and decreasing with the changing seasons. Water temperatures also vary from natural sources, such as geology and groundwater inputs and snowmelt (Caissie 2006; Lee and Synder 2009), but also vary due to human impacts to the urban environment such as warm waste water inputs, deforestation and reduced streamside shade, warm stormwater runoff, and climate change (Morrill, Conklin and Bales 2005; Nelson and Palmer 2007; Somers et al 2013; McGrane 2016; Chang, Watson and Strecker 2017; Brans et al 2018). While overall stream health depends on a complex combination of geomorphology, hydrology, and water quality, stream temperature is a cornerstone to stream health as it controls many biotic and abiotic processes (Caissie 2006; Nelson and Palmer 2007; Jackson et al. 2016). Brans et al. (2018) in northern Belgium found that urban ponds were on average $3^{\circ} \mathrm{C}$ higher compared to rural ponds. In their study of 40 rivers, Kaushal et al. (2010) found significant increases in monthly river temperature at 20 locations around the United States with at least 24 years of record. Most studies have not looked in depth at anthropogenically altered watersheds and compared trends in stream temperature and 
streamflow directly. High stream temperatures can be detrimental to aquatic species, including plants, benthic macroinvertebrates, and fish (Caissie 2006; Kaushal et al. 2010; Jackson et al. 2016; Chang, Watson and Strecker 2017). Increases in water temperature influence species abundance and spatial distribution, alter stream metabolism and nutrient cycling, and reduce dissolved oxygen (Morrill et al. 2005, Caissie 2006; Culler et al. 2018). In a city, a perfect storm of problematic effects of urbanization come together to degrade these aquatic ecosystems. To put it succinctly, urban areas have less infiltration and groundwater recharge, altered base flow, which when combined with the urban heat island effect and warmer stormwater runoff lead to overall flashier hydrologic regimes and warmer streams (Figure 1). 


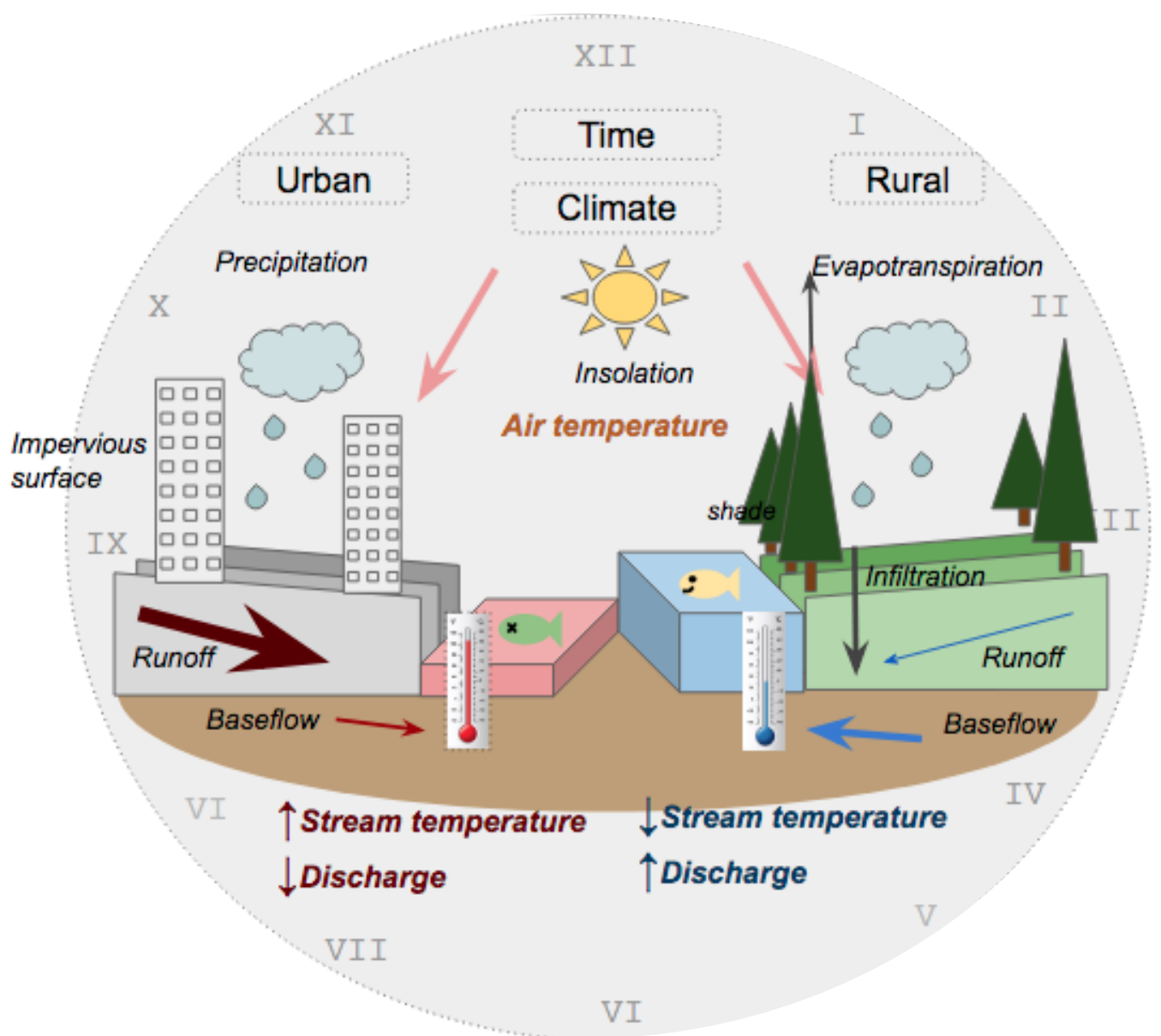

Figure 1: Conceptual diagram of major processes and systems of water in urban landscape

In their study of freshwater salmon in Washington State, Mantua et al. (2010) considered both streamflow and summertime stream temperature extremes and concluded that a changing climate conducive to lower flows and warmer stream temperatures will reduce salmon reproduction success. Honea et al. (2016) predicted that increases in air temperatures and winter precipitation will lead to higher flows during the egg-incubation period in the salmon's life cycle, and lower flows with higher stream temperature during summer. 
The relationship between discharge and stream temperature is unquestionable. Typically, higher discharge is associated with lower stream temperatures because of increased thermal capacity and decrease travel time of flow, although air temperature, precipitation, flow, solar radiation, and land-use can all affect stream temperature (Caissie 2006; Nelson and Palmer 2007, Webb and Nobilis 2007; Johnson and Wilby 2015; Gray, Robertson, and Rogala 2018; Winfree et al. 2018). Previous research has examined the relationship between air temperature and stream temperature for large geographical areas. These research studies have generally found strong relationships between the two, such that one is able to accurately use air temperature alone to predict stream temperature (Mohseni, Stefan, and Erickson 1998; Morrill, Bales, and Conklin 2005). Other research has further employed the addition of discharge to model stream temperature (Webb, Clack, and Walling 2003, Van Vliet et al. 2011, Sohrabi et al. 2017, Chang, Watson, and Strecker 2017, Piotrowski and Napiorkowski 2019). Most of these studies rely on the landmark study of Mohseni, Stefan, and Erickson (1998), who created a nonlinear regression model to represent the relationship of air temperature and stream temperature. Many adapted multiple regression nonlinear models for stream temperature that includes both air temperature and discharge has been successful, especially to model stream temperatures during periods of discharge extremes (Webb, Clack and Walling 2003, Van Vliet et al. 2011, Kelleher et al 2012, Piotrowski and Napiorkowski 2019). This study is novel as it investigates four separate indicators of urban streamflow and stream temperature, that have not been examined thus far in the study area. Additionally, examining distinct models of thermal sensitivity throughout both watersheds contributes 
to new understanding of thermal controls in both watersheds that can be helpful to inform numerous agencies in charge of watershed and resource management.

This thesis explores these complex relationships by asking three main questions:

1. Are there trends of streamflow and stream temperature metrics in the Johnson Creek and Tualatin River watersheds, and how do these trends vary at different temporal scales?

2. How sensitive is stream temperature to changes in air temperature and discharge?

3. How does thermal sensitivity vary along an urban/rural gradient? 


\section{Study Area}

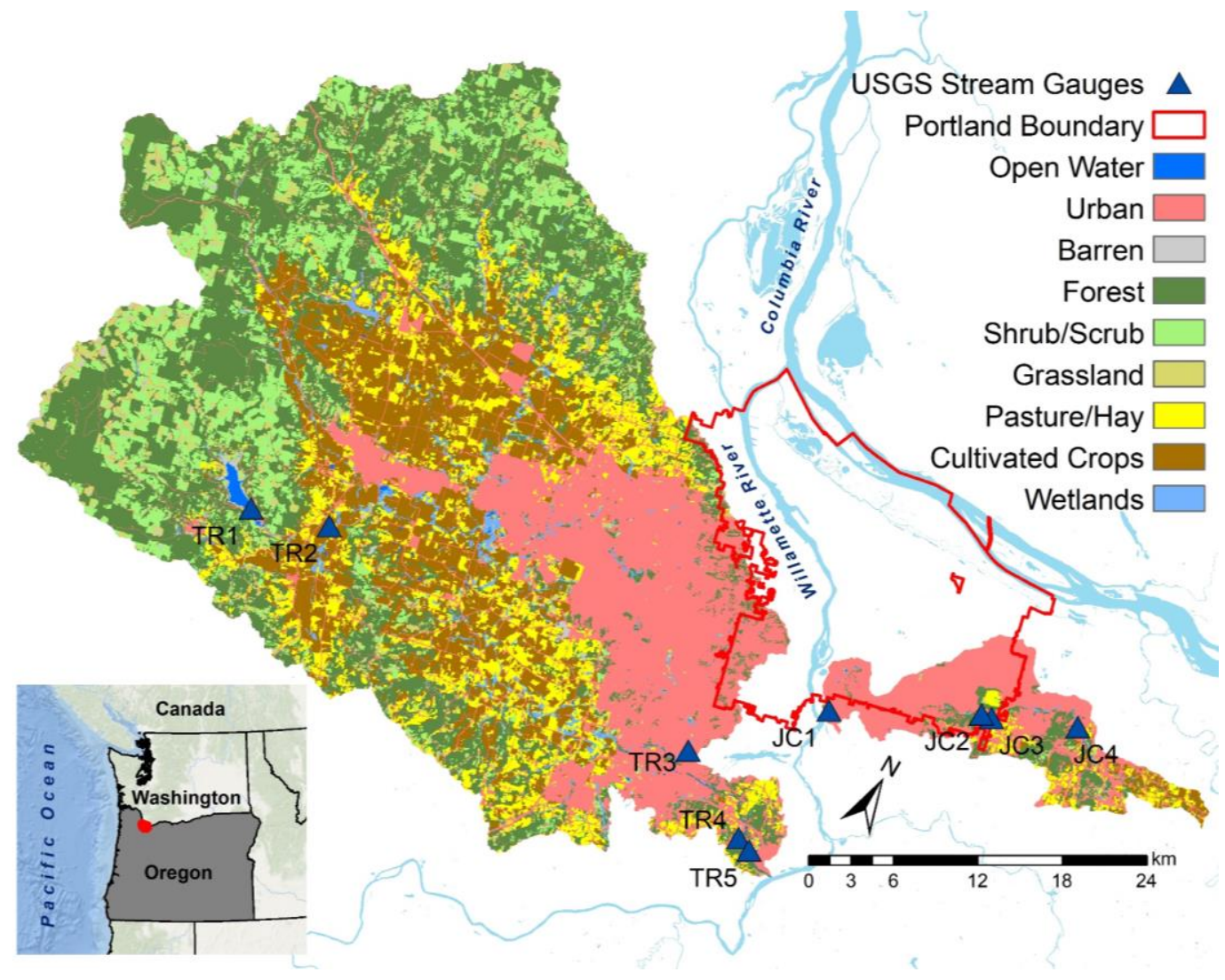

Figure 2: Study site of Tualatin River Watershed and Johnson Creek Watershed.

TR1: Scoggins Creek below Henry Hagg TR2: Tualatin River near Dilley TR3: Fanno Creek at Durham TR4: Tualatin River at Oswego Dam TR5: Tualatin River at West Linn JC1: Johnson Creek at Milwaukie JC2: Johnson Creek at Sycamore JC3: Kelley Creek at SE 159th Dr JC4: Johnson Creek at Regner Rd

The Johnson Creek Watershed and the Tualatin River Watershed (Figure 2) are located within Oregon's Portland Metropolitan Area as part of the greater Willamette River Watershed. Land use and hydroclimatic characteristics in the two watersheds are shown in Table 1 (Homer et al. 2015). 
Table 1: Land use and watershed characteristics between the Tualatin River and Johnson Creek study areas.

\begin{tabular}{cccccccccc}
\hline $\begin{array}{c}\text { Water- } \\
\text { shed }\end{array}$ & $\begin{array}{c}\% \\
\text { Develo } \\
\text { ped }\end{array}$ & $\begin{array}{c}\text { Forest } \\
\text { Agricul } \\
\text { ture }\end{array}$ & $\begin{array}{c}\text { Water- } \\
\text { shed } \\
\text { area } \\
\left(\mathrm{km}^{2}\right)\end{array}$ & $\begin{array}{c}\text { Stream } \\
\text { length } \\
(\mathrm{km})\end{array}$ & $\begin{array}{c}\text { Mean } \\
\text { dischar } \\
\text { ge } \\
(\mathrm{cms})\end{array}$ & $\begin{array}{c}\text { Mean } \\
\text { Air } \\
\text { Temp } \\
(\mathrm{C})\end{array}$ & $\begin{array}{c}\text { Annual } \\
\text { Mean } \\
\text { Total } \\
\text { Precip- } \\
\text { itation } \\
\left(\mathrm{mm}^{2}\right)\end{array}$ & $\begin{array}{c}\text { Populat } \\
\text { ion } \\
\text { density } \\
(\text { person } \\
\text { s per } \\
\left.\mathrm{km}^{2}\right)\end{array}$ \\
\hline $\begin{array}{c}\text { Tualatin } \\
\text { River }\end{array}$ & 25 & 30 & 27 & 1836 & 134 & 41.0 & 11.6 & 985.0 & 272 \\
$\begin{array}{c}\text { Johnson } \\
\text { Creek }\end{array}$ & 67 & 15 & 15 & 140 & 38 & 2.2 & 12.4 & 916.9 & 1214 \\
\hline
\end{tabular}

Discharge data provided from the US geological survey. Air temperature and precipitation data provided by the Northwest Regional Climate Center 1981-2010 30-year normals. Population density calculated by dividing population of watershed by the watershed area.

The Johnson Creek and Tualatin River watersheds are characterized by a wet, cool season from October to March and experiences a drought season during summer months. The Tualatin River watershed and the Johnson Creek watershed both experience greatest precipitation inputs from October to March, with highest streamflow occurring during the winter and typical low flows during the summer. These two watersheds are largely fed by rainwater precipitation and rarely experience regular snow accumulations (Chang 2007). From 2000 to 2010 alone, the Portland Metropolitan area including Portland, Hillsboro and Vancouver, WA experienced a 15.5\% increase in population alone (Population Research Center 2019). From 2006 to 2011, any form of land cover change was primarily the conversion to further developed land cover classification in both watersheds (Homer et al. 2015). 


\section{Data and Methods}

\subsection{Data}

Primarily, 10 USGS stations located in the Johnson Creek and Tualatin River Watersheds provided data used in long term analysis and thermal sensitivity analysis. Daily air temperature and precipitation data from the Portland International Airport was downloaded from the National Oceanic and Atmospheric Administration's (NOAA) Climate Data Online website. These stations summarized in Table 2:

Table 2: Data sources

\begin{tabular}{|c|c|c|c|c|}
\hline Station ID & Station Name & $\begin{array}{l}\text { Drainage area } \\
\left(\mathrm{km}^{2}\right)\end{array}$ & $\begin{array}{l}\text { Stream } \\
\text { Temperature } \\
\text { record }\end{array}$ & $\begin{array}{l}\text { Discharge } \\
\text { record }\end{array}$ \\
\hline \multicolumn{5}{|c|}{ Johnson Creek Watershed } \\
\hline 14211550 & Johnson Creek at Milwaukie & 137.7 & $1998-2018$ & $1990-2018$ \\
\hline 14211500 & Johnson Creek at Sycamore & 69.4 & $1998-2018$ & $1940-2018$ \\
\hline 14211499 & Kelley Creek at SE 159th & 12.2 & $2000-2018$ & $2000-2018$ \\
\hline 14211400 & Johnson Creek at Regner Rd & 39.8 & $1999-2018$ & $1998-2018$ \\
\hline \multicolumn{5}{|c|}{ Tualatin River Watershed } \\
\hline 14202980 & $\begin{array}{l}\text { Scoggins Creek below Henry } \\
\text { Hagg }\end{array}$ & 100.5 & $2002-2018$ & $1975-2006$ \\
\hline 14203500 & Tualatin River near Dilley & 323.7 & $\begin{array}{l}1963-1968 \\
2016-2018\end{array}$ & $1939-2018$ \\
\hline 14206900 & Fanno Creek at $56^{\text {th }}$ & 61.4 & - & $1990-2018$ \\
\hline 14206950 & Fanno Creek at Durham & 81.5 & $2002-2018$ & $2000-2018$ \\
\hline 14207500 & Tualatin River at West Linn & 1833.7 & $\begin{array}{c}1963-1968 \\
1975-1981\end{array}$ & $1928-2018$ \\
\hline 14207200 & Tualatin River at Oswego Dam & 1828.5 & $1991-2018$ & $\mathrm{n} / \mathrm{a}$ \\
\hline
\end{tabular}




\begin{tabular}{ccc}
\hline & Air Temperature & $\begin{array}{c}\text { Precipitation } \\
\text { Record }\end{array}$ \\
\hline Portland International Airport & $1940-2018$ & $1940-2018$ \\
\hline
\end{tabular}

\subsection{Metrics}

Discharge and stream temperature metrics were derived on a yearly as well as monthly basis. Certain metrics were only derived for specific months as their significance is most valuable during certain months, such as stream temperature metrics during summer months when temperatures are at their maximum. A total of 11 additional locations of stream temperature data in the Tualatin River watershed primarily located in smaller tributaries are included for their limited period of record for comparison with stream temperature metrics.

Table 3: Metrics derived from stream temperature, discharge, and precipitation data

\begin{tabular}{|c|c|c|c|c|}
\hline Dataset & Resolution & Derived Metrics & Season & Associated Literature \\
\hline Discharge & Daily & $\begin{array}{l}\text { Baseflow index } \\
\text { Richards-Baker } \\
\text { Flashiness Index } \\
\text { Mean runoff ratio } \\
\text { TQmean }\end{array}$ & $\begin{array}{l}\text { Dry } \\
\text { Annual } \\
\text { Wet } \\
\text { Wet }\end{array}$ & $\begin{array}{l}\text { Chang and Psaris 2013, Poff } 1996 \\
\text { Baker et al. } 2004 \\
\text { Velpuri and Senay 2013, Chang } 2007 \\
\text { Lee and Snyder 2009, Konrad et al. } \\
\text { 2005, Chang } 2007\end{array}$ \\
\hline $\begin{array}{l}\text { Stream } \\
\text { Temperature }\end{array}$ & Daily & $\begin{array}{l}\text { \# of days exceeding } 17.8 \\
\text { C } \\
\text { 7-day moving average of } \\
\text { daily maximum stream } \\
\text { temperature } \\
\text { 7-day moving average of } \\
\text { daily minimum stream } \\
\text { temperature } \\
\text { Thermal flashiness }\end{array}$ & $\begin{array}{l}\text { Dry } \\
\text { Dry } \\
\text { Dry } \\
\text { Dry }\end{array}$ & $\begin{array}{l}\text { Watson and Chang 2017, Grabowski } \\
\text { et al } 2016 \\
\text { Watson and Chang 2017, Chang and } \\
\text { Psaris 2013, } \\
\text { Grabowski et al 2016, OR DEQ } \\
\text { Grabowski et al 2016 } \\
\text { Grabowski et al 2016, Baker et al. } \\
2004\end{array}$ \\
\hline
\end{tabular}




\subsubsection{Discharge Metrics}

Four metrics were extracted from daily discharge data. A baseflow index (BFI), after Poff 1996 and Chang and Psaris (2013), is the minimum daily flow divided by the average annual daily flow (equation 1) and is shown in Figure 3. BFI is a proxy for groundwater contributions to the stream. Streams with a low BFI may be more at risk to changes in air temperature, especially during the warmer summer months (Chang and Psaris 2013).

$B F I=\frac{\min (\text { dailyflow })}{\text { mean }(\text { Annualdailyflow })}$

Equation 1

The Richards-Baker flashiness index (equation 2) is dimensionless and measures the oscillations in discharge relative to total discharge (Baker et al. 2004). Hydrographs that are flashy are typical in streams that have considerable human alteration such as dam construction or land use change (Baker et. al 2004). Human alteration that negatively affects a natural flow regime in a stream (i.e., flashiness) can negatively influence these native aquatic flora and fauna communities (Poff et al. 1997, Baker et al. 2004).

$R-B$ Index $=\frac{\sum_{i=1}^{n}\left|q_{i}-q_{i}-1\right|}{\sum_{i=1}^{n} q_{i}}$ Equation 2

Where $\mathrm{q}=$ discharge, $\mathrm{q}_{i}=$ daily mean discharge for day $i$ and $\mathrm{q}_{i-1}=$ daily mean discharge at day $i-1$. 
The mean runoff ratio, or runoff coefficient is measured as the percentage ratio of runoff depth to precipitation for the watershed area that drains to the stream gauge. Trends of changes in this attribute can be attributed to human or water management changes in a watershed, with higher runoff ratios typically occurring in more urbanized watersheds with higher impervious surface coverage as less water infiltrates into the ground (Chang 2007, Velpuri and Senay 2013).

The fourth discharge metric is fraction of time that streamflow exceeds the mean streamflow (TQmean) and has also been described as another way to measure flashiness. Ratios below 30\% are typical of urbanized streams (Konrad et al. 2005, Chang 2007).

\subsubsection{Stream temperature Metrics}

Four stream temperature metrics will be extracted from USGS stream temperature data. The 7-day moving average of daily maximum (7DADTmax) and daily minimum (7DADTmin) stream temperature will represent the extreme temperatures recorded at each gauging station (Chang and Psaris 2013, Grabowski et al. 2016, Watson and Chang 2017).

The number of days with 7-day moving average of daily maximum temperature exceeding $17.8^{\circ} \mathrm{C}$ will be used as in Grabowski et al. (2016) and Watson and Chang (2017) as a biological metric of salmon health as it is used by the Oregon Department of Environmental Quality (Oregon Department of Environmental Quality 2006). 
Thermal flashiness, developed by Grabowski et al. (2016) is a derivation of Richards-Baker Flashiness Index of Baker et al. (2004) meant to represent the inter-daily range of mean stream temperatures is shown by equation 4 :

Thermal flashiness, for all $i=\operatorname{sum}\left(T_{i-} T_{i-1}\right) / \operatorname{sum}\left(T_{i}\right)$

Equation 3

where $T_{i}=$ daily mean temperature for day $i$ and $T_{i-l}=$ daily mean temperature at day $i-$ $I$ (Baker et al. 2004; Grabowski et al. 2016). Typically, headwater streams will show greater inter-daily range of temperature as they are more thermally sensitive to air temperature (Grabowski et al. 2016).

\subsection{Mann-Kendall trend analysis}

Long term trend analyses were conducted using the Mann-Kendell trend test. The Mann-Kendall test is a non-parametric, rank-based test to detect monotonic increasing or decreasing trends. We derived eight metrics (four stream temperature and four discharge described in Table 3) and analyzed for detecting monotonic trends for various USGS gauging stations in the study watersheds. Due to varying length of record of stream temperature and discharge across all stations, Mann-Kendall tests were run for the entire period of record for all stations to understand any apparent existing trends individually, as well as for all stations since 2002 to be able fairly compare trends across the landscape. The Mann-Kendall test statistic, $\tau$ range from -1 to 1 , with a positive value indicating a positive monotonic trend and a negative value indicating a negative monotonic trend 
(Yue, Pilon and Cavadias 2002; Lee and Synder 2009). $\tau$ values near zero indicate no trend. The statistical significance of the trend is based on the p-value, with p-values set a $0.01,0.05$, and 0.10 , indicating a statistically significant trend. Lower significance levels such as the 0.1 level are common for the Mann-Kendall test for hydrologic exploration (Yue, Pilon and Cavadias 2002). Mann-Kendall trend tests are frequently used in place of linear regression on hydro-climatological time series data due to its ability to better deal with outliers and non-normal distribution (Chang 2007; Yue, Pilon, and Cavadias 2002; Yue et al. 2002; Hamed 2007; Razavi and Vogel 2018; Kaushal et al 2010; Esterby 1996; Khaliq, Ouarda, and Gachon 2009) Since Mann-Kendall trend tests require serial dependence, which often times is violated in hydrologic trend detection, the Yue-Pilon pre-whitening approach to determine trends with Mann Kendall analysis was utilized using the zyp package using $\mathrm{R}$ programming software version 3.5.1 (Yue et al. 2002; R Core Team 2018; Bronaugh and Werner 2019). This method first detrends the time series prior to pre-whitening to provide a more accurate estimate of trend that is not influenced by positive serial autocorrelation nor removed entirely by pre-whitening. After prewhitening, the trend is placed back into the time series for the Mann-Kendell test.

\subsection{Quantifying thermal sensitivity with nonlinear regression}

For research question 2, bivariate nonlinear regression, modeled after Mohseni et al. (1998) (equation 4) was used to quantify the relationship between air temperature and stream temperature and assess stream's unique thermal sensitivity. In this model, air temperature is linked to water temperature since both are responding to similar energy 
balance components (Caissie, El-Jabi, and Satish 2001). Kelleher et al. (2012) defined thermal sensitivity as "the sensitivity of stream temperature of a given site to change in air temperature, quantified as the slope of the regression line between air temperature and stream temperature". This nonlinear regression can be better than simple linear regression at modeling stream temperature because it more accurately predicts high stream temperatures $\left(>20^{\circ} \mathrm{C}\right)$ as well as low temperatures $\left(<0^{\circ} \mathrm{C}\right)$, which tend to level out as they approach the upper and lower temperature bounds (asymptotes) of the fitted sine function (Mohseni et al. 1998; Mohseni et al. 1999). Using this nonlinear regression, the position of events in the time series is not important, whereas time series-based or predictive models make use of the serial autocorrelation inherent in stream temperature data (Caissie, El-Jabi, and Satish 2001). The nonlinear equation for stream temperature is as follows:

$T_{s}=\mu+\frac{\alpha-\mu}{1+\epsilon^{\gamma(\beta-T a)}}$

\section{Equation 4}

where $T s=$ estimated stream temperature, $T a=$ measured air temperature for the period of interest. Four parameters: $\mu=$ minimum stream temperature; $\alpha=$ maximum stream temperature; $\gamma=$ function of the steepest slope (inflection point) of the $T$ s function (when plotted against $\mathrm{T} a$ ); and $\boldsymbol{\beta}=$ air temperature at this inflection point. This nonlinear equation was also modified to include a separated discharge term that allows for the inverse relationship between discharge and stream temperature to be modeled in addition 
to air temperature as in van Vliet et al. (2011) (equation 5). An inverse function was chosen as opposed to a negative function of discharge, as it reflects a reduction in thermal capacity and reduced dilution capacity for anthropogenic heat sources that exist in urban watersheds (van Vliet et al. 2011).

$T_{w}=\mu+\frac{\alpha-\mu}{1+\epsilon^{\gamma\left(\beta-T_{a}\right)}}+\frac{\eta}{Q}+\epsilon$

\section{Equation 5}

with $\gamma=\frac{4 \tan \theta}{\alpha-\mu}$

Equation 5 shows the modified bivariate nonlinear regression, where $\mu=$ lower bound of water temperature $\left({ }^{\circ} \mathrm{C}\right) ; \alpha=$ upper bound of water temperature $\left({ }^{\circ} \mathrm{C}\right) ; \gamma=$ measure of the slope at inflection point (steepest slope) of the S-shaped relation (C1); $\boldsymbol{\beta}$ air temperature at inflection point $\left({ }^{\circ} \mathrm{C}\right) ; \eta=$ fitting parameter $\left({ }^{\circ} \mathrm{C} \mathrm{m}^{3} \mathrm{~s}-{ }^{1}\right) ; \mathrm{T} w=$ water temperature $\left({ }^{\circ} \mathrm{C}\right)$; Tair =air temperature $\left({ }^{\circ} \mathrm{C}\right) ; \mathrm{Q}=$ river discharge $\left(\mathrm{m}^{3} \mathrm{~s}-{ }^{1}\right) \varepsilon=$ error term $\left({ }^{\circ} \mathrm{C}\right)$ and $\tan \boldsymbol{\theta}=$ slope at inflection point (-) (Van Vliet et al. 2011). Tan $\boldsymbol{\theta}$ in equation 5 is analogous to the slope coefficient in a linear regression and represents thermal sensitivity (Kelleher et al. 2011).

Models were created for both the entire year of record for each station as well as for the only summer months when stream temperatures are highest. Additionally, the nonlinear regression was compared to a simple ordinary least squares regression for both 
time periods. Equations were also fitted with the inverse discharge parameter to compare to equations without the influence of discharge. The 7-day moving average of daily maximum stream temperature and 7-day average of daily maximum air temperature were modelled, as well as the raw daily values of maximum stream temperature and maximum air temperature. This results in a total of 16 regression equations for each of six stations included in analysis. In situ air temperature data is not necessary as other studies have found good agreement between air and water temperature data for distances of up to 270km (Mohseni, Stefan, and Erickson 1998; Kelleher et al. 2012). The distance from the furthest gauging station and Portland International airport is just under 20 kilometers.

To compare model performance across different models, the root-mean-square error (RMSE) was calculated using the package hydroGOF in $\mathrm{R}$ and is commonly employed as an alternative for goodness of fit in hydrology (Caissie, El-Jabi, and StHilaire 1998; Caissie, El-Jabi, and Satish 2001; Morrill, Bales, and Conklin 2005; Ahmadi-Nedushan et al. 2007; Benyahya et al. 2007; Zambrano-Bigiarnini 2017). RMSE is given by:

$$
R M S E=\sqrt{\frac{\sum_{i=1}^{n}\left(T_{s i m, i}-X_{o b s, i}\right)^{2}}{n}}
$$

where $T_{o b s}$ is observed values and $T_{\text {sim }}$ is modelled values at time/place $i$. A smaller RMSE indicates a better model performance, with RMSE in units of the simulated and observed values, in this case, degrees celsius (Zambrano-Bigiarnini 2017). Standard goodness of fit indicators, such as the coefficient of determination, $\mathrm{R}^{2}$, cannot be used to accurately compare across ordinary least squares and nonlinear regression. Standardized 
coefficients of linear multiple regression of stream temperature are summarized in Table 5 to obtain an overall idea of relative influence of air temperature and discharge on stream temperature. 


\section{Results}

\subsection{Trend of streamflow and stream temperature}

The results of the Mann-Kendall trend tests for each station since 2002 are summarized in Tables 4 through 12. Trends since the entire period of record for each station are shown in the appendix. Values in red indicate a statistically significant increasing trend and values in blue indicate a statistically significant decreasing trend. Out of all possible trends, at Kelley Creek, $31 \%$ of the discharge trends were significant while no temperature trends were significant, at Johnson Creek at Regner Rd, $45 \%$ of the stream temperature trends were significant and $19 \%$ of the discharge trends were significant, $50 \%$ of the stream temperature trends and $31 \%$ of the discharge trends were significant at Johnson Creek at Sycamore, and 28\% of the stream temperature and 22\% of the discharge trends were significant at Johnson Creek at Milwaukie. In the Tualatin River watershed, $46 \%$ of discharge trends were significant, $15 \%$ of discharge trends at Scoggins Creek below Henry Hagg reservoir were significant, $18 \%$ of the discharge trends were significant at Fanno Creek at $56^{\text {th }}, 25 \%$ of discharge trends and $25 \%$ of stream temperature trends were significant at Fanno Creek at Durham, and 13\% of stream temperature trends and $32 \%$ of discharge trends were significant at the Tualatin River at Oswego Dam. 
Table 4: Mann-Kendall test results for 7 -day moving average of daily maximum temperature October 2002- September 2018. $\tau$ values in red indicate a significant increasing trend and values in blue indicate a significant decreasing trend. $\mathrm{p}$ is significance level where values are significant at $* 0.10, * * 0.05$, $* * * 0.01$. Stations are listed from highest to lowest in each watershed

\begin{tabular}{llllllllllllll}
\hline & Jun & & Jul & & Aug & & Sep & & \multicolumn{2}{c}{ Year } \\
\hline Stations & $\tau$ & p & $\tau$ & p & $\tau$ & p & $\tau$ & p & & $\tau$ & $p$ \\
7DADmax - Since 2002 & & & & & & & & & & & & & \\
& & & & & & & & & & & & &
\end{tabular}

\section{Johnson Creek}

\begin{tabular}{ccccccc}
\hline Regner Rd & 0.20 & 0.24 & $0.47 * *$ & $0.43 * *$ & $0.35 *$ \\
\hline Kelley Cr & 0.08 & 0.13 & 0.13 & 0 & 0.16 \\
\hline Sycamore & 0.22 & $0.37 * *$ & $0.38 * *$ & $0.42 * *$ & $0.40 * *$ \\
Milwaukie & -0.20 & $-0.34 *$ & $-0.32 *$ & $-0.73 * * *$ & $-0.34 *$ \\
\hline
\end{tabular}

\section{Tualatin River}

\begin{tabular}{lccccc}
\hline Scoggins Cr & 0.10 & 0.03 & 0 & 0.08 & -0.13 \\
\hline Fanno Cr Durham & $0.18 * * *$ & 0.37 & $0.18 *$ & 0.37 & $0.50 *$ \\
\hline Oswego Dam & 0.10 & 0.03 & 0.15 & 0.25 & 0.07 \\
\hline
\end{tabular}


Table 5: Mann-Kendall test results for 7 -day moving average of daily minimum temperature October 2002- September 2018. $\tau$ values in red indicate a significant increasing trend and values in blue indicate a significant decreasing trend. $\mathrm{p}$ is significance level where values are significant at $* 0.10, * * 0.05, * * * 0.01$

\begin{tabular}{llllllllllllll}
\hline & Jun & & Jul & & Aug & & Sep & & \multicolumn{2}{c}{ Year } \\
\hline Stations & $\tau$ & p & $\tau$ & p & $\tau$ & p & & $\tau$ & p & $\tau$ & $p$ \\
7DADmin - Since 2002 & & & & & & & & & & & & & \\
\hline
\end{tabular}

Johnson Creek

\begin{tabular}{cccccc}
\hline Regner Rd & 0.17 & $0.33 *$ & $0.32 *$ & 0.22 & 0.14 \\
Kelley Cr & -0.13 & 0.12 & 0.02 & -0.08 & 0.07 \\
Sycamore & 0.15 & 0.17 & $0.33 *$ & 0.23 & 0.05 \\
Milwaukie & 0.05 & -0.07 & -0.08 & 0.08 & 0.14 \\
\hline Tualatin River & & & & & \\
\hline Scoggins Cr & 0.20 & 0.20 & 0.20 & 0.03 & 0.03 \\
Fanno Cr Durham & 0.28 & 0.2 & 0.20 & 0.30 & 0.09 \\
Oswego Dam & 0.10 & 0.12 & $0.32 *$ & 0.07 & 0.02 \\
\hline
\end{tabular}


Table 6: Mann-Kendall test results for the total number of days above 17.8C October 2002- September 2018. $\tau$ values in red indicate a significant increasing trend and values in blue indicate a significant decreasing trend. $\mathrm{p}$ is significance level where values are significant at $* 0.10, * * 0.05, * * * 0.01$

\begin{tabular}{lccccccccccccc}
\hline & Jun & & Jul & & Aug & & \multicolumn{2}{c}{ Sep } & & \multicolumn{2}{c}{ Year } \\
\hline Stations & $\tau$ & $\mathrm{p}$ & $\tau$ & $\mathrm{p}$ & $\tau$ & $\mathrm{p}$ & $\tau$ & $\mathrm{p}$ & & $\tau$ & $\mathrm{p}$ \\
\# of Days above 17.8 C - Since 2002 & & & & & & & & & \\
\hline
\end{tabular}

Johnson Creek

\begin{tabular}{cccccc}
\hline Regner Rd & 0.25 & 0.08 & 0.22 & $0.43 * *$ & $0.40 * *$ \\
Kelley Cr & 0.14 & 0.08 & -0.05 & 0.10 & -0.02 \\
Sycamore & $0.29 *$ & -0.05 & 0.06 & $0.38 * *$ & $0.50 * * *$ \\
Milwaukie & 0.02 & 0.03 & -0.14 & $-0.43 * *$ & -0.02 \\
\hline Tualatin River & & & & & \\
\hline Scoggins & - & - & - & 0.05 & -0.12 \\
Fanno Cr Durham & 0.28 & 0.06 & $0.36 *$ & 0.26 & $0.41 * *$ \\
Oswego Dam & 0.17 & -0.02 & - & 0.30 & - \\
\hline
\end{tabular}


Table 7: Mann-Kendall test results for thermal flashiness October 2002- September 2018. $\tau$ values in red indicate a significant increasing trend and values in blue indicate a significant decreasing trend. $\mathrm{p}$ is significance level where values are significant at $* 0.10, * * 0.05, * * * 0.01$

\begin{tabular}{llllllllllllll} 
& Jun & & Jul & & Aug & & Sep & & \multicolumn{2}{c}{ Year } \\
\hline Stations & & $\tau$ & $\mathrm{p}$ & $\tau$ & $\mathrm{p}$ & $\tau$ & $\mathrm{p}$ & $\tau$ & $\mathrm{p}$ & & $\tau$ & $\mathrm{p}$ \\
Thermal Flashiness- Since 2002 & & & & & & & & & & & & \\
\hline
\end{tabular}

Johnson Creek

\begin{tabular}{cccccc}
\hline Regner Rd & 0.17 & 0.08 & -0.03 & -0.25 & -0.17 \\
Kelley Cr & 0.12 & -0.02 & -0.15 & -0.15 & 0.03 \\
Sycamore & 0.13 & -0.18 & 0.02 & -0.23 & -0.17 \\
Milwaukie & -0.15 & 0.05 & -0.15 & $-0.45 * *$ & -0.25 \\
\hline Tualatin River & & & & & \\
\hline Scoggins Cr & -0.27 & -0.02 & -0.05 & -0.02 & -0.30 \\
Fanno Cr Durham & 0.12 & -0.07 & -0.16 & -0.03 & -0.09 \\
\hline Oswego Dam & 0.08 & -0.05 & -0.17 & 0.30 & $-0.32 *$ \\
\hline
\end{tabular}


Table 8: Mann-Kendall test results for baseflow index October 2002- September 2018. $\tau$ values in red indicate a significant increasing trend and values in blue indicate a significant decreasing trend. $\mathrm{p}$ is significance level where values are significant at $* 0.10, * * 0.05, * * * 0.01$

\begin{tabular}{lllllllllllllll} 
& \multicolumn{1}{c}{ Jun } & & & Jul & & & Aug & & Sep & & \multicolumn{2}{c}{ Year } \\
\hline Stations & $\tau$ & $\mathrm{p}$ & $\tau$ & $\mathrm{p}$ & $\tau$ & $\mathrm{p}$ & $\tau$ & $\mathrm{p}$ & & $\tau$ & $\mathrm{p}$ \\
Base Flow Index - Since 2002 & & & & & & & & & & & & \\
\hline
\end{tabular}

Johnson Creek

\begin{tabular}{|c|c|c|c|c|c|c|c|c|c|c|}
\hline Regner Rd & 0.20 & & 0.03 & & 0.03 & & 0.15 & & 0.02 & \\
\hline Kelley Cr & -0.43 & $* *$ & -0.50 & $* * *$ & 0.37 & $* *$ & 0.50 & $* * *$ & 0.28 & \\
\hline Sycamore & 0.23 & & 0.15 & & 0.28 & & 0.20 & & 0.19 & \\
\hline Milwaukie & 0.36 & $* *$ & 0.22 & & 0.15 & & 0.12 & & 0.08 & \\
\hline \multicolumn{11}{|l|}{ Tualatin River } \\
\hline Dilley & 0.45 & $* *$ & 0.12 & & 0.17 & & -0.23 & & 0.12 & \\
\hline Fanno Cr Durham & -0.27 & & -0.33 & $*$ & 0.22 & & -0.07 & & -0.68 & $* * *$ \\
\hline Fanno Cr 56th & -0.18 & & -0.38 & $* *$ & -0.12 & & -0.10 & & -0.50 & $* * *$ \\
\hline Oswego Dam & 0.37 & $* *$ & 0.22 & & 0.43 & $* *$ & 0.10 & & 0.02 & \\
\hline
\end{tabular}




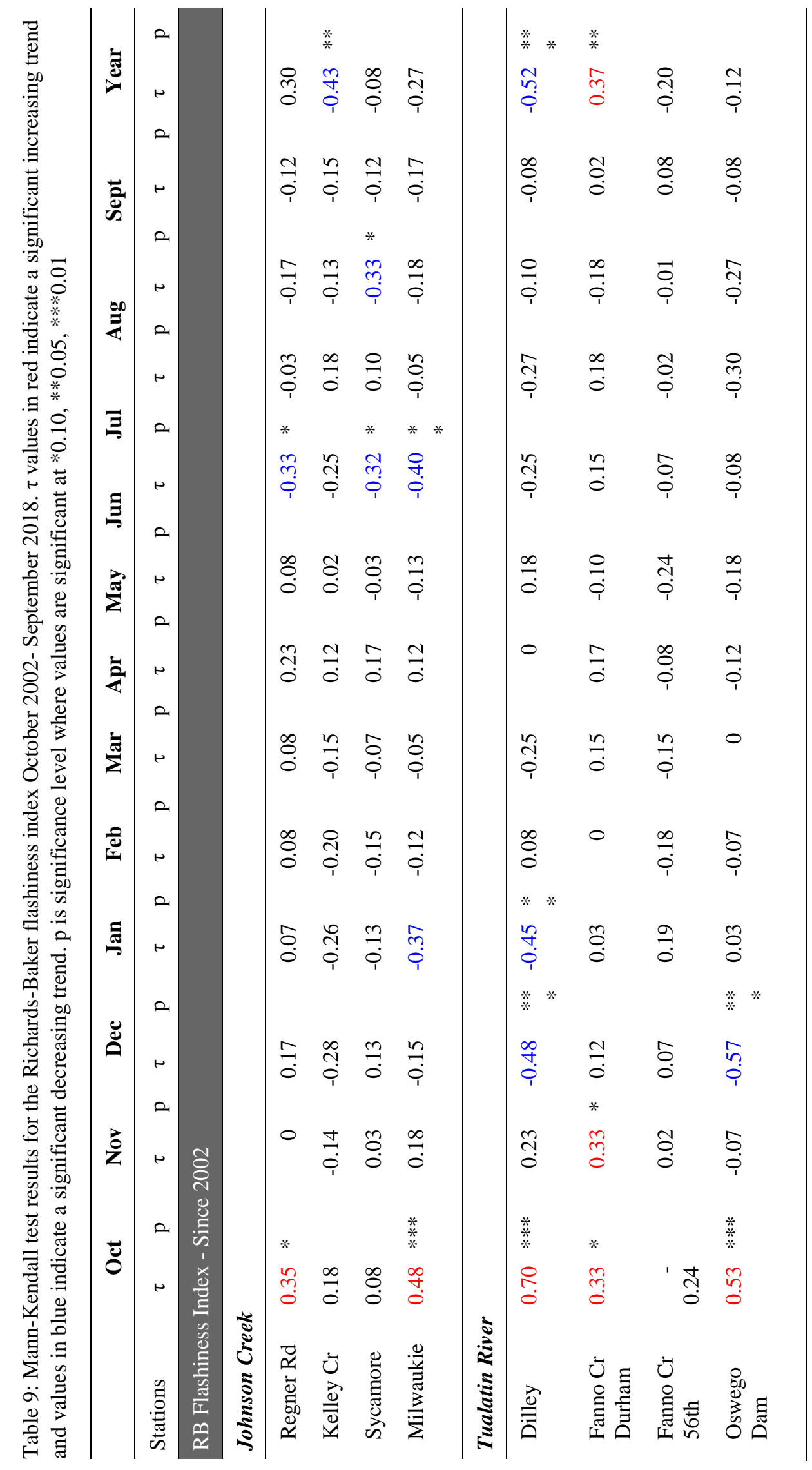




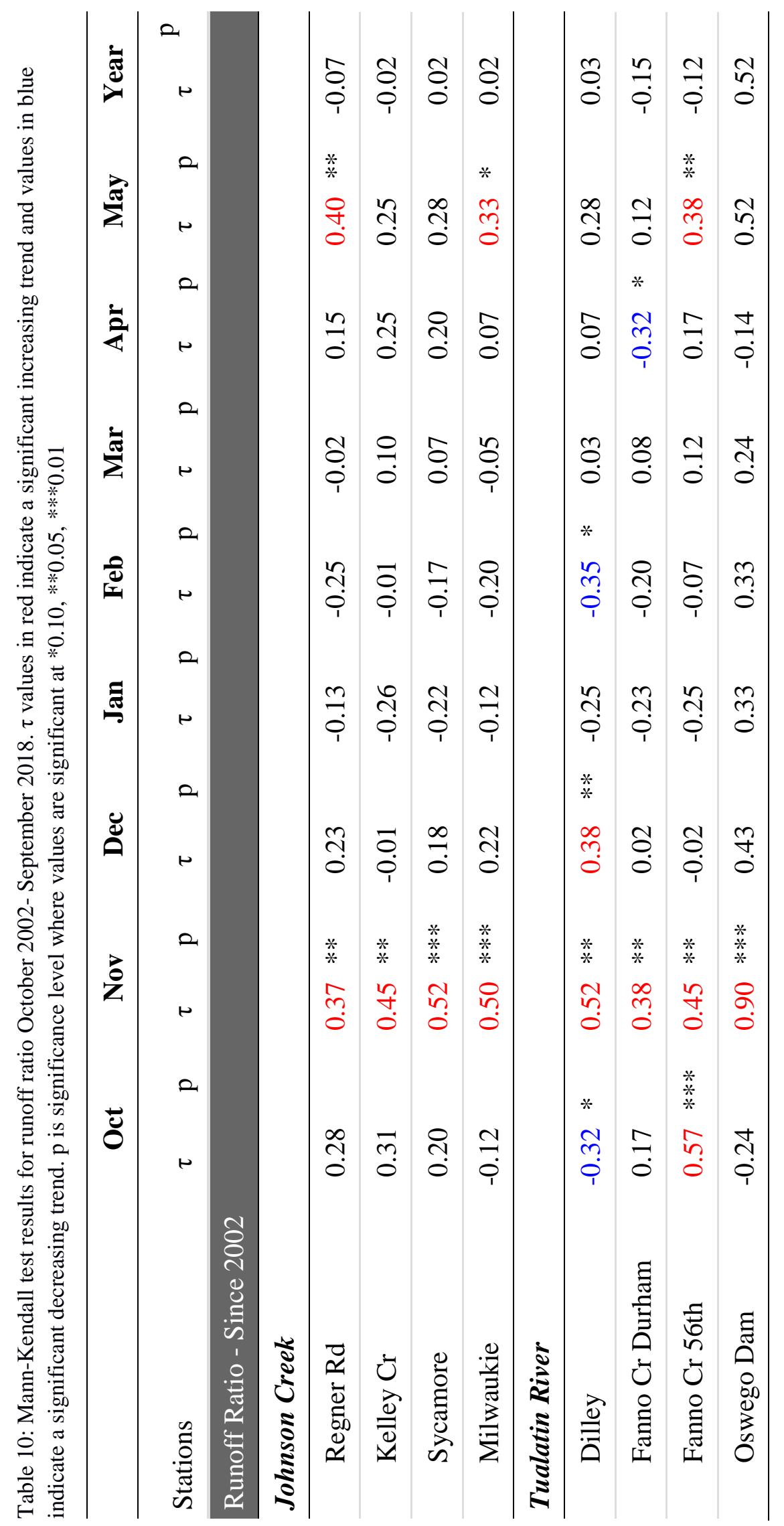




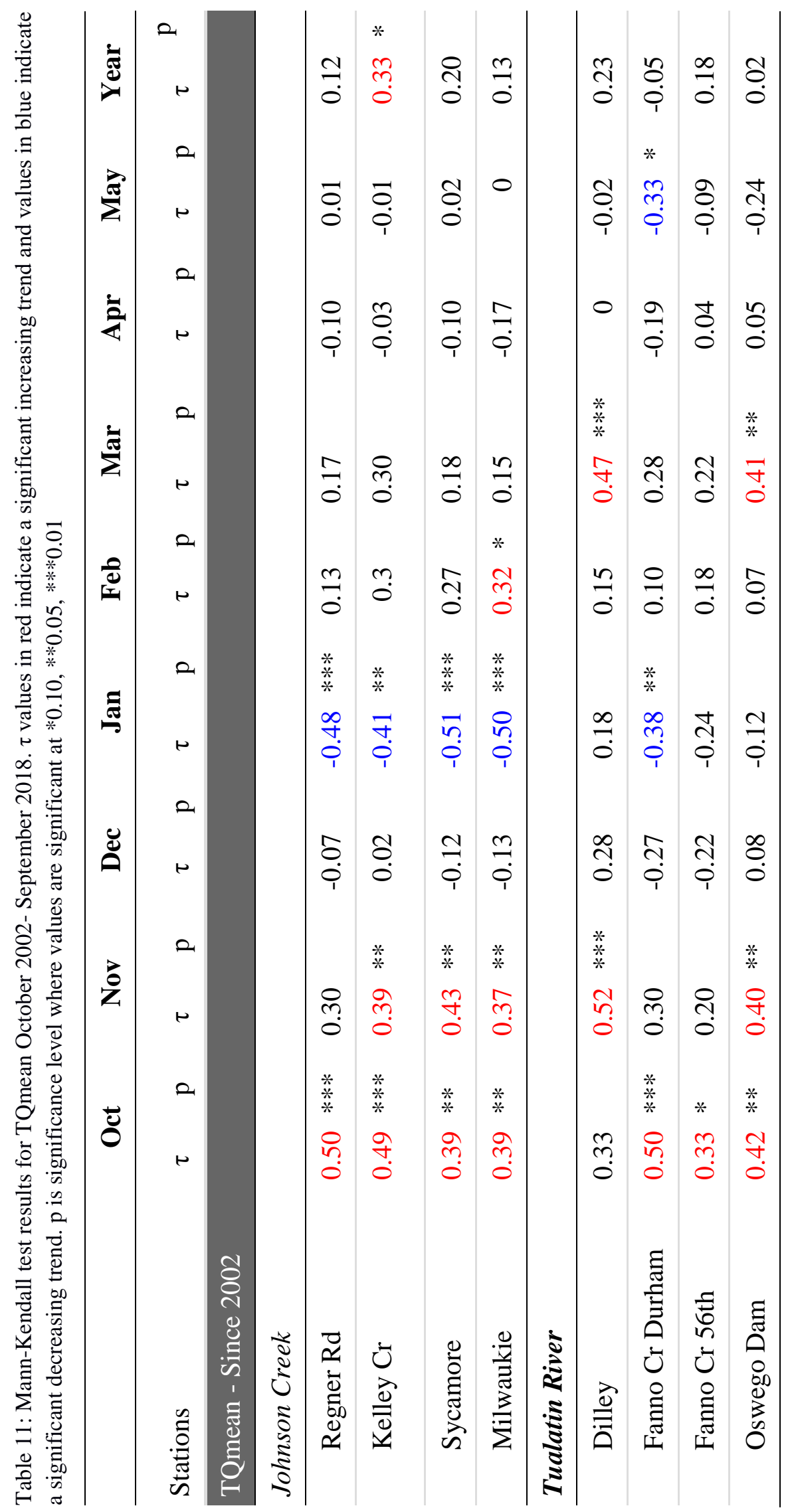




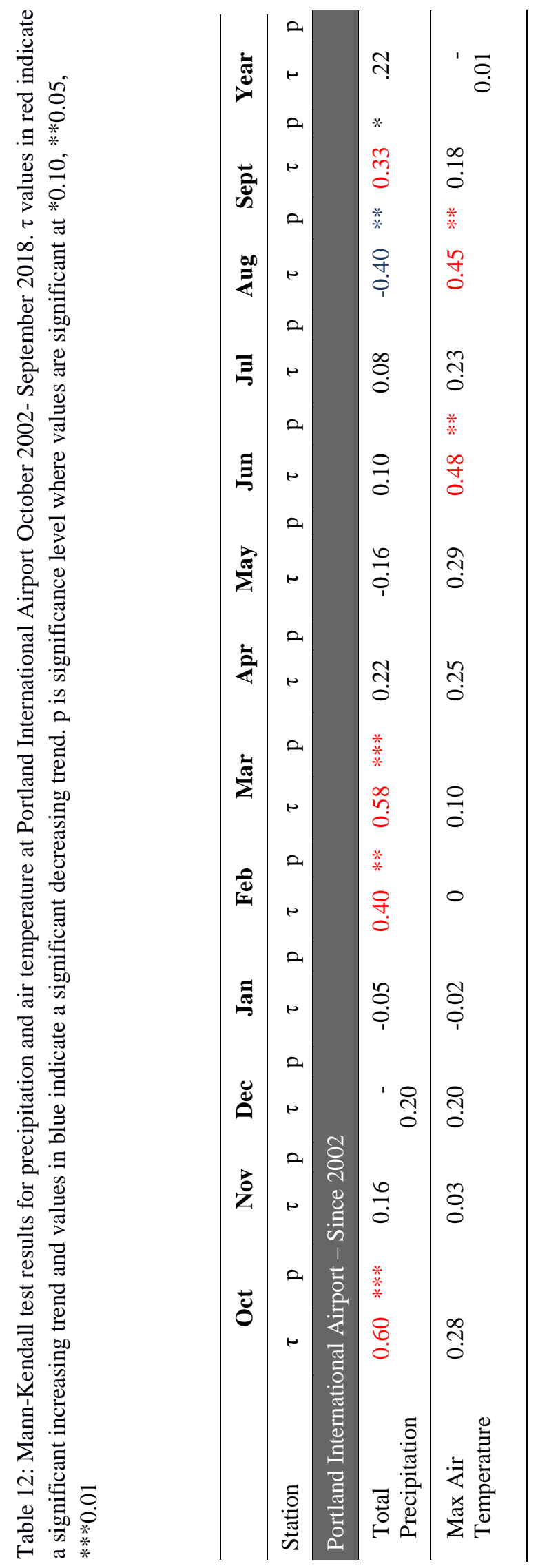




\subsubsection{Trend in stream temperature}

For 7DADmax post-2002, Regner Rd and Sycamore stations in Johnson Creek showed increasing trends for late summer months August and September, and by water year, with Sycamore showing a significant increasing trend for July as well. The Durham station in the Tualatin River Watershed showed significant increasing trends for June, August, and the water year. In contrast, the Milwaukie station in Johnson Creek showed significant decreasing trends for July-September, and for the water year. For 7DADmin, Regner Rd maintained increasing trends for July and August, while Sycamore and Oswego Dam showed increasing trends for August stream temperatures only.

For the number of days above 17.8 C, Regner Rd and Sycamore stations showed significant increasing trends for September and the water year, with an additional increasing trend in June for the Sycamore station. Fanno Creek at Durham showed significant increasing trends in August and the water year. Again, Milwaukie showed a significant decreasing trend of the number of days above $17.8 \mathrm{C}$ for the month of September.,

Few trends existed for thermal flashiness, with only two significant trends total: a significant decreasing trend for the Milwaukie station in September, and a significant decreasing trend at the Oswego Dam annually.

\subsubsection{Trend in streamflow}

Baseflow index decreased and increased for different stations across the study area. Since 2002, Kelley Creek showed significant decreasing trends in BFI from June- 
July but showed increasing trends for August-September. Both Fanno Creek locations showed significant decreasing trends in BFI for July and annually, while Milwaukie, Dilley and Oswego Dam showed increasing trends for June. Oswego dam also showed an increase in BFI for August.

For the Richards Baker flashiness index, overall, if trends are present, increasing trends generally occurred during the early water year while decreasing trends occurred in early winter in the Tualatin River Watershed, and summer months in Johnson Creek Watershed. We found five significant increasing trends for October flashiness at Regner Rd, Milwaukie, Dilley, Durham, and Oswego Dam stations in both watersheds. For the water year, Kelley Cr and Dilley showed significant decreasing trends while Durham showed increasing trends.

Most notably, runoff ratios showed significant increasing trends for the month of November for every station in both watersheds. Other trends for this metric seem dependent on the station in question in terms of patterns of trends. No annual trends appeared for any station annually.

TQmean appears showed significant trends in flashiness for the month of October similar to the results found for the Richard Baker flashiness index. This index appeared to pick up on more increasing trends for flashiness for the months of October and November post-2002. There were significant decreasing trends of TQmean for January for Regner Rd, Kelley Cr, Sycamore, Milwaukie, and Durham stations. 


\subsection{Thermal sensitivity and nonlinear regression}

Results for the nonlinear regression are plotted in Figures 3 through 8, with lines of the model relationship drawn above plotted circles of air temperature and discharge values. RMSE and thermal sensitivity values are summarized in Table 13 and 14, respectively. Table 15 includes the linear models to gain a simple understanding of the standardized relationship of model variables. 
14211499 - Kelley $\mathrm{Cr}$ at 159th
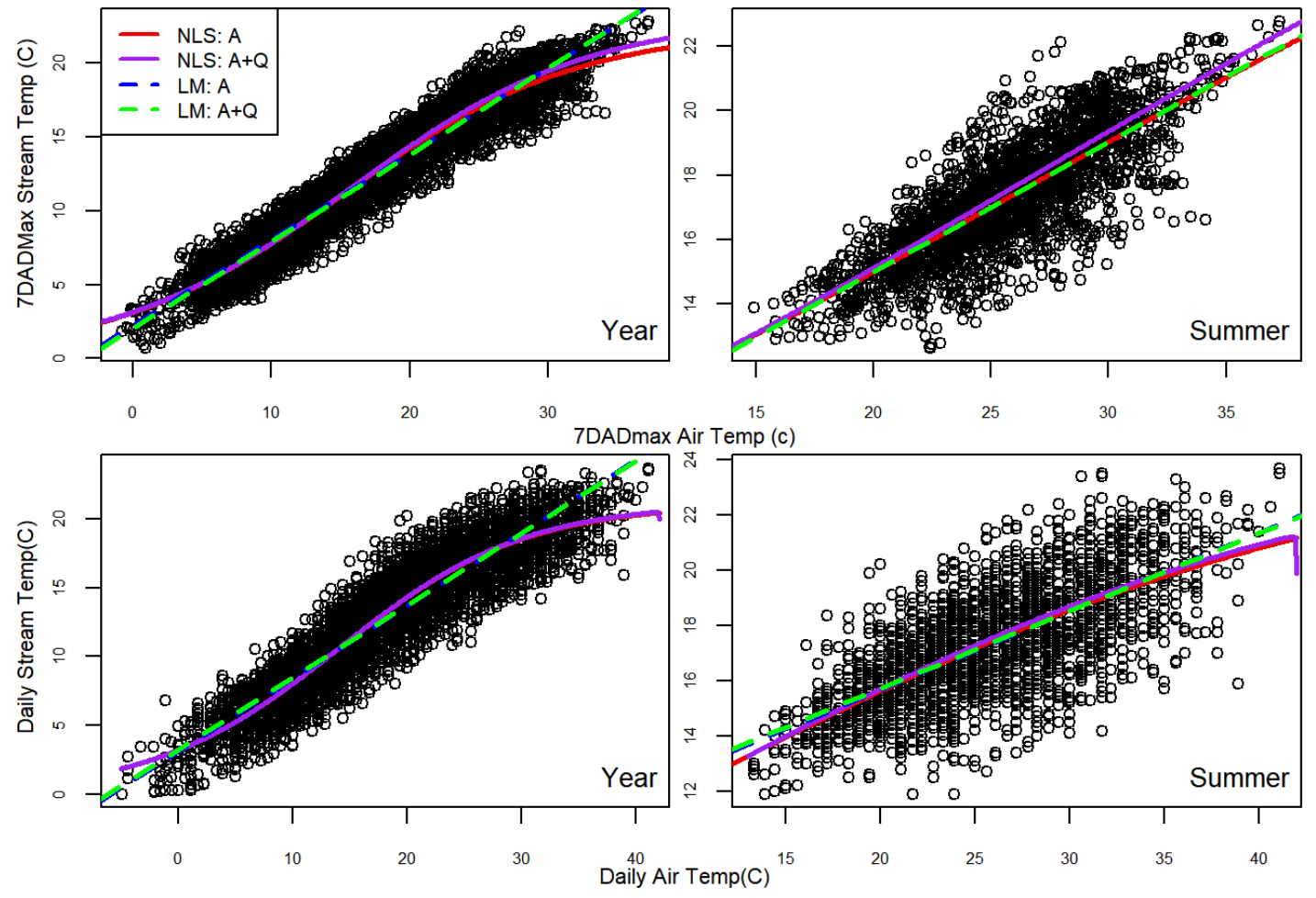

Figure 3: Thermal sensitivity at Kelley Creek

The top plots show the 7-day moving average values of stream temperature plotted against 7 day moving average of daily maximum air temperature, while the bottom plots show raw daily stream and air temperature values. The left plots show annual relationships with the right plots show summer relationships. Red lines indicate a nonlinear least squares regression of stream temperature vs. air temperature, while the purple line shows the nonlinear relationship of stream temperature vs. air temperature and discharge. The blue dashed line shows the linear relationship between stream temperature and air temperature, while the dashed green line shows the linear relationship between stream temperature vs air temperature and discharge. 
14211400 - Johnson Cr at Regner Rd
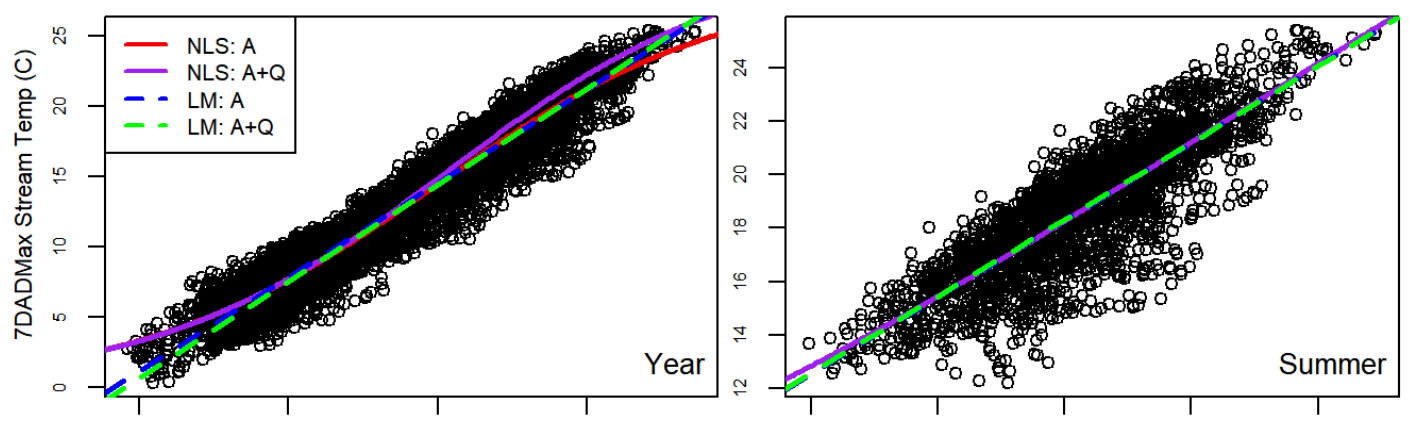

$0 \quad 10$

20

30

20

25

30

35

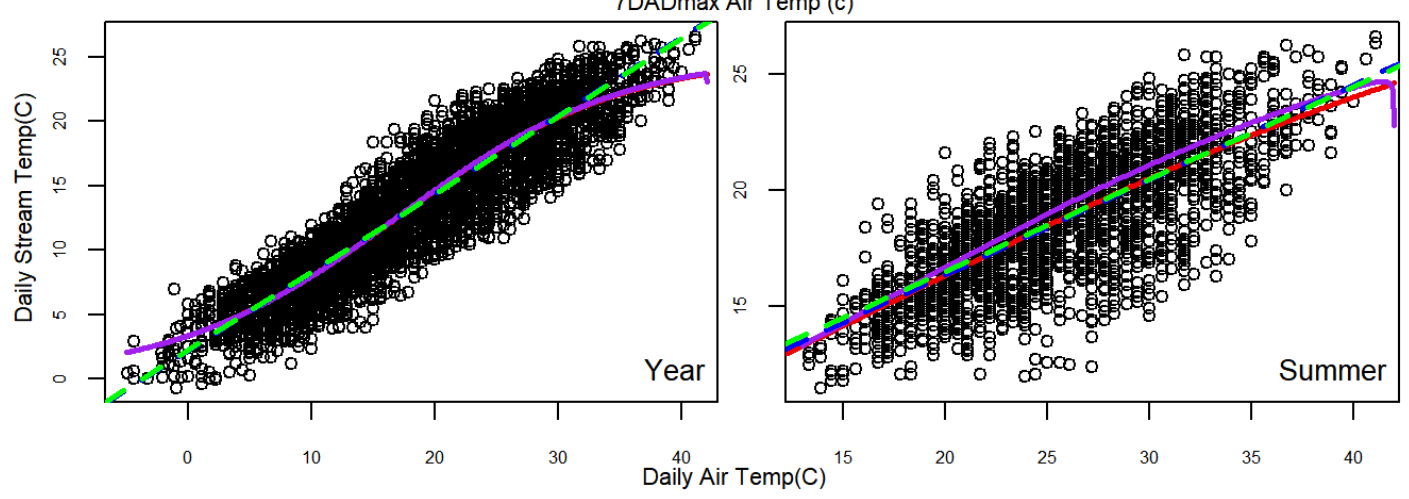

Figure 4: Johnson Creek at Regner Rd

The top plots show the 7-day moving average values of stream temperature plotted against 7 day moving average of daily maximum air temperature, while the bottom plots show raw daily stream and air temperature values. The left plots show annual relationships with the right plots show summer relationships. Red lines indicate a nonlinear least squares regression of stream temperature vs. air temperature, while the purple line shows the nonlinear relationship of stream temperature vs. air temperature and discharge. The blue dashed line shows the linear relationship between stream temperature and air temperature, while the dashed green line shows the linear relationship between stream temperature vs air temperature and discharge. 
14211500 - Johnson Cr at Sycamore
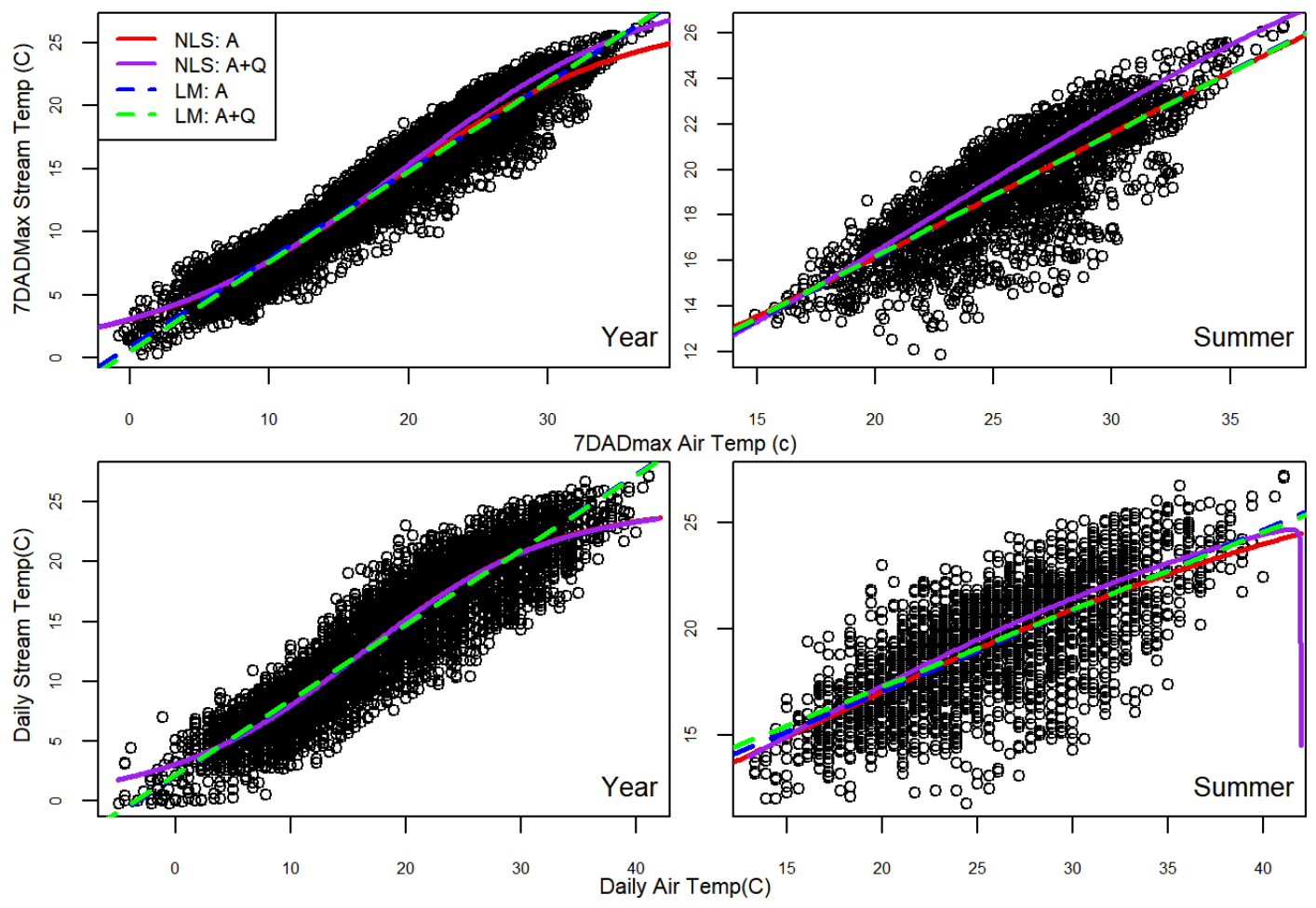

Figure 5: Johnson Creek at Sycamore

The top plots show the 7-day moving average values of stream temperature plotted against 7 day moving average of daily maximum air temperature, while the bottom plots show raw daily stream and air temperature values. The left plots show annual relationships with the right plots show summer relationships. Red lines indicate a nonlinear least squares regression of stream temperature vs. air temperature, while the purple line shows the nonlinear relationship of stream temperature vs. air temperature and discharge. The blue dashed line shows the linear relationship between stream temperature and air temperature, while the dashed green line shows the linear relationship between stream temperature vs air temperature and discharge. 
14211550 - Johnson $\mathrm{Cr}$ at Milwaukie
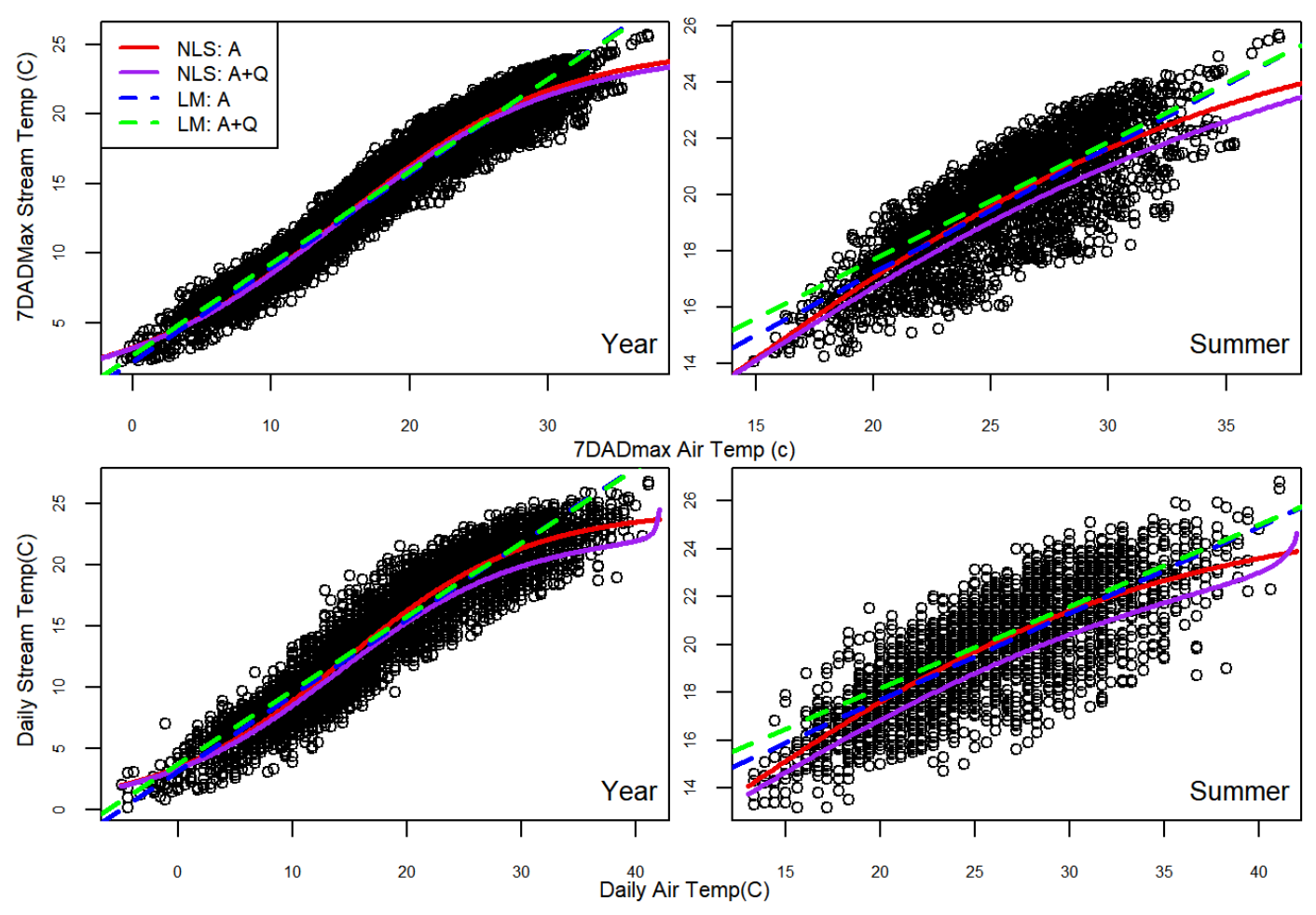

Figure 6: Johnson Creek at Milwaukie

The top plots show the 7-day moving average values of stream temperature plotted against 7 day moving average of daily maximum air temperature, while the bottom plots show raw daily stream and air temperature values. The left plots show annual relationships with the right plots show summer relationships. Red lines indicate a nonlinear least squares regression of stream temperature vs. air temperature, while the purple line shows the nonlinear relationship of stream temperature vs. air temperature and discharge. The blue dashed line shows the linear relationship between stream temperature and air temperature, while the dashed green line shows the linear relationship between stream temperature vs air temperature and discharge. 
14206950 - Fanno $\mathrm{Cr}$ at Durham
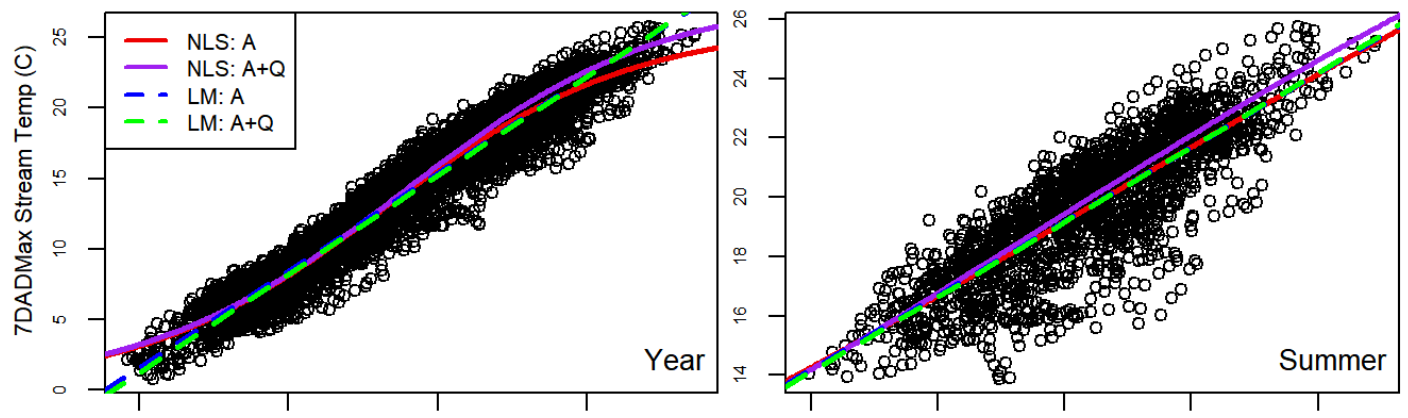

$0 \quad 10$

20

7DADmax Air Temp (c)

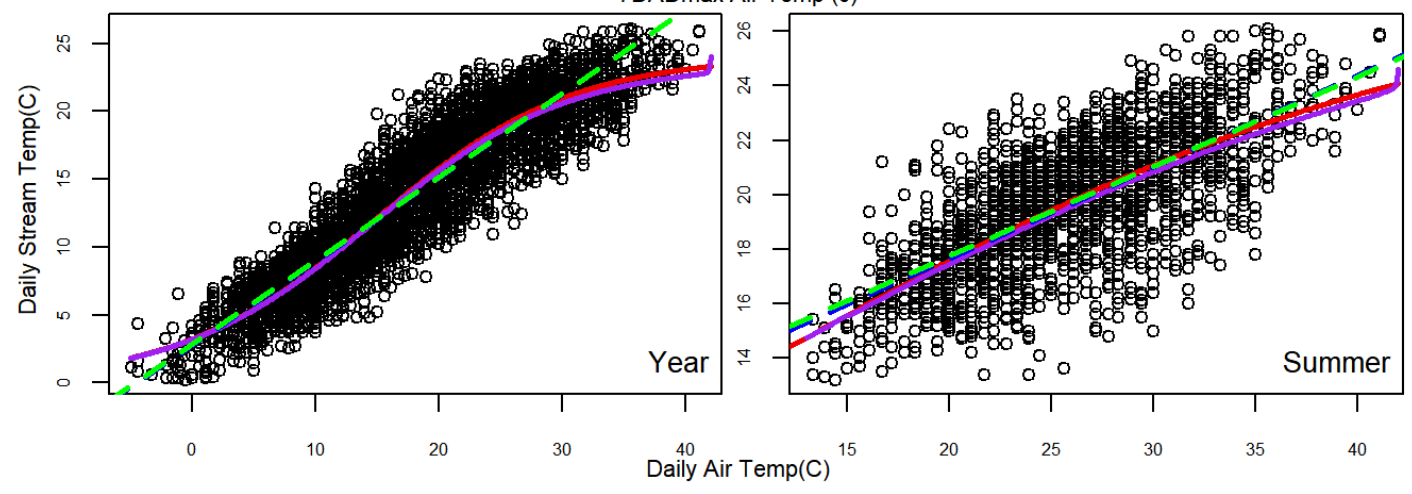

Figure 7: Fanno Creek at Durham

The top plots show the 7-day moving average values of stream temperature plotted against 7 day moving average of daily maximum air temperature, while the bottom plots show raw daily stream and air temperature values. The left plots show annual relationships with the right plots show summer relationships. Red lines indicate a nonlinear least squares regression of stream temperature vs. air temperature, while the purple line shows the nonlinear relationship of stream temperature vs. air temperature and discharge. The blue dashed line shows the linear relationship between stream temperature and air temperature, while the dashed green line shows the linear relationship between stream temperature vs air temperature and discharge. 
14207200 - Tualatin River at Oswego Dam
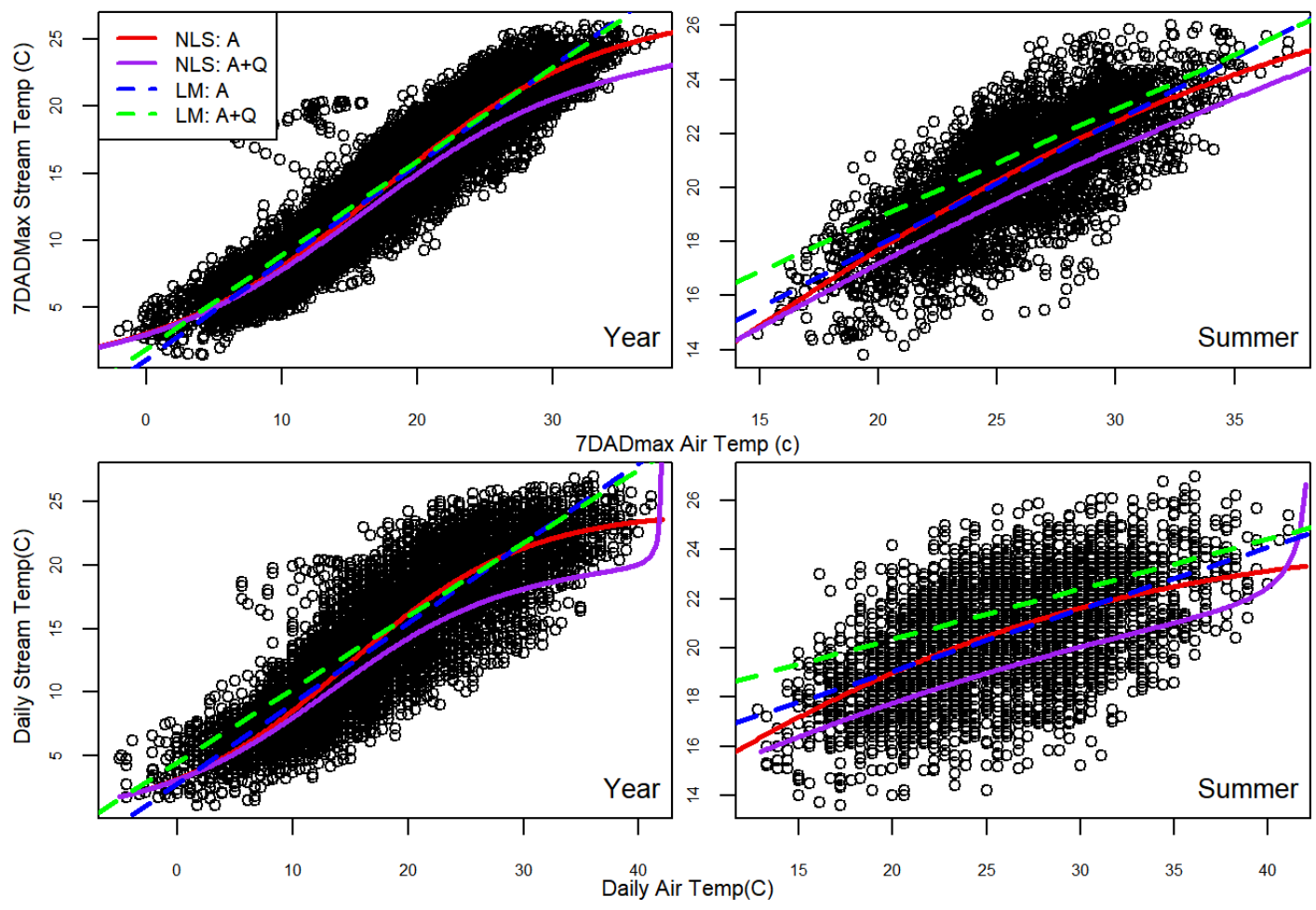

Figure 8: Tualatin River at Oswego Dam

The top plots show the 7-day moving average values of stream temperature plotted against 7 day moving average of daily maximum air temperature, while the bottom plots show raw daily stream and air temperature values. The left plots show annual relationships with the right plots show summer relationships. Red lines indicate a nonlinear least squares regression of stream temperature vs. air temperature, while the purple line shows the nonlinear relationship of stream temperature vs. air temperature and discharge. The blue dashed line shows the linear relationship between stream temperature and air temperature, while the dashed green line shows the linear relationship between stream temperature vs air temperature and discharge. 


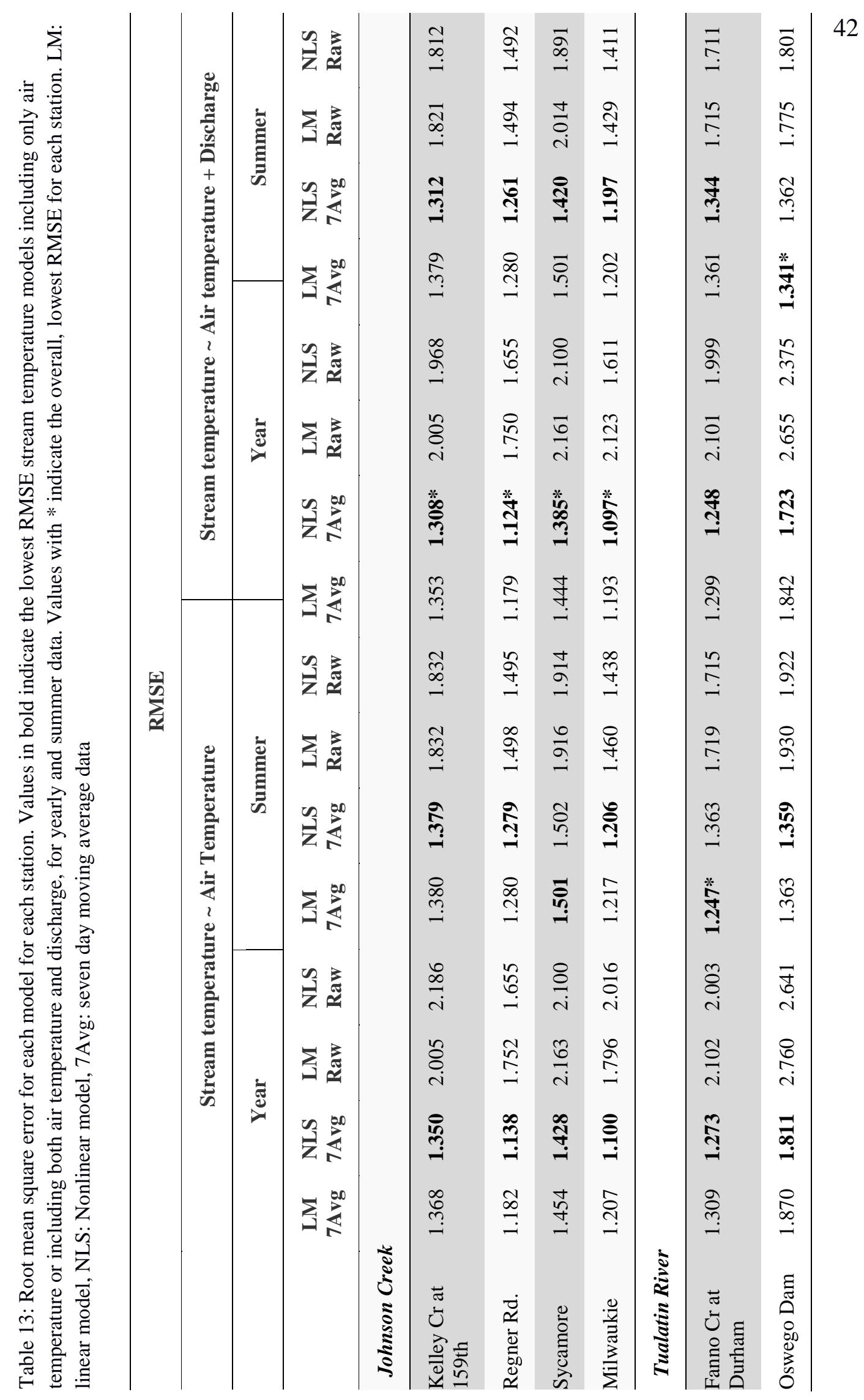




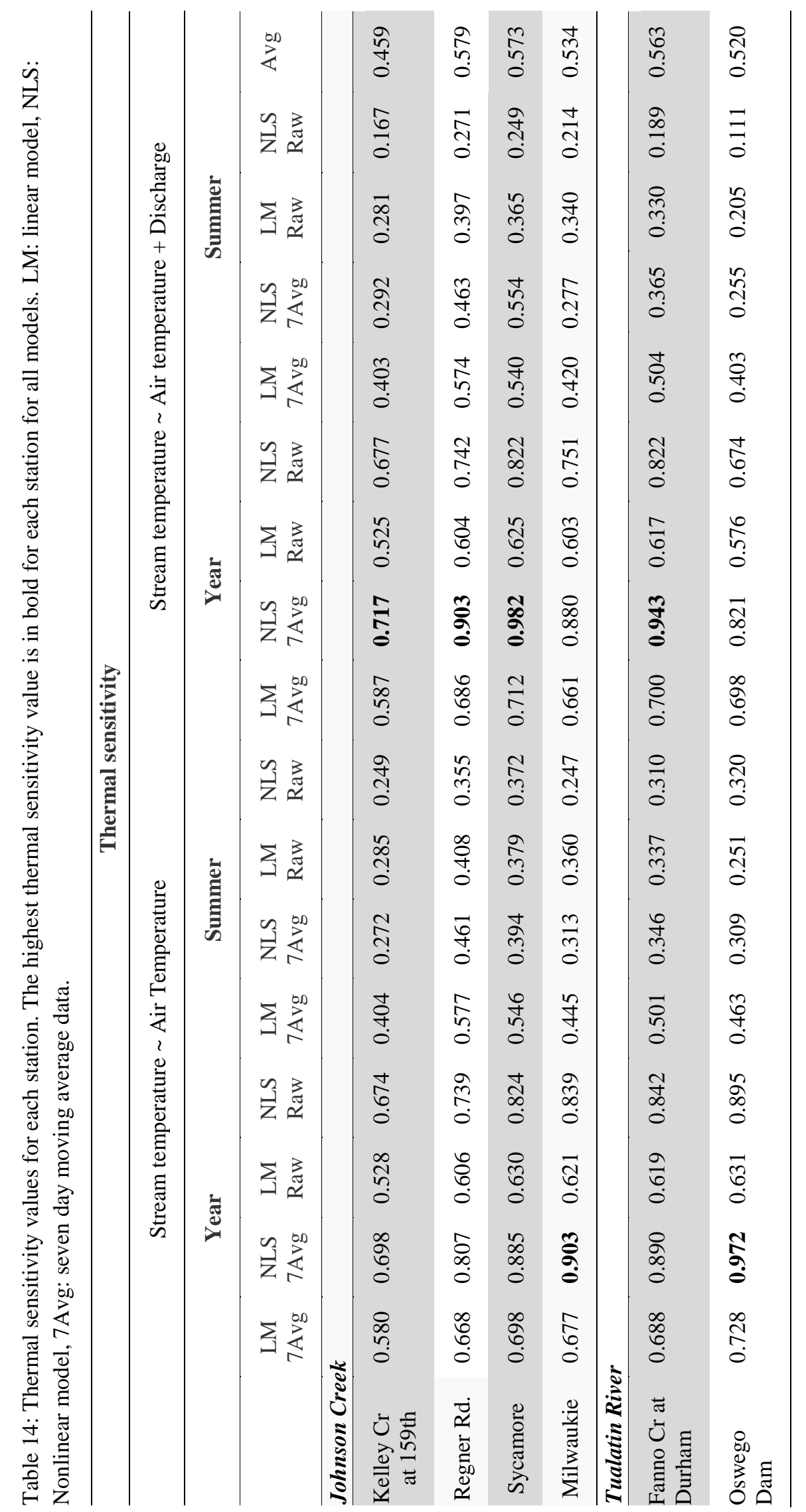




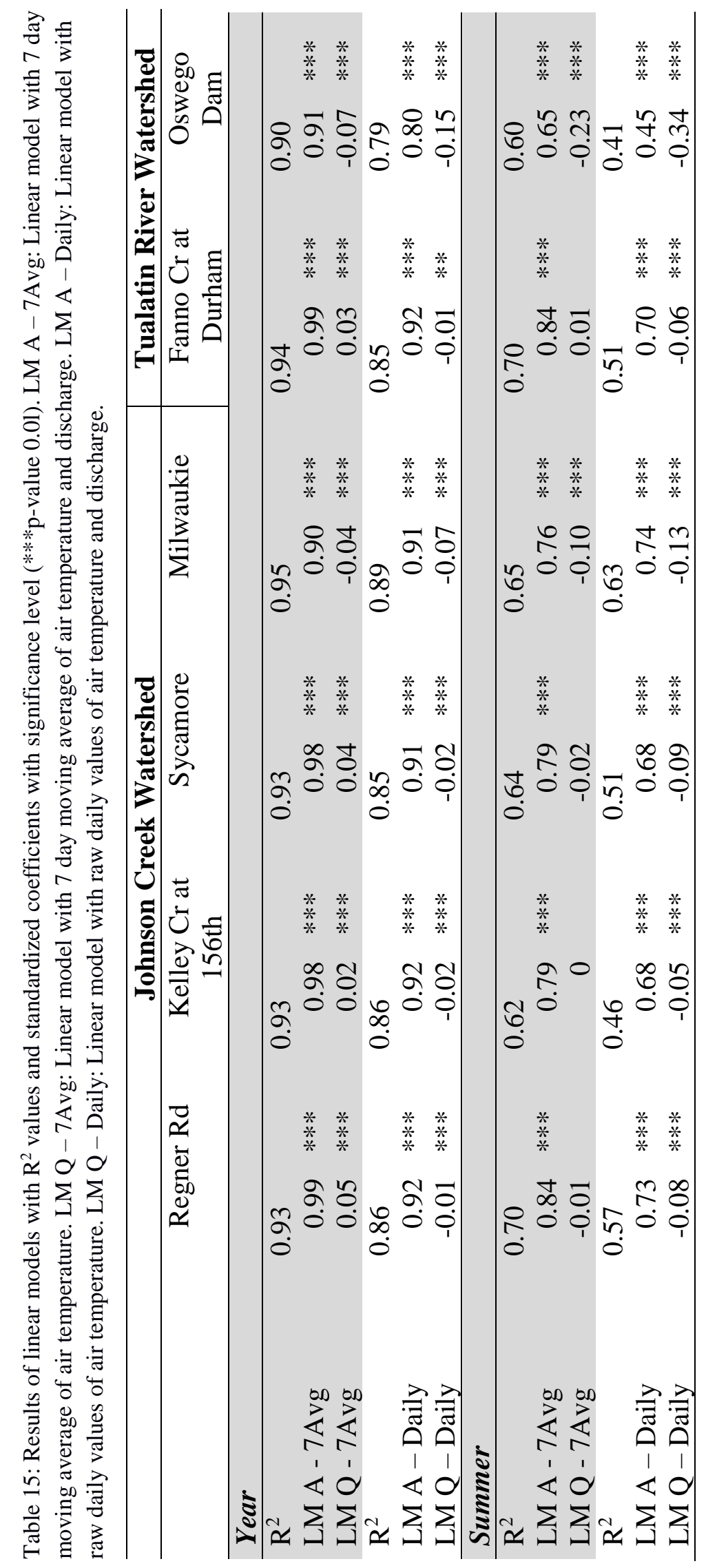


Plots of 7 day moving-average values in Figures 3 through 8 show less scatter than plots of raw values. As such, RMSE values across all six stations for all 16 models indicated that overall, the fit improved with the addition of discharge to the regression models for 7 day moving average values. For the models of stream temperature as a function of air temperature for yearly data, the nonlinear model of 7 day moving average of stream temperature and air temperature had the lowest RMSE. For the models of stream temperature as a function of air temperature for summer data, the nonlinear model of 7 day moving average of stream temperature and air temperature typically also had the lowest RMSE, except for Johnson Creek at Sycamore and Fanno Cr at Durham, which both had a lower RMSE for the linear 7 day moving average models. For the models of stream temperature as a function of air temperature and discharge, again, the nonlinear models for 7 day moving average values had lowest for both yearly data and summer data, except for the Tualatin River at Oswego dam in summer, which had the lowest RMSE for the linear 7 day moving average model.

Out of all stations for all possible models, four out of six stations showed the lowest overall RMSE for the nonlinear 7 day moving average model of stream temperature as a function of air temperature and discharge. These four stations are all in the Johnson Creek Watershed. The two remaining stations, Fanno Creek at Durham and the Tualatin River at Oswego Dam, had the lowest RMSE for a linear models of summer stream temperature. The Durham station was lowest for the model only including air temperature, while the Oswego Dam station was lowest when including both air temperature and discharge. When looking at the yearly data, the lowest RMSE was also 
for the nonlinear 7 day moving average model of stream temperature as a function of air temperature and discharge.

Kelley Cr, Regner Rd and Sycamore stations in the Johnson Creek watershed and Fanno $\mathrm{Cr}$ at Durham in the Tualatin River Watershed both had highest thermal sensitivity when accounting for discharge, whereas the resultant location's thermal sensitivity was highest when accounting for air temperature alone. Thermal sensitivity values were all highest for the nonlinear models and were all higher when accounting for the yearly values as opposed to summer values only.

Linear models with the highest $\mathrm{R}^{2}$ for year and summer were both 7 day moving average models. $\mathrm{R}^{2}$ values were above 0.90 for all yearly models and between 0.60 and 0.70 for the summer linear models. For the summer 7 day moving average models, discharge was insignificant for Regner Rd, Kelley Cr, Sycamore and Durham, but highly significant for Milwaukie and Oswego Dam at the bottom of each respective watershed. Standardized coefficients for discharge were larger for the downstream stations and were generally smaller the further up the watershed. The magnitude of discharge coefficients was generally larger for models using raw data and were always significant. At all stations, air temperature has a larger respective influence on stream temperature compared to discharge. This difference is smallest for the Tualatin River at Oswego Dam daily summer model where discharge appears to show more of an influence. In general, summer daily value models showed discharge having the largest effect of the other three models for each respective station. Generally, at each station, summer stream temperature 
seems more influenced by discharge than any other model for their respective stations, although air temperature always has a greater influence on stream temperature. 


\section{Discussion}

\subsection{Stream temperature and discharge trends}

Trends for discharge and stream temperature are helpful to compare directly to trends in precipitation and air temperature at Portland International Airport (Table 19). Sometimes these trends coincide, while other times they do not. While trends for the entire year of record of each station are interesting, it is harder to compare across stations and draw meaningful conclusions, so more discussion is devoted to post-2002 trends.

\subsubsection{Stream temperature trends}

Generally, if a stream temperature trend is present, the trend indicates an overall warming occurring in stream in both the Johnson Creek and Tualatin River Watersheds in summer months. Warming trends in similar, recent literature have also found significant increasing stream temperature trends across the globe in Northern Germany (Arora et al. 2016) the Volga River in Russia (Bui et al. 2018), the Pacific Continental US (Arismendi et al. 2012; Isaak et al. 2012), and the entire continental US (Kaushal et al. 2010). The Johnson Creek at Milwaukie station showed significant decreasing trends in maximum temperature for most summer months post-2002. The decreasing trend in the Milwaukie stations is likely due to the complex hydrogeology of Johnson Creek with significant groundwater contributions in the lower watershed effectively cooling the stream despite warm summer temperatures (Lee and Snyder 2009). A significant increase in baseflow index during the month of June may trickle over to the following summer months helping to explain decreasing stream temperature trends, though concomitant trends in baseflow 
are absent for July, August, and September. Additionally, the lower portions of Johnson Creek watershed flowing through the Milwaukie station had been developed much longer ago, whereas other the three stations likely have gone through more recent land use change, which could help explain increasing stream temperature or increasing streamflow flashiness trends generally absent at Milwaukie. Additionally, years of installation of riparian restoration projects seeking to increase shade throughout the watershed could also help to explain reduction in stream temperature metrics. Riparian shade is commonly recognized as a successful way to reduce stream thermal sensitivity (Johnson and Wilby 2015; Woltemeade and Hawkins 2016; Arora et al. 2018; Wondzell, Diabat, and Haggerty 2019). Kelley Creek and Scoggins Creek gauging stations showed no significant trends in stream temperature. Both stations are located in the upper portions of Johnson Creek and Tualatin River Watershed, respectively. Additionally, water temperatures for Scoggins Creek never reach critical high temperature threshold and is also located downstream of the dam at Henry Hagg lake that can significantly influence and alter the natural stream temperature regime.

Certain summer increasing trends in stream temperature coincide with highly significant increasing maximum air temperature trends in August since 2002 at the Portland International Airport, though air temperature trends are absent for the months of July, September and annually. Highly significant trends in air temperature are present for each summer month and annually since 1940. Other studies have also concluded air temperature as the most important determinant of increasing stream temperature when compared to other explanatory variables such as discharge and anthropogenic landcover changes (Isaak et al. 2010; Kaushal et al. 2010; Seekell and Pace 2011; Van Vliet et al 
2011; Arora et al. 2016; Chen et al 2016a; Woltemade and Hawkins 2016; Culler et al. 2018). While air temperature trends may be able to explain increasing trends in maximum and minimum stream temperature metrics, the lack of air temperature trends in July, September and annually since 2002 could be attributed to factors other than hydroclimatological characteristics, such as increasing urbanization and impervious surfaces (Kaushal et al. 2010) or changes in land use, which has been discussed in other literature in the area (Chang 2007; Chen et al. 2016a; Arora et al. 2018; Wondzell, Diabat, and Haggerty 2019).

For 7DADmax, the increasing trend at Johnson Creek at Regner Rd in August appeared to coincide with an increasing trend in 7DADmin, while the September and annual increasing trends also coincided with increases in the number of days above 17.8 ${ }^{\circ} \mathrm{C}$. Late summer stream temperatures appear to be increasing generally, which is picked up by multiple stream temperature metrics. No significant simultaneous trends in baseflow index coincided with these increasing temperature trends so stream temperature trends may not be strongly related to any trends in discharge. Correlations of trends of stream temperature metrics and baseflow index trends, including lagged monthly relationships were not significant (not shown), which may further indicate that changing land cover characteristics as possible explanatory variables could explain these trends and warrant further investigation. This absence of discharge trends could be due to depleted soil moisture, soaking up precipitation as it falls on surfaces, and allowing for less water to flow in streams. The highly significant decreasing trend in precipitation in August coupled with the increasing trend in August air temperature could be largely to contribute to these increases in stream temperature. The significant increasing trends in stream 
temperatures found in this study is noteworthy and can have negative implications for water quality and aquatic biota under a changing climate (Isaak et al. 2012; Chang, Watson and Strecker 2017).

\subsubsection{Discharge trends}

In general, stream temperature trends do not appear to coincide with any significant base flow index trends. This indicates that discharge, specifically baseflow, is not explicitly causing any increases trends in stream temperature in both the Johnson Creek and Tualatin River watersheds. Other work in the study area has addressed trends in discharge. Velpuri and Senay (2013) found significant decreasing trends in runoff ratio for the Tualatin River from 1950-2009. Additionally, Chang (2007) found one significant trend of wet season runoff ratio for Tualatin River at Dilley station from 1951-2000. In this study no annual trends were found for runoff ratio for any station for its entire period of record, nor since 2002. Lee and Snyder (2009) found no evidence for any trends of runoff ratio or TQmean for the Sycamore station in Johnson Creek, though Chang (2007) found a significant decreasing trend in TQmean from 1951 to 1975, and a significant increasing trend from 1976-2000. While we found no annual trends in runoff ratio nor TQmean at the Sycamore station during either the annual or monthly time period, a significant increasing trend in TQmean was found annually at Kelley Creek since 2002, suggesting some changes to equilibrium in more recent years, such as the continued recent development of the Kelley Creek watershed in the early 2000s (Levell and Chang 2008). It is important to remember that trends are sensitive to the time period under 
investigation as well as climate variability (e.g El Nino) influencing the study area (Chang 2007, Velpuri and Senay 2013).

One noteworthy discovery shows every station in both watersheds with discharge records show significant increasing runoff ratio for the month of November. Five out of eight of these stations with a significant increasing runoff ratio trend for November (Kelley Cr, Sycamore, Milwaukie, Dilley and Oswego Dam) also showed highly significant increasing trends of TQmean in November. This means that at these five stations in November since 2002, these stations are experiencing an increasing proportion of runoff to streams from precipitation as well as increasing time that streamflow is greater than mean stream flow which is somewhat contradictory to what one might expect if urbanization and impervious surface runoff was to blame. Typically, higher TQmean (in this case, increasing trends in TQmean) is indicative of more suburban streams (Konrad et al. 2005). No significant increasing trends in precipitation were found for the month of November, which could explain these increases. In October, increasing trends in TQmean is also occurring at seven out of eight stations except for the Dilley station. These streams are all generally urbanizing areas, so increases in TQmean likely coincide to increases of October precipitation at PDX since 2002 (Table 19). Cooley and Chang (2017) also found there to be highly significant increasing trends in October precipitation intensity and monthly precipitation volume in the study area in October months. The significant November trends found in this study may indicate a trickle effect from the increased precipitation in October. Since these two months are at the beginning of the water year, this finding may have important implications for shifting water quality, 
such as increased early season turbidity. Further explorations of this implication should be considered in future research throughout the two watersheds.

\subsection{Relation between stream temperature, air temperature and discharge}

Evaluating results from linear regression helps to gain preliminary estimates of the relationship between stream temperature, air temperature and discharge (Kelleher et al 2012). By looking at the standardized coefficients of air temperature and discharge, it is apparent that air temperature had a much larger influence on stream temperature than does discharge, which is in line with other literature, especially of streams of similar order and drainage area (Ahmadi-Nedushan et al. 2007; Isaak et al. 2010; Kaushal et al. 2010; Koch and Grenewald 2010; Seekell and Pace 2011; Van Vliet et al 2011; Arora et al. 2016; Chen et al 2016a; Letcher et al. 2016; Naresh and Rehana 2017; Culler et al. 2018).

Based on RMSE, nonlinear modelling produced a better fit than did a simple linear model at all stations when looking at daily data for all years. This supports previous works that the air-stream temperature, and sometimes discharge, relationships are better fitted with a sine function than a linear function (Mohseni, Stefan and Erickson 1998; Morrill Conklin and Bales 2005; Keller et al. 2012; Zeiger et al. 2016). The nonlinear model including discharge showed a lower RMSE though the degree that discharge improved models declined as a stream's thermal sensitivity increased (van Vliet et al 2011; Hilderbrand 2014). Research has shown that discharge has a larger effect on stream temperature in larger basins with greater discharge, which could explain that while it may improve model fit, generally the magnitude of impact is still quite small 
(Web, Clack, and Walling 2003; Van Vliet et al. 2011). While discharge improved the nonlinear models which also had the lowest RMSE, standardized coefficients of air temperature and discharge in linear multiple regression models further showed air temperatures importance in determining stream temperature, though like other studies, discharge's relative impact on stream temperature was generally more significant in summer when discharge is lower compared to the whole year (Webb, Clack and Walling 2003; Culler et al. 2018, Van Vliet et al. 2011). Models with the lowest RMSE for summer values were generally a mixture of nonlinear and linear regression models, showing that the relationship between stream temperature and air temperature becomes more linear in certain areas of the watersheds. The outperformance of nonlinear models by linear models in the region has been shown in other recent literature, specifically Fanno Creek in the Tualatin River watershed (Piotrowski and Napiorkowski 2019). The amount of variance explained is much greater when accounting for the entire years' worth of data. Less variance is explained in summer which indicates that other variables may need to be accounted for to improve model fit in models' summer thermal sensitivity.

\subsection{Thermal sensitivity along an urban-rural gradient}

When examining thermal sensitivity values, thermal sensitivity generally increases from upstream to downstream as the streams accumulate thermal energy (Hilderbrand et al. 2014). This is evident in the many thermal sensitivity models in this study. Hilderbrand et al. (2014) found that lower thermal sensitivity values were related to steep stream channel gradients and higher proportions of forest area in their respective 
watersheds. Higher slope and rugged terrain can allow for less interaction with air temperatures as water quickly drains from the landscape (Hilderbrand et al. 2014; Meier et al. 2003). Indeed, gaging stations in these areas have greater contributing forest coverage and higher mean slope.

Thermal sensitivity values are different depending on the model used. Generally, for the upstream Regner Rd, Kelley Cr, Sycamore and Fanno Creek at Durham stations, thermal sensitivity is greater when accounting for discharge. For Johnson Creek at Milwaukie and Tualatin River at Oswego Dam, thermal sensitivity is greater without discharge. This is most likely due to the inverse function of discharge included in the nonlinear regression models. As more discharge flows through the lowest stations of both Johnson Creek and Tualatin Rivers, the inverse function likely lowers thermal sensitivity, reflecting larger stream's increased thermal capacity from the rural headwaters to the urbanized outlets (Webb, Clack and Walling 2003).

\subsection{Implications for watershed management}

It is important to be able to identify a stream's thermal sensitivity, especially when considering impending climate change. Aquatic plants and animals in streams with higher thermal sensitivity are more at risk with rising air temperatures (Kelleher et al. 2012; Chang and Psaris 2013; Hilderbrand et al. 2014; Chang, Watson and Strecker 2017; Piotrowski and Napiorkowski 2019). On the contrary, streams with lower thermal sensitivities may be more resilient to climate change. Based on the average values of thermal sensitivity at each location, the Regner Rd and Sycamore stations are more sensitive to air temperature than the other two stations in the Johnson Creek watershed, 
while the Fanno Creek at Durham location is more sensitive than the Oswego Dam in the Tualatin River Watershed. This seems to indicate that thermal sensitivity is at least in part a function of watershed size. Watershed managers, knowing of streams' thermal sensitivities, may be better able to funnel resources into areas of the watershed that are more at risk with restoration practices to reduce air temperatures influence on stream temperature, such as tree planting to encourage shade (Johnson and Wilby 2015). Knowledge of more sensitive areas may also help local government be more efficient in their responsibilities of protecting EPA endangered and threatened species.

Knowledge of trends related to stream temperature and discharge at certain locations of both watersheds can also help to elucidate the site-specific issues that may exist or may worsen, calling for more specialized restoration practices in distinct locations. The increasing temperature trends at the Sycamore, Regner Rd and Durham stations couple with increased thermal sensitivity will be something to watch in the warming climate to come.

By investing smarter in the environment, other ecosystem services are guaranteed to benefit the surrounding community. While direct restoration, or other best management approaches towards watershed protection may meet specific project or government goals, other ecosystem services, such as urban heat mitigation, health benefits, improved wildlife connectivity, green space and recreation and increasing property values are sure to benefit the residents of the community as well as the economy. 


\subsection{Suggestions for future research}

As stream temperature and discharge modelling is complex, further exploring the spatial relationship of stream temperature metrics and thermal sensitivity can help to explore what, if any, landscape controls exist on stream temperature and discharge. Spatial modelling can also help further explain the nuances inherent in the urban-rural gradient. The lower $\mathrm{R}^{2}$ values of summer thermal sensitivity models indicate that the introduction of additional explanatory variables can help to explain further thermal sensitivity variance. Exploring landscape characteristics such as land use, imperviousness and topography, are likely candidate variables. This type of analysis would require more site-specific data throughout the watershed but would have important implications to further pinpoint and categorize specific reaches to guide best management practices for improving water quality. Additionally, many other models of varying complexity can be

utilized, which may better model stream temperature, air temperature and discharge relationships at each specific location (e.g. Arora et al 2018; Piotrowski and Napiorkowski 2019). Further extrapolating models for climate change applications could help to inform future water quality conditions and could further inform research by use of time series analyses (Ahmadi-Nedushan et al 2007; Benyahya et al. 2007; Cole et. al. 2014; Elga, Jan, and Okke 2015; Valipour 2015; Chang, Watson and Strecker 2017; Wang, Qiu, Li 2018). 


\section{Conclusions}

This research takes advantage of spatially and temporally detailed data to offer better understanding of local discharge and temperature trends and relationships that can inform watershed managers and planners of changing water resources and their implication on aquatic habitat and species, and water resources. This research showed significant stream temperature and discharge trends, some of which could be associated with hydroclimactic trends, and some of which do not coincide with any trends in air temperature nor precipitation. For example, certain increasing trends in 7 day moving average of daily maximum stream temperature can be associated with increasing August trends in air temperature and decreasing trends in August precipitation, but no significant increasing trends in air temperature were found in July, September, or annually. Interesting trends in streamflow were also found, with increases in runoff ratio and TQmean in early fall. All stations post 2002 showed increasing runoff ratio for November. Some of these trends coincide with recent increases in October precipitation intensity (Cooley and Chang 2017), though no significant increases in November precipitation were detected. Further research is needed to better explore the relationships between stream temperature and landscape characteristics that could exacerbate or be the cause of these increasing or decreasing trends as the controls on stream temperature and discharge are complex.

Further modelling shows that stream temperature is more sensitive to air temperature compared to discharge. Stations with larger contributing area showed increased thermal sensitivity without including discharge, whereas higher thermal sensitivity was found at stations with smaller contributing areas while accounting for 
discharge. Overall, models improved when including discharge, though some summer models were best modelled by linear equations as summer stream temperature air temperature relationships are more linear.

Generally, thermal sensitivity values increased from upstream rural to downstream urban areas, though thermal sensitivity values, as well as RMSE are different depending on the data used, the model used, and the time period examined. Increasing temperature trends at the Johnson Creek at Sycamore, Johnson Creek at Regner Rd, and the Fanno Creek at Durham stations showed significant increasing trends in seven day moving average of daily maximum. These stations also had generally higher thermal sensitivity values. As such, these stations may be more at risk in terms of climate warming and could be labeled as "at risk" reaches. While this research has significant implications for current and future water quality, further exploring the spatial relationship of thermal sensitivity and other stream temperature metrics across the watershed could better inform best management practices in these urbanizing watersheds and identify resilient (low temperature, low sensitivity) sites versus at risk (high temperature, high sensitivity) sites. 


\section{Spatial analysis of thermal sensitivity in Johnson Creek Watershed, Oregon}

\section{Introduction}

On a global scale, cities are growing and continuing to urbanize, which can critically impair water systems and water quality in these urbanized areas (Pickett et al. 2001; Caissie 2006; Nelson and Palmer 2007; Grimm et al. 2008; McGrane 2016; United Nations 2018). Many urbanizing streams are suffering or at the danger of suffering from the 'urban stream syndrome', characterized by changes to discharge regimes, higher concentrations of pesticides, herbicides and fertilizers, the growth of invasive species, declining water quality and destruction of geomorphological function (Paul and Meyer 2001; Walsh et al. 2005). Of interest in this study is declining water quality in terms of stream temperature's sensitivity to changes in air temperature, or thermal sensitivity.

Thermal sensitivity can be best explained as the slope of the regression line (relationship) between air temperature and stream temperature. It is widely accepted that the slope of the linear regression of air temperature and stream temperature is further complicated by site characteristics (land use, topography, shade) that either builds stream resilience or promotes stream susceptibility to atmospheric heat exchange and warming (Kelleher et al. 2012; Chang and Psaris 2013). For example, streams in urban environments may be warmer than they would otherwise be due to industrial waste water inputs, stormwater runoff, the urban heat island affect, artificial ponds, and climate change. Streams with high inputs of these anthropogenic changes may be more sensitivity to air temperature (Morrill, Conklin and Bales 2005; Caissie 2006; Nelson and Palmer 
2007; Brans et al. 2018). This relationship with the environment has important implications for identifying resilient or susceptible reaches, particularly in the context of a warming climate in the Pacific Northwest (Rana et al. 2017). In Johnson Creek, certain portions of the creek regularly exceed the salmon and trout rearing and migration criterion $\left(18^{\circ} \mathrm{C}\right)$, but even small increases in water temperatures can create physiologically stressful conditions for stream biota (Kaushal et al. 2010; Mantua et al. 2010; Honea et al. 2016; Chang, Watson and Strecker 2017; Culler et al. 2018). Better understanding the thermal regime of streams, specifically a reaches' thermal sensitivity, is becoming increasingly vital as environments adapted to particular climates are expected to warm and aquatic biota are further threatened by inhospitable habitat.

There are many ways to model stream temperature in urbanizing watersheds with varying strengths along a continuum of ease and accuracy (see Esterby 1996; Caissie 2006; Benyahya et al. 2007; Webb et al 2008; Elga, Jan, and Okke 2015; Gallice et al. 2015; Piotrowski and Napiorkowski 2019). Air temperature is commonly employed as an explanatory variable for modelling stream temperature (Caissie 2006), and generally produces models explaining large proportions of the variance in stream temperature (Mohseni, Stefan, and Erickson 1998; Morrill, Conklin and Bales 2005; van Vliet et al 2011). Thermal sensitivity is commonly quantified using ordinary least squares regression or Mohseni, Stefan, and Erickson's (1998) nonlinear regression model and modified versions of the model (Stefan, and Erickson 1998; Erickson and Stefan 2000; Caissie, El-Jabi, and Satish 2001; Mohseni, Erickson, and Stefan 2002; Webb, Clack, and Walling 2003; Mohseni,; Morrill, Bales, and Conklin 2005; Van Vliet et al 2011; 
Kelleher et al. 2012; Mayer 2012; Chang and Psaris 2013; Mcgrath, Neumann, and Nichol 2017; Naresh and Rehana 2017; Piotrowski and Napiorkowski 2019).

Various best management practices can help to improve water quality, namely stream temperature. Riparian restoration is a common practice in the Johnson Creek Watershed undertaken by many overlapping jurisdictions to mitigate the effect that urbanization has degraded nearstream environments. Stream buffer restoration plantings improve water quality by shading the stream from direct solar insolation thereby preventing thermal pollution (Johnson and Wilby 2015; Wondzell et al 2019). Another best management practice in the watershed is green infrastructure (GI) installation. The installation of engineered GI within a watershed functions to improve water quality returning stormwater to the natural hydrologic cycle by storing rainwater, encouraging infiltration so less stormwater is warmed on impervious surfaces and recharging baseflow and groundwater (Peninno et al. 2016; Prudencio and Null 2018; Zhang and Chui 2019) that can contribute cool water to streams. The additional ability of GI to cool air temperatures through evaporation from vegetated facilities (Prudencio and Null 2018; Zhang and Chui 2019) could affect stream thermal sensitivity. While GI is installed on the small scale, the cumulated benefits of small-scale GI is designed to improve water quality on the large scale. Detailed spatial data of restoration and green infrastructure exists for the Johnson Creek watershed (Baker et al. 2019). Recent literature calls for more catchment scale analyses of the hydro-ecological benefits of GI practices (Zhang and Chui 2019), specifically regarding water temperature (Prudencio and Null 2018). 
Spatial analysis of water quality is important in revealing the defining landscape characteristics that can affect water quality parameters of interest and helps to inform local stakeholders of unique controls on thermal sensitivity (Mainali and Chang 2018). This study explores the spatial relationships of landscape characteristics on thermal sensitivity along an urban-rural gradient near the Portland Metropolitan Area, USA to explore the extent of site characteristic controls on thermal sensitivity. Landscape characteristics can be summarized by various weighted and spatial techniques. Commonly employed techniques attempt to settle the debate on the issue of scale of influence; techniques include areal averages of explanatory variables, inverse distance weighted variables, variables summarized at the subwatershed scale, and varying widths of stream buffers (see Table 1). Previous research shows a variety of spatial weights, explanatory variables, and spatial scales have been used for many study areas, further showing the need of this study to consider many complex explanatory variables in explaining thermal sensitivity. Current ideas debate if explanatory variables can affect water quality overall as an overall cumulative effect or if variables in greater proximity to the stream exert a stronger influence on water quality. 


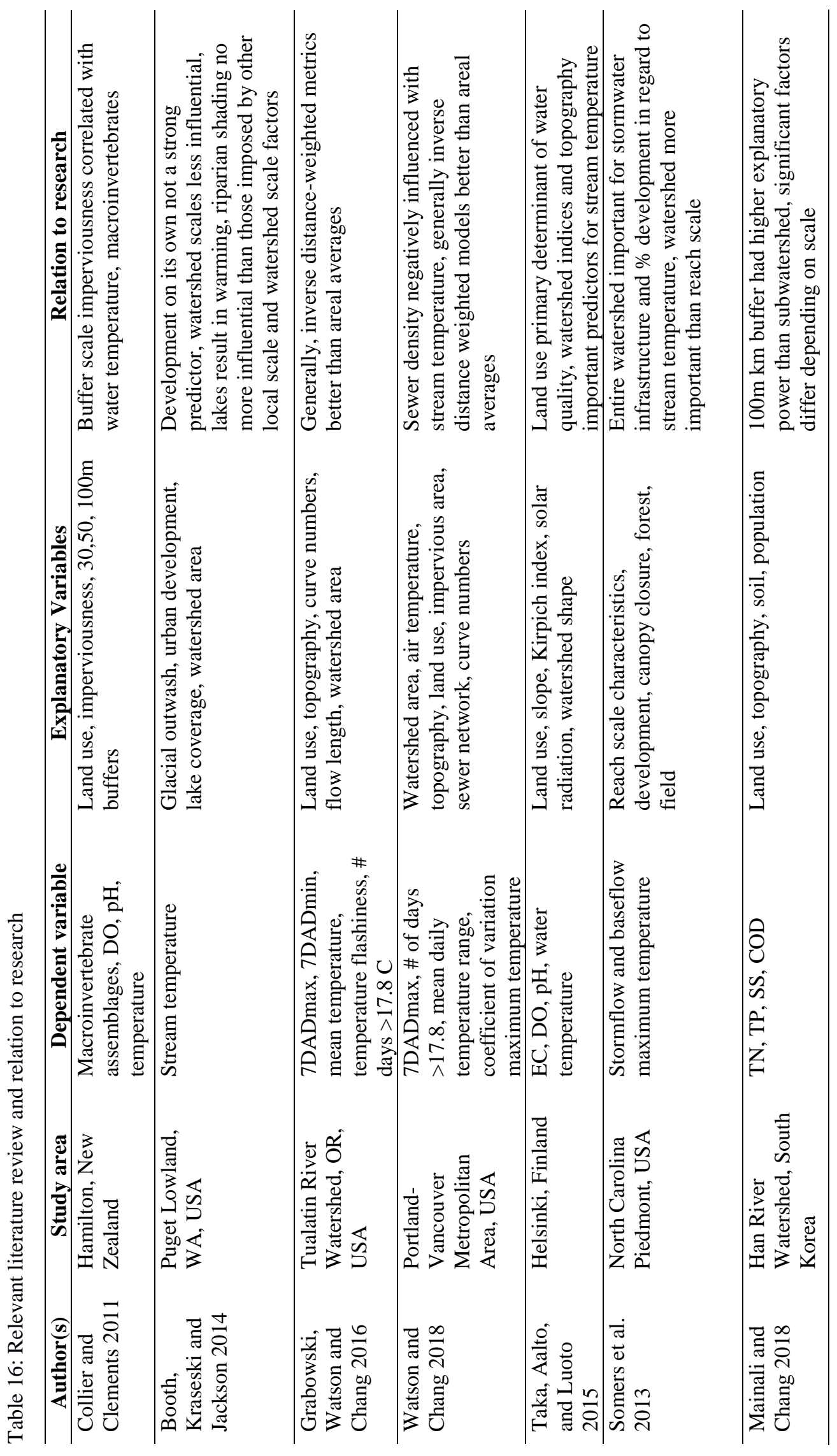




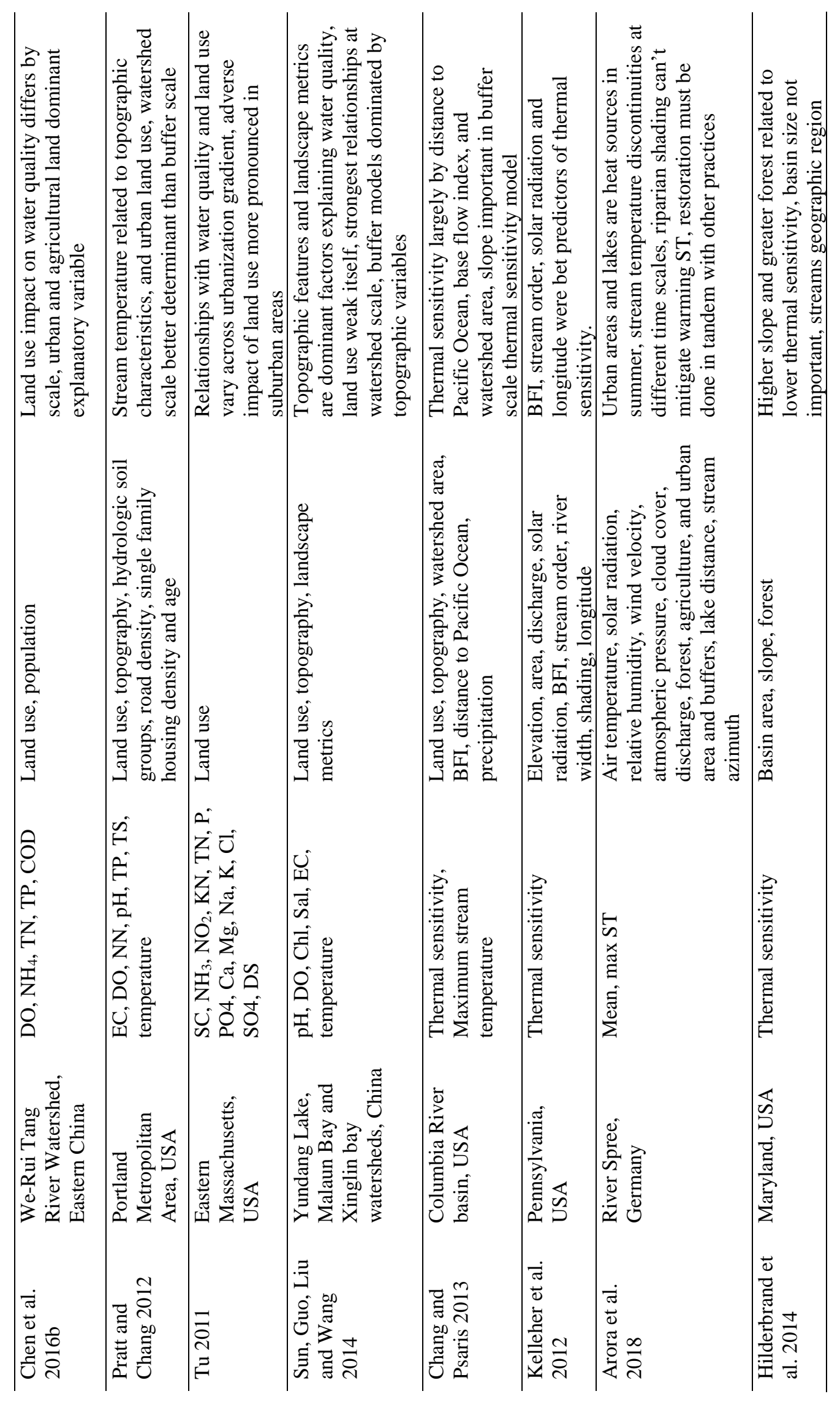

65 


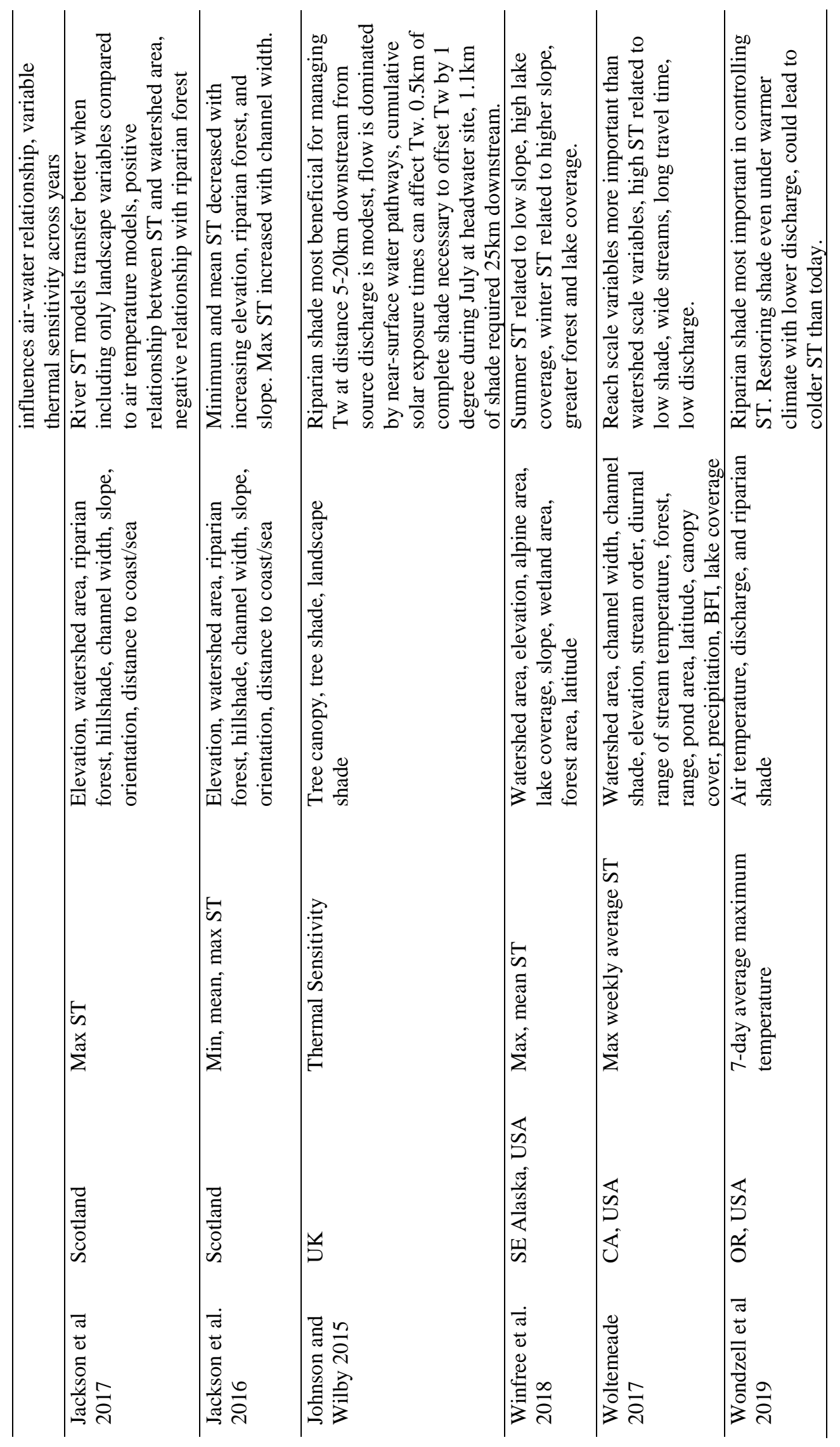

66 
Previous studies did not examine what landscape variables explain thermal sensitivities in a small mixed watershed with a rich combination of natural and anthropogenic explanatory variables summarized with varying weights and scales. The unique inclusion of detailed restoration and GI spatial data can help to inform local stakeholders about best management practices effectiveness as whole on thermal sensitivity. As such, this study asks three questions:

1. Which landscape characteristics best explain thermal sensitivity in the Johnson Creek Watershed?

2. Do areal average variables or inverse distance weighted variables explain the variation of thermal sensitivity? How do these relationships compare using subwatershed and buffer summarized variables? How do models of mainstem versus tributary compare?

3. Is there a significant relationship between restoration projects or green infrastructure projects related to thermal sensitivity? 


\section{Methods:}

\subsection{Study area}

The Johnson Creek watershed is located just East of Portland, located in both Multnomah and Clackamas counties. It flows from Boring, Oregon until it reaches its confluence with the Willamette river, in Milwaukie Oregon traveling nearly 42 kilometers in stream distance. Due to its location encompassing multiple jurisdictions, many agencies work together to manage the Johnson Creek watershed, including the City of Portland, City of Gresham, East Multnomah Soil and Water conservation districts, and the Johnson Creek watershed Council. The Johnson Creek watershed experiences a marine west coast climate with its wet season during late fall to spring, and the dry season coinciding with summer. The study area is mapped in Figure 1. Johnson Creek is $67 \%$ developed, has a stream length of $38 \mathrm{~km}$, and a watershed area of $140 \mathrm{~km}^{2}$ (Homer et al. 2015). Precipitation is typically in the form rainfall and more precipitation falls in the southeast portion of the watershed due to topography (Lee and Snyder 2009). Snow is not a regular part of the precipitation regime (Chang 2007). In the north and west portions of

the watershed, runoff does not flow directly into the watershed due to permeable geology, sewershed, and groundwater flow away from the creek. The increases in flow at the Milwaukie gauging station is due to substation inflow from Crystal Spring creek (Lee and Snyder 2009). A great overview of Johnson Creek's hydrology can be found in Lee and Snyder (2009). Stream restoration projects are a large part of watershed management 
with recent literature citing improved sediment dynamics and streamflow characteristics (e.g Levell and Chang 2008; Ahilan et al 2018).

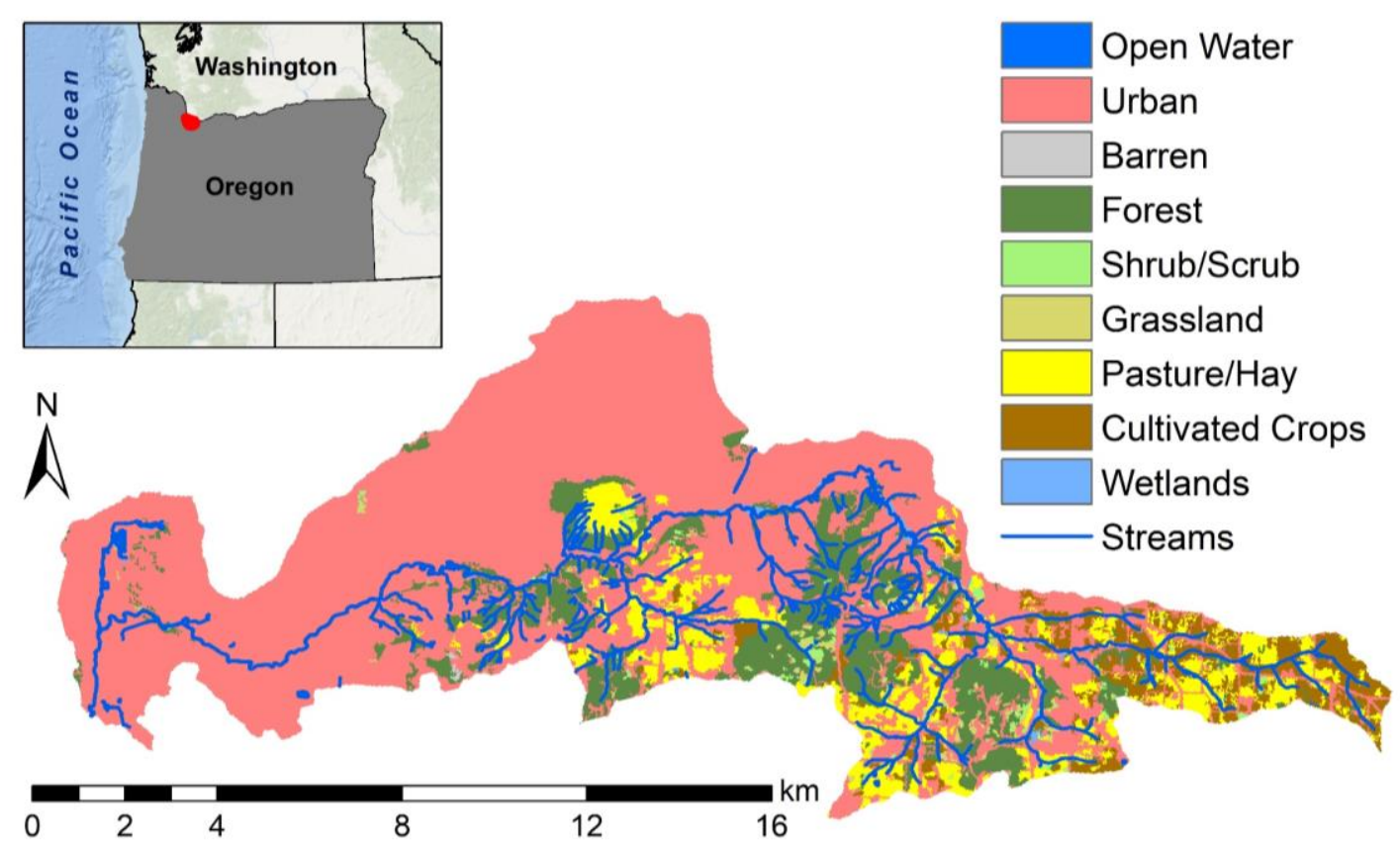

Figure 9: Study area of Johnson Creek watershed with a simplified base map of 2011 NLCD (Homer et al. 2015).

According to the City of Portland Bureau of Environmental services' watershed report card, Johnson Creek's water quality score is a C+ with stream temperature receiving an average score of 1.8 on a scale from 1 (bad) to 10 (good) (City of Portland 2015). Water quality in Johnson Creek is a concern with various jurisdictions working to improve water quality as an ecosystem service by tree planting, restoration projects, green infrastructure installation, fish passage projects, as well as conservation registry (Johnson Creek Watershed Council, City of Portland 2013). Johnson Creek is diverse in land use and has a long history of urbanization. In the 1930s, the Works Progress Administration attempted to control flooding by purposefully incising the channel for 
many stream miles. Recent years have been experiencing urban infill, though residential growth in the area had strengthened beginning in the 1970s (City of Portland 2013). As such, lower areas of the watershed are highly urbanized and have been for quite some time while the headwaters and upper watersheds are primarily forested or agricultural land. Traveling from the outlet to the headwaters, Johnson Creek is the epitome of an urban-rural gradient.

\subsection{Stream temperature data}

We used five years of daily summer stream temperature data collected by the Johnson Creek watershed council, The City of Gresham, The City of Portland, East Multnomah Soil and Water Conservation District, and the USGS from 2009 to 2018. Additional data for the years 2015-2018 were shared by the City of Gresham. Due to significant differences in variation of air-water temperature regression parameters (Hilderbrand et al. 2014), stream temperature data were compared year by year for the months of July and August when stream temperatures are at their highest, to single out a 'typical' meteorological year. A typical year was defined as plus or minus one degree Celsius of mean seven-day moving average of daily maximum air temperature for July and August. The mean was 28.04 degrees Celsius. As such, the years 2009, 2012, 2013, 2014, and 2016 were retained for analysis and transformed into thermal sensitivity using $R$ programming software version 3.5.1 (R Core Team 2018). Maximum air temperature values for Portland International Airport were used to relate stream temperature to air 
temperature for these summer months. Thermal sensitivity was defined as the slope of the regression line between seven day moving average of daily maximum air temperature and seven average daily maximum stream temperature. Thermal sensitivity was calculated at a total of 89 locations throughout the Johnson Creek watershed. A larger thermal sensitivity indicates a greater sensitivity of stream temperature to air temperature.

\subsection{Independent variables}

A total of 74 independent variables were developed for analysis to explain thermal sensitivity. Variables were created using ArcGIS 10.5. After joining the thermal sensitivity values created in $R$ to the spatial location of each sampling site, the Arc Hydro extension was used to delineate sub watersheds from each of these locations. Independent variables were calculated for the entire sub watershed of each sampling location, as well as upstream of each location within a $100 \mathrm{~m}$ buffer which has been used in other spatial research (e.g. Collier and Clements 2011; Pratt and Chang 2012; Mainali and Chang 2019). Elevation, slope, imperviousness, normalized difference vegetation index (NDVI), and normalized difference built-up index (NDBI) were continuous raster-based variables that were also transformed into inverse distance-weighted (IDW) raster's weighted on their distance to the sampling point of each sub watershed. This way, variables were able to exert more influence closer to the stream temperature monitoring location, as opposed to areal average values. IDW for water quality has also been explored in other works (Somers et al. 2013, Grabowski, Watson and Chang 2016, Watson and Chang 2018), and 
has generally been found increase model performance in comparison to areal average values.

Where detailed measurements of watershed shading were unfeasible to collect, utilization of the NDVI as a proxy for shade were created from Landsat 8 OLI imagery (30m) in $R$ programming software version 3.5.1 (R Core Team 2018) and has been used to analyze restoration efforts and spatial and temporal trends in vegetation greenness in other studies (Hensaw et al. 2013; Norman et al. 2014; Jarchow, Nagler and Glenn 2016; Wilson et al 2016; Wilson and Norman 2018). The standard equation for NDVI is:

$$
\text { (NIR-Red)/(NIR+Red) }
$$

\section{Equation 1}

Where NIR is the near infrared and Red is the red light within the electromagnetic spectrum picked up on Landsat 8 multispectral imagery. NDVI ranges between 0 and 1 with values closer to 1 , indicating a "greener" surface, or more vegetation. Similarly, the NDBI was also created using equation 2:

\section{$(\mathrm{SWIR}-\mathrm{NIR}) /(\mathrm{SWIR}+\mathrm{NIR})$}

\section{Equation 2}

Where SWIR is shortwave infrared and NIR is near infrared light. NDBI typically ranges between -1 and 1 with values greater than zero indicating more built up surface. After these datasets were created, they were exported as $30 \mathrm{~m}$ resolution raster files and further summarized by watershed and buffer extent. 
Table 2 summarizes the description of the independent variables and their sources.

Table 17: Explanatory variables used in analysis

\begin{tabular}{|c|c|c|c|}
\hline Dataset & Derived variable & Data source & $\begin{array}{c}\text { Hypothesized } \\
\text { Relationship }\end{array}$ \\
\hline Sewershed & $\begin{array}{l}\text { Grey Infrastructure density } \\
\text { Green infrastructure density }\end{array}$ & $\begin{array}{l}\text { City of Portland 2015; } \\
\text { City of Gresham } 2018\end{array}$ & $\begin{array}{l}\text { Positive } \\
\text { Negative }\end{array}$ \\
\hline Restoration & $\%$ Restored area & $\begin{array}{l}\text { Jarrad (2016); Multnomah Soil \& } \\
\text { Water Conservation District }\end{array}$ & Negative \\
\hline $\begin{array}{l}\text { Impervious land } \\
\text { cover }\end{array}$ & $\%$ Impervious area & $\begin{array}{l}\text { NLCD } 2011 \text { Percent Developed } \\
\text { Imperviousness (Xian et al. } \\
\text { 2011) }\end{array}$ & Positive \\
\hline Land cover & $\begin{array}{l}\% \text { Open Water } \\
\% \text { Developed } \\
\% \text { Forest } \\
\% \text { Barren } \\
\% \text { Agriculture } \\
\% \text { Grassland } \\
\% \text { Wetlands }\end{array}$ & $\begin{array}{l}\text { NLCD } 2011 \text { Land Cover } \\
\text { (Homer et al. 2015) }\end{array}$ & $\begin{array}{l}\text { Positive } \\
\text { Positive } \\
\text { Negative } \\
\text { Positive } \\
\text { Positive } \\
\text { Positive } \\
\text { Negative }\end{array}$ \\
\hline Elevation/Slope & $\begin{array}{l}\text { Mean elevation } \\
\text { STD Elevation } \\
\text { Mean Slope } \\
\text { STD slope } \\
\end{array}$ & 2014 OLC Metro lidar project & $\begin{array}{l}\text { Negative } \\
\text { Positive } \\
\text { Negative } \\
\text { Positive } \\
\end{array}$ \\
\hline Distance based & $\begin{array}{l}\text { Upstream flow distance } \\
\text { Downstream flow distance } \\
\text { Upstream distance to ponds }\end{array}$ & $\begin{array}{l}\text { Johnson Creek Watershed } \\
\text { Council }\end{array}$ & $\begin{array}{l}\text { Positive } \\
\text { Negative } \\
\text { Positive }\end{array}$ \\
\hline NDVI & $\begin{array}{l}\text { Mean NDVI } \\
\text { STD NDVI }\end{array}$ & Landsat 8 OLI & $\begin{array}{l}\text { Negative } \\
\text { Positive }\end{array}$ \\
\hline NDBI & $\begin{array}{l}\text { Mean NDBI } \\
\text { STD NDBI }\end{array}$ & Landsat 8 OLI & $\begin{array}{l}\text { Positive } \\
\text { Positive }\end{array}$ \\
\hline Soil & $\begin{array}{l}\text { Hydrologic Soil B } \\
\text { Hydrologic Soil D }\end{array}$ & $\begin{array}{l}\text { SSURGO Multnomah and } \\
\text { Clackamas Soil Survey }\end{array}$ & $\begin{array}{l}\text { Negative } \\
\text { Positive }\end{array}$ \\
\hline
\end{tabular}

\subsection{Statistical analysis}

Explanatory variables were compared using Pearson's correlation coefficient. We tested the relationship of thermal sensitivity and independent variables for both the watershed 
and stream buffer scale, and for both the areal average and inverse distance weighted average, and for both mainstem only and tributary only stream temperature locations by developing six unique multiple OLS regression models. Because thermal sensitivity values and models did not have any statistically significant spatial autocorrelation, OLS was an appropriate model. It was hypothesized that one particular model would best represent thermal sensitivity represented by model fit to elucidate landscape characteristics on watershed spatial thermal sensitivity. Using ArcMap 10.5 exploratory regression tool, all possible combinations of variables compared against thermal sensitivity, with suggested best combinations of variables suggested by adjusted $\mathrm{R}^{2}, \mathrm{AIC}$, and VIF. Models were further explored and finalized using R programming software version 3.5.1 (R Core Team 2018). 


\section{Results}

\subsection{Spatial variation of mean thermal sensitivity}

The mean thermal sensitivity in the Johnson Creek watershed was 0.30 , with a minimum of nearly 0 and a maximum of 0.57 . Tests for spatial autocorrelation showed that thermal sensitivity appears to be random throughout the watershed $(\mathrm{I}=-0.16, \mathrm{p}=0.71)$. Figure 2 shows the spatial variation of thermal sensitivity in Johnson Creek. A boxplot of thermal sensitivity values based on their location in the mainstem $(n=29)$ or tributary $(n=59)$ of the creek is shown in Figure 3. The mainstem stations generally had higher thermal sensitivity (95\% confidence: $0.31-0.41)$ values than the tributary stations (95\% confidence $0.22-0.30)$.

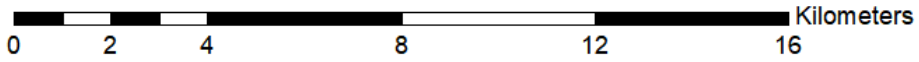

Thermal Sensitivity

- $0.01-0.20$

- $0.21-0.26$

- $0.27-0.36$

O $0.37-0.42$

O $0.43-0.57$

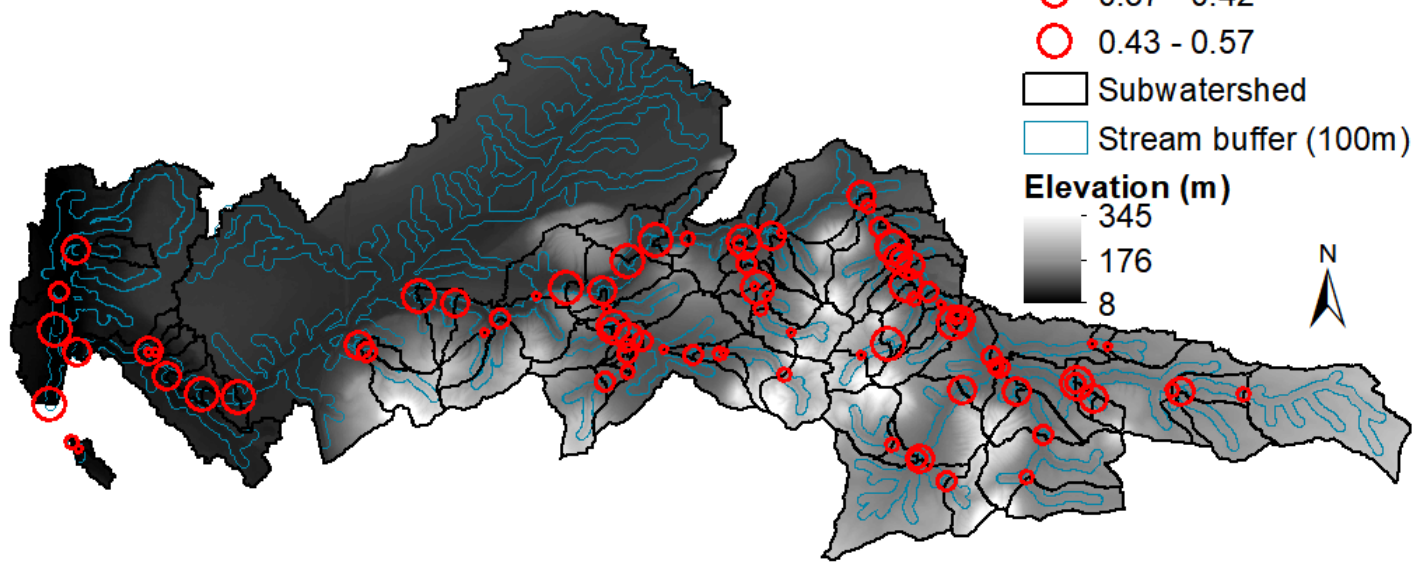

Figure 10: Thermal sensitivity values with subwatersheds and stream buffers throughout Johnson Creek watershed. 


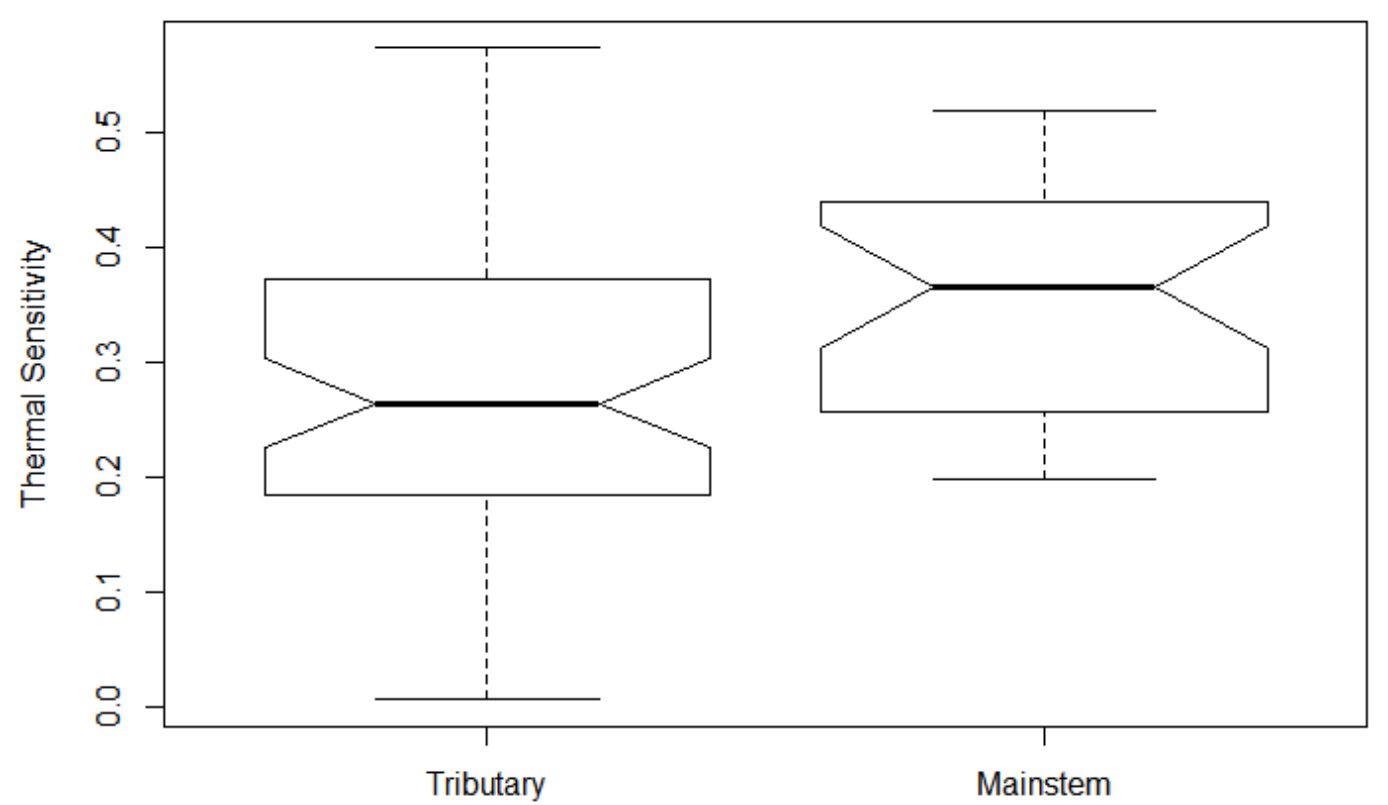

Figure 11: Thermal sensitivity values between mainstem locations $(n=29)$ and tributary locations $(n=59)$. Since the notches of two plots, or confidence intervals, do not overlap this is strong evidence that the two medians are significantly different $(\mathrm{p}=0.05)$ (Chambers et al. 1983; R Core Team 2018).

\subsection{Correlation between thermal sensitivity and independent variables}

Table 18: Correlations between thermal sensitivity and explanatory variables. P-value $* * *=0.01, * *=0.05$, $*=0.1, \wedge$ Mean Air Temp at site 


\begin{tabular}{|c|c|c|c|c|c|}
\hline & & Watershed & & Stream buffer & $100 \mathrm{~m})$ \\
\hline & & Thermal Sensitivity & $\mathbf{p}$ & $\begin{array}{l}\text { Thermal } \\
\text { Sensitivity }\end{array}$ & $\mathbf{p}$ \\
\hline Areal & & & & & \\
\hline Average & $\%$ Open water & 0.15 & & 0.15 & \\
\hline & $\%$ Developed & -0.04 & & -0.02 & \\
\hline & $\%$ Forest & -0.06 & & -0.05 & \\
\hline & $\%$ Barren & 0.04 & & 0.06 & \\
\hline & $\%$ Grassland & -0.04 & & 0.01 & \\
\hline & $\%$ Agriculture & 0.09 & & 0.05 & \\
\hline & \% Wetlands & 0.25 & $* *$ & 0.17 & \\
\hline & Mean \% Impervious & -0.04 & & -0.04 & \\
\hline & SD \% Impervious & 0.22 & $* *$ & -0.14 & \\
\hline & Mean NDVI & -0.03 & & -0.05 & \\
\hline & SD NDVI & 0.31 & $* * *$ & 0.21 & $*$ \\
\hline & Mean NDBI & 0.06 & & 0.07 & \\
\hline & SD NDBI & 0.27 & $* * *$ & 0.21 & $* *$ \\
\hline & Mean Elevation & -0.01 & & -0.01 & \\
\hline & SD elevation & 0.32 & $* * *$ & 0.30 & $* * *$ \\
\hline & Mean Slope & -0.05 & & -0.15 & \\
\hline & SD slope & 0.19 & $*$ & 0.07 & \\
\hline IDW & Mean \% Impervious & -0.04 & & -0.01 & \\
\hline & SD \% Impervious & 0.04 & & 0.06 & \\
\hline & Mean NDVI & 0.06 & & 0.03 & \\
\hline & SD NDVI & 0.27 & $* * *$ & 0.04 & \\
\hline & Mean NDBI & 0.10 & & 0.04 & \\
\hline & SD NDBI & -0.02 & & 0.01 & \\
\hline & Mean elevation & -0.07 & & 0.02 & \\
\hline & SD elevation & -0.01 & & 0.02 & \\
\hline & Mean slope & -0.07 & & -0.14 & \\
\hline & SD slope & 0.02 & & -0.09 & \\
\hline Other & Area & 0.37 & $* * *$ & 0.37 & $* * *$ \\
\hline & Restoration area & -0.15 & & -0.16 & \\
\hline & Green infra. density & -0.03 & & 0.14 & \\
\hline & Gray infra. density & 0.01 & & 0.03 & \\
\hline & Hydrologic Soil Type B & 0.05 & & 0.28 & $* * *$ \\
\hline & Hydrologic Soil Type D & -0.04 & & 0.11 & \\
\hline & Max Air Temp & 0.15 & & & \\
\hline & Mean Air Temp & -0.07 & & $-0.04^{\wedge}$ & \\
\hline & Downstream flow length & -0.09 & & & \\
\hline & Upstream flow length & 0.39 & $* * *$ & & \\
\hline & Distance to nearest upstream pond & 0.28 & $* * *$ & & \\
\hline
\end{tabular}


Table 3 shows Pearson correlation coefficients between independent variables and thermal sensitivity. The strongest significant correlation was with upstream flow length $(r=0.39)$, followed by area of the watershed and area of the $100 \mathrm{~m}$ buffer $(r=0.37)$, then areal average standard deviation $(\mathrm{r}=0.32)$ and areal average standard deviation of NDVI $(\mathrm{r}=0.27)$. There were only 16 significant correlations out of 72 possible explanatory relationships. Correlations are generally quite low, with no correlation exceeding 0.39 . Similar low correlations were found in Booth, Kraseski, and Jackson (2014) in the Puget Lowlands of Washington State.

\subsection{Regression model results}

Table 4 summarizes the results of each model. Distance to nearest upstream pond and the proportion of hydrologic soil type B were highly significant but were not found to be included in the best regression models explaining thermal sensitivity. Models results, denoted by $\mathrm{R}^{2}$ and AIC, were similar to one another, though the model of best fit was the model that only included mainstem stations but was allowed to include explanatory variables of either spatial scale. Model residuals for all models appeared normally distributed, showed equal variance, with no influential outliers (not shown). 


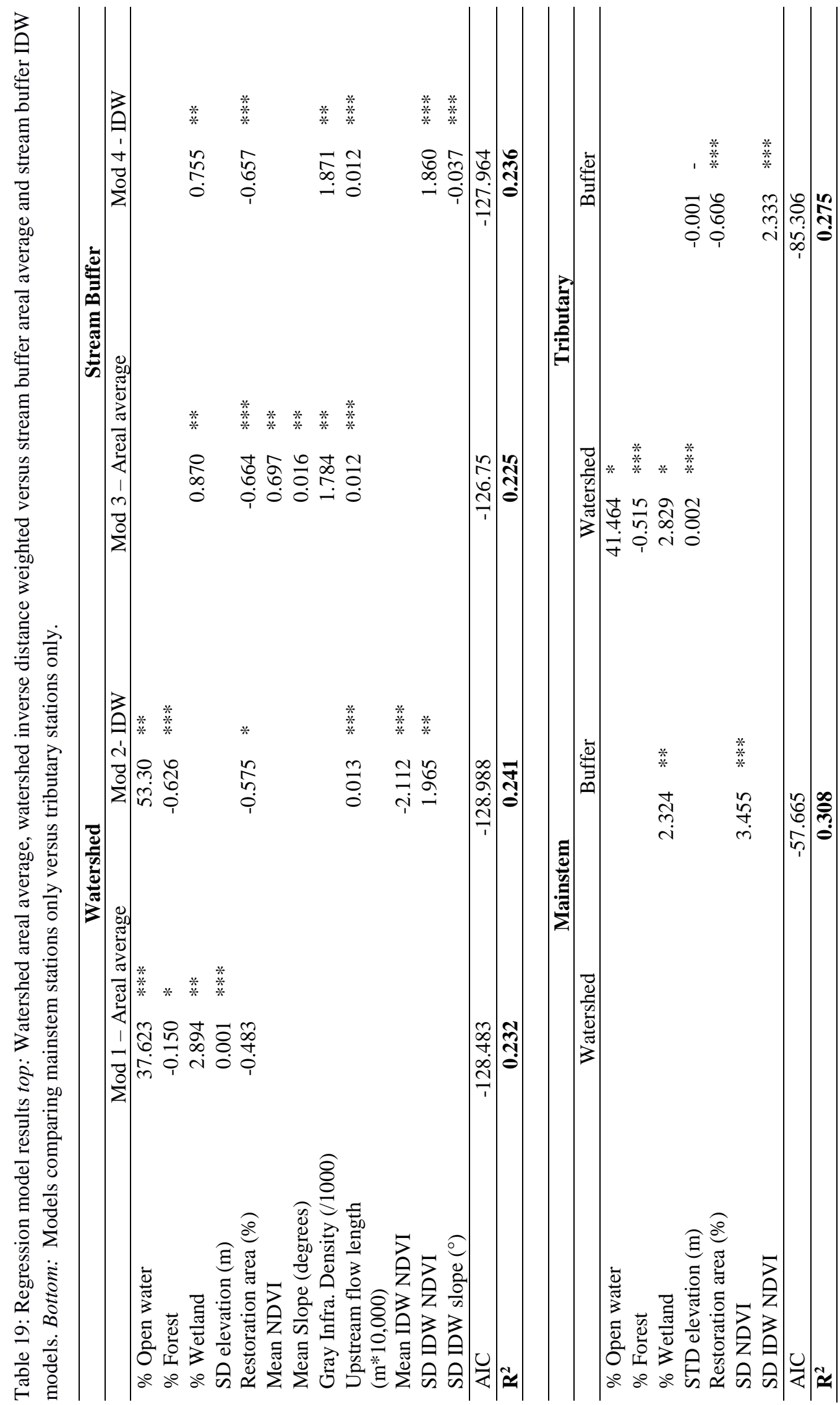


$\mathrm{R}^{2}$ values were quite low across all models, with models explaining no more than $31 \%$ of the variance of thermal sensitivity. These values appeared much lower than other studies that examined thermal sensitivity as a response variable (i.e. Kelleher et al 2012; Chang and Psaris 2013), though these studies were of much larger study areas in heterogenous landscapes with differing climates, and they were able to include discharge as an additional parameter.

The three land cover types that showed up significant in models were \% open water, $\%$ forest (as hypothesized in Chapter 1 ), and \% wetland, while the others were insignificant. NDVI values showed up as significant, while the NDBI did not. Generally, IDW models had higher $\mathrm{R}^{2}$ and lower AIC compared to their areal average counter parts. Watershed models in general were better in terms of $\mathrm{R}^{2}$ and AIC in comparison to stream models. In comparing mainstem-only and tributary only models, mainstem had a higher $\mathrm{R}^{2}$ while including fewer explanatory variables. 


\section{Discussion}

\subsection{Thermal sensitivity and explanatory variables}

\subsubsection{Significant correlations not included in spatial models}

The positive relationship found between the distance to nearest upstream pond is counter-intuitive to what is currently known in the Johnson Creek watershed. Typically, the greater open water coverage and proximity to open water would show a positive relationship, particularly if the waterbody is shallow with little surrounding shade, absorbing direct insolation, and if it the water has long residence times (Booth, Kraseski and Jackson 2014; Woltemeade 2017; Arora et al. 2108; Brans et al. 2018; Winfree et al. 2018). The positive correlation found in this study could indicate that there were not enough points upstream and downstream of ponds to model this known relationship, and that there are other factors within the watershed and stream buffer that also have a strong association with thermal sensitivity. While distance to nearest upstream pond was not significant in spatial models, the percent of wetlands was significant in three of the four models, indicating that these relatively shallow wetlands likely experience direct insolation and therefore tend to warm surface waters as they flow through these locations, similar to how they would warm from ponding. More data on pond depth or wetland depth, as well as if ponds empty water into the stream from the surface warmed layer or the deep, cooler layer of the temperature gradient within these waterbodies could help to elucidate energy flux dynamics in Johnson Creek waterbodies (Bond 2018; Holzer 2018). The existence of wetlands in both stream buffer models indicate that this is a localized phenomenon. Additionally, the positive relation of hydrologic soil type B within the 
buffer with thermal sensitivity is unexpected given that it was expected that B soil would represent well-draining areas with cool groundwater inflow. This counterintuitive finding could be due in large part to vast impervious surface areas with hydrological soil type B, which is generally located in the lower portions of the watershed. These soils may also be compacted so that water may be contributing to overland flow as opposed to groundwater recharge which is sensitive to air temperatures (McGrane 2016).

\subsubsection{Importance of Forest and NDVI}

The inclusion of forest in the watershed models indicates that areas of dense forest land use may impact thermal sensitivity on the watershed scale more so than the stream buffer scale. Mean IDW NDVI for the watershed model was significantly negative, which is important, especially when considering stream buffer models as stream temperatures are likely to be affected by riparian shading immediately in the vicinity of the stream (Johnson and Wilby 2015; Jackson et al. 2016; Jackson et al. 2017; Woltemeade 2017; Wondzell et al. 2019) In contrast, the significant positive relationship of mean NDVI in the buffer areal average model contrasts with hypothesized relationships of increased NDVI in the stream buffer leading to decreased thermal sensitivity from a streamside shade effect. STD IDW NDVI were found to be positively significant in both IDW models, implying that patchy areas of vegetation are no substitute for consistent forested land. The fact that NDVI is significant in both watershed and stream models indicates that vegetation is an important predictor for thermal sensitivity across multiple scales (Pratt and Chang 2012; Booth, Kraseski and Jackson 
2014; Hilderbrand et al. 2014; Johnson and Wilby 2015; Jackson et al. 2016; Jackson et al. 2017; Woltemeade 2017; Wondzell et al. 2019).

\subsubsection{Importance of topography}

The importance of topographic variables has been extensively supported in other literature (i.e. Pratt and Chang 2012; Chang and Psaris 2013; Hilderbrand et al., 2014; Sun et al. 2014; Taka, Aalto, and Luoto 2015; Grabowski, Jackson et al., 2016; Woltemeade 2017; Mainali and Chang 2018; Watson and Chang 2018; Winfree et al. 2018). In the watershed models, the positive relationship with standard deviation of elevation in the areal average model may be related to areas of the watershed that have more highly variable topography, which is typical for the areas of the watershed characterized by extinct volcanic cinder cones, such as Powell Butte (Lee and Snyder 2009). The upstream portion of this watershed has greater impermeable soils, so perhaps ponding of shallow water on the landscape makes water more susceptible to heat exchange warming (Lee and Snyder 2009). In the stream buffer models, the inverse relationship with mean slope and STD IDW slope suggests that thermal sensitivity is higher in areas with lower variable slope, or flatter areas where water may flow across these surfaces slower, therefore becoming warmed due to longer contact residence times (Chang and Psaris 2013; Hilderbrand et al 2015, Sun et al. 2014; Jackson et al. 2016). Increasing upstream flow length is positively related to thermal sensitivity, intuitively indicating that stream temperature sites lower in their respective watersheds, with larger contributing area are more sensitive to air temperature due to long travel times and heat accumulation (Johnson and Wilby 2015; Woltemeade et al. 2017). 


\subsection{Weights and scales}

Inverse distance weighted models generally were better than areal average models, which is consistent with other literature in modelling water quality (Somers et al. 2013; Grabowski, Watson and Chang 2016; Watson and Chang 2018). When examining the entire subwatershed versus stream buffer in modeling thermal sensitivity, the best fit models included subwatershed characteristics, which supports other literature exploring scale and water quality (Pratt and Chang 2012; Somers et al. 2014; Sun et al. 2014). These findings indicate that modelling stream temperature should consider the whole watershed, but with variables weighted higher closer to stream temperature measurements. Merely including average explanatory variables in an upstream buffer may cut out an important overall cumulative effect that the contributing landscape has on water quality.

\subsection{Mainstem versus tributary models}

The mainstem model outperformed the tributary model marginally, though included fewer explanatory variables. The inclusion of watershed, buffer, areal average and inverse distanced weighted variables allows for better understanding of the complex interplay between scales and weights on distinctly different reaches of the watershed. Greater thermal sensitivity for the mainstem stations $(n=29)$ is associated with greater buffer-scale wetland area and greater standard deviation of NDVI. Again, an increase in open water can warm stream temperatures, particularly if the water is shallow and unshaded, (Booth, Kraseski and Jackson 2014; Woltemeade 2017; Arora et al. 2018; Brans et al. 2018; Winfree et al. 2018) and greater patchiness of streamside vegetation 
will warm stream temperatures (Johnson and Wilby 2015; Woltemeade 2017; Wondzell et al. 2019). Thermal sensitivity in mainstem stations appears to be largely controlled by mostly buffer-scale controls, suggesting the importance of riparian conditions.

The positive relationship with watershed-scale wetland area, open water (Booth, Kraseski and Jackson 2014; Woltemeade 2017; Arora et al. 2018; Brans et al 2018; Winfree et al. 2018), standard deviation of elevation and the negative relationship with forest area indicates that tributary sites, in comparison to mainstem sites, are more influenced by watershed scale processes. In addition, buffer-scale decreased restoration area and increasing standard deviation of inverse distance weighted NDVI suggest that thermal sensitivity values are more greatly influenced by vegetation at the small-scale immediately surrounding the stream (Woltemeade 2017; Johnson and Wilby 2015; Wondzell et al. 2019). Watersheds are a functioning system, but in terms of water quality in the stream, different weights and scales exert different influences throughout the watershed.

\subsection{Importance of best management practices on thermal sensitivity}

Interestingly, restoration area showed up in five of six models, though it was insignificant in the watershed areal average model. Contradictory literature discusses the importance of scale in restoration area, with some citing a greater watershed approach (Violin et al. 2011; Pratt and Chang 2012) and others stressing the importance of buffer scale restoration to improve water quality (Johnson and Wilby 2015; Wondzell et al. 2019). Restoration area was always negatively related to thermal sensitivity, indicating 
that greater proportions of restored environment help to reduce thermal sensitivity by providing shade (Johnson et al. 2007; Johnson and Wilby 2015; Wondzell et al. 2019). This has important implications for the many agencies seeking to improve water quality in the study watershed. It may be a sign that restoration efforts have started to reduce thermal sensitivity in portions of the watershed, and that the effect of restoration is significant at both the watershed and stream buffer scale. The significance of restoration in the tributary only model may indicate that effects to restore riparian shade should occur in tributaries as opposed to mainstem sections to slow the accumulation of thermal pollution (Johnson and Wilby 2015; Wondzell et al. 2019). Continued efforts to restore this watershed should be continued at both the watershed scale, as well as streamside.

Green infrastructure density did not show up as significant in any models. Green infrastructure may not be effective for reducing heat or mitigating thermal sensitivity in the Johnson Creek watershed, despite other potential benefits of increasing infiltration into the watershed subsurface. Increasing infiltration has benefit in terms of urban hydrology (Pennino et al. 2016; Aulenbach et al. 2017), though the benefits of increased infiltration may not be cooling stream temperatures in Johnson Creek. While the restoration variable was expressed as a proportion of total area, area attributes of GI facilities was not available for all data, and as such, was included as a count variable. Greater spatial resolution of GI facilities and their attributes may improve model fit but was not feasible for this study.

Interestingly, gray infrastructure density of sewer nodes and inputs showed up as highly significant in both stream buffer scale models. This is the only indicator that is a 
direct measure of development throughout the models. In general, there is little to no stormwater grey infrastructure in the headwaters of the watershed stream buffer, with the downstream half of the watershed showing increasing grey infrastructure within the stream buffer. Increases in gray infrastructure density within the buffer is related to higher thermal sensitivity, indicating that this dense, developed area could quickly convey water warmed water from impervious surfaces directly to the stream (Nelson and Palmer 2007; Somers et al. 2014). A similar study just west of the study area found the opposite finding (Watson and Chang 2018), which they assumed that sewer network shaded and cooled water before entering nearby streams. This could indicate that the effect that storm sewer systems have on water quality in the Portland metropolitan area is variable from watershed to watershed. 


\section{Conclusions}

The thermal sensitivity of stream temperature in the Johnson Creek watershed can be largely explained by topographic variables, NDVI and forested area, open water and wetlands, restoration area and grey infrastructure. Relationships are mostly unsurprising with higher restoration and less variable vegetation leading to less thermal sensitivity, and more variable or flatter topography, open water and gray infrastructure leading to higher thermal sensitivity, supporting previous hypotheses in chapter one. Areal average and inverse distance weighted variables summarized at both watershed and buffer scales were important in both models of mainstem-only and tributary-only stream temperature monitoring sites. Inverse distance weighted models were generally better than areal average models when choosing a specific weighting scheme, and the watershed inverse distance weighted model explained the most variation of thermal sensitivity. Chapter one concluded that thermal sensitivity was largely controlled by air temperature, and this chapter adds the landscape characteristics further exacerbate thermal sensitivity (greater patchy vegetation, flatter or variable topography, greater grey infrastructure) or mitigate thermal sensitivity (greater forest coverage, greater NDVI, greater restoration projects, steeper slopes).

The low coefficients of determination indicate that thermal sensitivity of urban stream temperature during the summer months is relatively difficult to capture and characterize across the heterogeneous landscape. While the relationships found are highly significant, other explanatory variables may have not appropriately represented or this urban watershed may be much more complex with a high degree of human disturbance that is 
difficult to capture completely. Other studies have been able to include discharge as an additional parameter (Kelleher et al. 2012; Watson and Chang 2018), which may improve model fit. Additionally, Johnson Creek has substantial groundwater inputs, of which representative spatial data was absent in this study. The literature review table highlights that many other hydrogeological variables can be captured spatially to more accurately model water quality.

This study has important implications for watershed managers as well as restoration practices. This study helps to better understand the physical characteristics that dictate thermal sensitivity of stream temperature to air temperature in the Johnson Creek Watershed to be able to better allocate resources protect and improve water quality in mixed use watershed under future climate change. Reaches that are more resilient with lower thermal sensitivity may be less vital for focused restoration efforts, whereas locations with higher thermal sensitivity should be avidly monitored, especially since climate change is expected to increase air temperatures in the region. The inclusion of restoration area as a significant explanatory variable in reducing thermal sensitivity is a testament to years of restoration work that has taken place in the watershed. 


\section{Conclusions}

Trends of discharge and stream temperature are apparent throughout both Johnson Creek and Tualatin River watersheds. The thermal sensitivity of stream temperature to air temperature is greater in certain portions of each respective watershed, and the more pronounced trends in stream temperature appear to coincide at temperature monitoring stations that are also more thermally sensitive. Further exploration of thermal sensitivity in the Johnson Creek watershed points to land use, topography, grey infrastructure and restoration as significant determinants of thermal sensitivity summarized by various scales and weights. The influence that landscape factors have on thermal sensitivity is scale-dependent and spatial weight dependent. Both chapters highlight specific locations and elucidate the unique characteristics in determining thermal sensitivity, which have real-life implications for watershed management. Reaches that are more resilient with lower thermal sensitivity and no apparent concerning trends in discharge or stream temperature may be less integral for focused restoration efforts and could serve as thermal refugia under a changing climate (Chang, Watson, and Strecker 2017; Mcgrath, Neumann, and Nichol 2017; Merriam et al. 2017; Fast 2018), whereas locations with higher thermal sensitivity and increasing trends in stream temperature or decreasing trends in discharge should be avidly monitored in response to land use change and climate change. More knowledge of watershed dynamics will surely help to inform local policy and watershed managers to better spend typically limited resources and money on the areas most in need or most likely to benefit from restoration or mitigation. While perhaps residents in these communities that are strife with degraded water quality could 
care less about fish habitat and stream temperature, residents would surely benefit, directly and indirectly, from the well-known positive implications of increased ecosystem services provided by watershed enhancement work, such as climate control, increased green space and opportunities for recreation, increased wildlife, flood and erosion control, and opportunities for education and eco-mental healthcare and spirituality.

Findings in this study may be specific to the study area and thus may not be generalizable to other urban watersheds. Urban watersheds are patchy and heterogeneous, and their patterns of developed or forested area may not be transferable to other urban watersheds. This research does show that relationships and patterns of stream temperature and discharge are not continuous across each representative watershed. In this way, a "one size fits all" approach to watershed restoration in either watershed is not recommended as different parts of each watershed are unique in land cover, and their relationship with discharge and air temperature; as such, future research in this area can consider other types of modeling, both simple and complex, of both stream temperature and discharge metrics. In terms of spatial analyses on stream temperature, relationships with other landscape variables could vary depending on the dependent variable in question, such as maximum or minimum stream temperature metrics. Variation of thermal sensitivity could be further explained by spatial variables that were not included in this research, such as discharge or groundwater inputs. Spatial analysis of other stream temperature metrics can capture other important aspects of stream temperature as a water quality indicator that were not included in this study. For example, exploring the 7-day moving average of daily maximum temperature could yield models that show different 
landscape controls on this metric, highlighting the importance of capturing these complex dynamics, despite their absence in the thermal sensitivity model. Additionally, spatial autocorrelation of other stream temperature metrics could highlight clustering of stream temperature issues or resilience in the watershed that could warrant further investigation. All of these suggestions could help guide restoration and best management practices in these urbanization watersheds. 


\section{References}

Ahilan, S., M. Guan, A. Sleigh, N. Wright, and H. Chang. 2018. The influence of floodplain restoration on flow and sediment dynamics in an urban river. Journal of Flood Risk Management 11 (S2):S986-S1001.

Ahmadi-Nedushan, B., A. St-Hilaire, T. B. M. J. Ouarda, L. Bilodeau, É. Robichaud, N. Thiémonge, and B. Bobée. 2007. Predicting river water temperatures using stochastic models: case study of the Moisie River (Québec, Canada. Hydrological Processes 21 (1):21-34.

Arismendi, I., S. L. Johnson, J. B. Dunham, R. Haggerty, and D. Hockman-Wert. 2012. The paradox of cooling streams in a warming world: Regional climate trends do not parallel variable local trends in stream temperature in the Pacific continental United States. Geophysical Research Letters 39 (10):1-7

Arora, R., K. Tockner, and M. Venohr. 2016. Changing river temperatures in northern Germany: trends and drivers of change. Hydrological Processes 30 (17):30843096.

Arora, R., M. Toffolon, K. Tockner, and M. Venohr. 2018. Thermal discontinuities along a lowland river: The importance of urban areas and lakes. Journal of Hydrology 564:811-823.

Aulenbach, B. T., M. N. Landers, J. W. Musser, and J. A. Painter. 2017. Effects of Impervious Area and BMP Implementation and Design on Storm Runoff and Water Quality in Eight Small Watersheds. JAWRA Journal of the American Water Resources Association 53 (2):382-399.

Baker, D. B., R. P. Richards, T. T. Loftus, and J. W. Kramer. 2004. A new flashiness index: Characteristics and applications to midwestern rivers and streams. JAWRA Journal of the American Water Resources Association 40 (2):503-522.

Benyahya, L., D. Caissie, A. St-Hilaire, T. B. M. Ouarda, and B. Bobée. 2007. A Review of Statistical Water Temperature Models. Canadian Water Resources Journal 32 (3):179-192.

Bhaskar, A. S., L. Beesley, M. J. Burns, T. D. Fletcher, P. Hamel, C. E. Oldham, and A. H. Roy. 2016. Will it rise or will it fall? Managing the complex effects of urbanization on base flow. Freshwater Science 35 (1):293-310. 
Bond, J. 2018. Influence of Beaver Ponds on Errol Creek. http://www.jcwc.org/wpcontent/uploads/2018/10/02-Bond-Errol_Beaver_Ponds_JCSymposium2018.pdf.

Booth, D. B., K. A. Kraseski, and C. Rhett Jackson. 2014. Local-scale and watershedscale determinants of summertime urban stream temperatures. Hydrological Processes 28 (4):2427-2438.

Brans, K. I., J. M. T. Engelen, C. Souffreau, and L. De Meester. 2018. Urban hot-tubs: Local urbanization has profound effects on average and extreme temperatures in ponds. Landscape and Urban Planning 176:22-29.

Briggs, M. A., Z. C. Johnson, C. D. Snyder, N. P. Hitt, B. L. Kurylyk, L. Lautz, D. J. Irvine, S. T. Hurley, and J. W. Lane. 2018. Inferring watershed hydraulics and cold-water habitat persistence using multi-year air and stream temperature signals. Science of the Total Environment 636:1117-1127.

Bronaugh, D., and A. Werner. 2019. zyp. CRAN. https://www.r-project.org.

Bui, M. T., V. V. Kuzovlev, Y. N. Zhenikov, L. Füreder, J. Seidel, and M. Schletterer. 2018. Water temperatures in the headwaters of the Volga River: Trend analyses, possible future changes, and implications for a pan-European perspective. River Research and Applications 34 (6):495-505.

Caissie, D. 2006. The thermal regime of rivers: a review. Freshwater Biology 51 (8):1389-1406.

Caissie, D., N. El-Jabi, and M. G. Satish. 2001. Modelling of maximum daily water temperatures in a small stream using air temperatures. Journal of Hydrology 251 (1):14-28.

Caissie, D., N. El-Jabi, and A. St-Hilaire. 1998. Stochastic modelling of water temperatures in a small stream using air to water relations. Canadian Journal of Civil Engineering 25 (2):250-260.

Chang, H. 2007. Comparative streamflow characteristics in urbanizing basins in the Portland Metropolitan Area, Oregon, USA. Hydrological Processes 21 (2):211222.

Chang, H., I. Jung, M. Steele, and M. Gannett. 2012. Spatial Patterns of March and September Streamflow Trends in Pacific Northwest Streams, 1958-2008. Geographical Analysis 44 (3):177-201.

Chang, H., and M. Psaris. 2013. Local landscape predictors of maximum stream temperature and thermal sensitivity in the Columbia River Basin, USA. Science of the Total Environment 461-462:587-600. 
Chang, H., E. Watson, and A. Strecker. 2017. Climate Change and Stream Temperature in the Willamette River Basin: Implications for Fish Habitat. In Bridging Science and Policy Implication for Managing Climate Extremes, World Scientific Series on Asia-Pacific Weather and Climate., 119-132. World Scientific https://doi.org/10.1142/9789813235663_0008 (last accessed 6 June 2018).

Chen, D., M. Hu, Y. Guo, and R. A. Dahlgren. 2016a. Changes in river water temperature between 1980 and 2012 in Yongan watershed, eastern China: Magnitude, drivers and models. Journal of Hydrology 533 (C):191-199.

Chen, Q., K. Mei, R. A. Dahlgren, T. Wang, J. Gong, and M. Zhang. 2016b. Impacts of land use and population density on seasonal surface water quality using a modified geographically weighted regression. Science of the Total Environment $572(\mathrm{C}): 450-466$.

City of Portland. 2013. Johnson Creek Watershed History. Environmental Services. https://www.portlandoregon.gov/bes/article/214282 (last accessed 19 March 2019).

City of Portland. 2015. Johnson Creek Report Card. Environmental Services. https://www.portlandoregon.gov/bes/article/526738 (last accessed 19 March 2019).

Collier, K., and B. Clements. 2011. Influences of catchment and corridor imperviousness on urban stream macroinvertebrate communities at multiple spatial scales. Hydrobiologia 664 (1):35-50.

Cooley, A., and H. Chang. 2017. Precipitation Intensity Trend Detection using Hourly and Daily Observations in Portland, Oregon. Climate 5 (1). http://www.mdpi.com/2225-1154/5/1/10.

Culler, L. E., Z. T. Wood, J. Diaz, S. B. Fey, D. Timmins, and M. P. Ayres. 2018. Streams in an uninhabited watershed have predictably different thermal sensitivities to variable summer air temperatures. Freshwater Biology 63 (7):676686.

Erickson, T. R., and H. G. Stefan. 2000. Linear Air/Water Temperature Correlations for Streams during Open Water Periods. Journal of Hydrologic Engineering 5 (3):317-321.

Esterby, S. R. 1996. Review of methods for the detection and estimation of trends with emphasis on water quality applications. Hydrological Processes 10 (2):127-149.

Fast, R. 2018. Salmon Sanctuaries in Portland. http://www.jcwc.org/wpcontent/uploads/2018/10/06-Fast-Salmon-Sanctuaries-in-Portland_JCWC.pdf. 
Ferreira, C. S. S., R. P. D. Walsh, T. S. Steenhuis, and A. J. D. Ferreira. 2018. Effect of Peri-urban Development and Lithology on Streamflow in a Mediterranean Catchment. Land Degradation \& Development 29 (4):1141-1153.

Grabowski, Z. J., E. Watson, and H. Chang. 2016. Using spatially explicit indicators to investigate watershed characteristics and stream temperature relationships. Science of the Total Environment 551-552:376-386.

Gray, B. R., D. M. Robertson, and J. . Rogala. 2018. Effects of air temperature and discharge on Upper Mississippi River summer water temperatures. River Research and Applications 0 (0). https://onlinelibrary.wiley.com/doi/abs/10.1002/rra.3278.

Grimm, N. B., S. H. Faeth, N. E. Golubiewski, C. L. Redman, J. Wu, X. Bai, and J. M. Briggs. 2008. Global change and the ecology of cities. Science (New York, N.Y.) 319 (5864).

Hamed, K. H. 2008. Trend detection in hydrologic data: The Mann-Kendall trend test under the scaling hypothesis. Journal of Hydrology 349 (3-4):350-363.

Henshaw, A. J., A. M. Gurnell, W. Bertoldi, and N. A. Drake. 2013. An assessment of the degree to which Landsat TM data can support the assessment of fluvial dynamics, as revealed by changes in vegetation extent and channel position, along a large river. Geomorphology 202:74-85.

Hilderbrand, R., M. Kashiwagi, and A. Prochaska. 2014. Regional and Local Scale Modeling of Stream Temperatures and Spatio-Temporal Variation in Thermal Sensitivities. Environmental Management 54 (1):14-22.

Holzer, K. 2018. Are all dams created equal? Comparison of the effects of human and beaver dams in Johnson Creek in Gresham. http://www.jcwc.org/wpcontent/uploads/2018/10/01-Holzer-JCWC-Science-Symposium-2018-BeaverDam-Temps.pdf.

Homer, C., J. Dewitz, L. Yang, S. Jin, P. Danielson, G. Xian, J. Coulston, N. Herold, J. Wickham, and K. Megown. 2015. Completion of the 2011 National Land Cover Database for the Conterminous United States - Representing a Decade of Land Cover Change Information. Photogrammetric Engineering \& Remote Sensing 81 (5):345-354.

Honea, J. M., M. M. McClure, J. C. Jorgensen, and M. D. Scheuerell. 2016. Assessing freshwater life-stage vulnerability of an endangered Chinook salmon population to climate change influences on stream habitat. Climate Research 71:127-137. 
Huang, J., and V. Klemas. 2012. Using remote sensing of land cover change in coastal watersheds to predict downstream water quality. Journal of Coastal Research 28 (4).

Isaak, D. J., C. H. Luce, B. E. Rieman, D. E. Nagel, E. E. Peterson, D. L. Horan, S. Parkes, and G. L. Chandler. 2010. Effects of climate change and wildfire on stream temperatures and salmonid thermal habitat in a mountain river network. Ecological Applications 20 (5):1350-1371.

Jackson, F. L., R. J. Fryer, D. M. Hannah, and I. A. Malcolm. 2017. Can spatial statistical river temperature models be transferred between catchments?(Report)(Author abstract). Hydrology and Earth System Sciences 21 (9).

Jackson, F. L., D. M. Hannah, R. J. Fryer, C. P. Millar, and I. A. Malcolm. 2016. Development of spatial regression models for predicting summer river temperatures from landscape characteristics: Implications for land and fisheries management. Hydrological Processes 31 (6):1225-1238.

Jarchow, C. J., P. L. Nagler, and E. P. Glenn. 2017. Greenup and evapotranspiration following the Minute 319 pulse flow to Mexico: An analysis using Landsat 8 Normalized Difference Vegetation Index (NDVI) data.(Report). Ecological Engineering 106 (PB).

Jarrad, M. 2016. Johnson Creek Restoration Sites 1990-2014. https://doi.org/10.7910/DVN/L4DDCR.

Jennings, D., and S. Jarnagin. 2002. Changes in anthropogenic impervious surfaces, precipitation and daily streamflow discharge: a historical perspective in a midatlantic subwatershed. Landscape Ecology 17 (5):471-489.

Johnson, M. F., and R. L. Wilby. 2015. Seeing the landscape for the trees: Metrics to guide riparian shade management in river catchments. Water Resources Research $51(5): 3754-3769$.

Johnson, T. E., J. N. Mcnair, P. Srivastava, and D. D. Hart. 2007. Stream ecosystem responses to spatially variable land cover: an empirically based model for developing riparian restoration strategies. Freshwater Biology 52 (4):680-695.

Kaushal, S., and K. Belt. 2012. The urban watershed continuum: evolving spatial and temporal dimensions. Urban Ecosystems 15 (2):409-435.

Kaushal, S. S., G. E. Likens, N. A. Jaworski, M. L. Pace, A. M. Sides, D. Seekell, K. T. Belt, D. H. Secor, and R. L. Wingate. 2010. Rising stream and river temperatures in the United States. Frontiers in Ecology and the Environment 8 (9):461-466. 
Kelleher, C., T. Wagener, M. Gooseff, B. Mcglynn, K. Mcguire, and L. Marshall. 2012. Investigating controls on the thermal sensitivity of Pennsylvania streams. Hydrological Processes 26 (5):771-785.

Khaliq, M. N., T. B. M. J. Ouarda, and P. Gachon. 2009. Identification of temporal trends in annual and seasonal low flows occurring in Canadian rivers: The effect of short- and long-term persistence. Journal of Hydrology 369 (1):183-197.

Konrad, C. P., D. B. Booth, and S. J. Burges. 2005. Effects of urban development in the Puget Lowland, Washington, on interannual streamflow patterns: Consequences for channel form and streambed disturbance. Water Resources Research 41 (7):n/a-n/a.

Konrad, C. P. (Christopher P. 2003. Effects of urban development on floods. Reston, Va.?]: U.S. Dept. of the Interior, U.S. Geological Survey.

Lee, K. K., and D. Snyder. 2009. Hydrology of the Johnson Creek Basin, Oregon. Reston, Va.: U.S. Dept. of the Interior, U.S. Geological Survey.

Levell, A. P., and H. Chang. 2008. Monitoring the channel process of a stream restoration project in an urbanizing watershed: a case study of Kelley Creek, Oregon, USA. River Research and Applications 24 (2):169-182.

Lins, H. F., and J. R. Slack. 1999. Streamflow trends in the United States. Geophysical Research Letters 26 (2):227-230.

Mainali, J., and H. Chang. 2018. Landscape and anthropogenic factors affecting spatial patterns of water quality trends in a large river basin, South Korea. Journal of Hydrology 564:26-40.

Mantua, N., I. Tohver, and A. Hamlet. 2010. Climate change impacts on streamflow extremes and summertime stream temperature and their possible consequences for freshwater salmon habitat in Washington State. Climatic Change 102 (1):187223.

Mayer, T. D. 2012. Controls of summer stream temperature in the Pacific Northwest. Journal of Hydrology 475:323-335.

Mcgrane, S. J. 2016. Impacts of urbanisation on hydrological and water quality dynamics, and urban water management: a review. Hydrological Sciences Journal 61 (13):2295-2311.

Mcgrath, E. O., N. N. Neumann, and C. F. Nichol. 2017. A Statistical Model for Managing Water Temperature in Streams with Anthropogenic Influences. River Research and Applications 33 (1):123-134. 
Meier, W., C. Bonjour, A. Wuest, and P. Reichert. 2003. Modeling the effect of water diversion on the temperature of mountain streams. Journal of Environmental Engineering 129 (8).

Merriam, E. R., R. Fernandez, J. T. Petty, and N. Zegre. 2017. Can brook trout survive climate change in large rivers? If it rains. Science of the Total Environment 607608:1225-1236.

Mohseni, O., T. R. Erickson, and H. G. Stefan. 2002. Upper bounds for stream temperatures in the contiguous United States.(Abstract). Journal of Environmental Engineering 128 (1).

Mohseni, O., H. Stefan, and T. Erickson. 1998. A nonlinear regression model for weekly stream temperatures. Water Resources Research 34 (10):2685-2692.

Molinero, J., A. Larrañaga, J. Pérez, A. Martínez, and J. Pozo. 2016. Stream temperature in the Basque Mountains during winter: thermal regimes and sensitivity to air warming. Climatic Change 134 (4):593-604.

Morrill, J., R. Bales, and M. Conklin. 2005. Estimating stream temperature from air temperature: Implications for future water quality. http://www.escholarship.org/uc/item/7k4804k7.

Naresh, A., and S. Rehana. 2017. Modeling stream water temperature using regression analysis with air temperature and streamflow over Krisha River. International Journal of Engineering Technology Science and Research 4 (11).

Nelson, K. C., and M. A. Palmer. 2007. Stream Temperature Surges Under Urbanization and Climate Change: Data, Models, and Responses. JAWRA Journal of the American Water Resources Association 43 (2):440-452.

Norman, L., M. Villarreal, H. R. Pulliam, R. Minckley, L. Gass, C. Tolle, and M. Coe. 2014. Remote sensing analysis of riparian vegetation response to desert marsh restoration in the Mexican Highlands. Ecological Engineering 70:241-254.

Ogden, F. L., N. Raj Pradhan, C. W. Downer, and J. A. Zahner. 2011. Relative importance of impervious area, drainage density, width function, and subsurface storm drainage on flood runoff from an urbanized catchment. Water Resources Research 47 (12):n/a-n/a.

Oregon Department of Environmental Quality. 2006. Willamette Basin TMDL. https://www.oregon.gov/deq/wq/tmdls/Pages/TMDLs-Willamette-Basin.aspx (last accessed 31 August 2018). 
Paul, M. J., and J. L. Meyer. 2001. Streams in the urban landscape.(Statistical Data Included). Annual Review of Ecology and Systematics 32.

Pennino, M. J., R. I. Mcdonald, and P. R. Jaffe. 2016. Watershed-scale impacts of stormwater green infrastructure on hydrology, nutrient fluxes, and combined sewer overflows in the mid-Atlantic region. Science of the Total Environment 565:1044-1053.

Pickett, S. T. A., M. L. Cadenasso, J. M. Grove, C. H. Nilon, R. V. Pouyat, W. C. Zipperer, and R. Costanza. 2001. Urban Ecological Systems: Linking Terrestrial Ecological, Physical, and Socioeconomic Components of Metropolitan Areas. Annual Review of Ecology and Systematics 32:127-157.

Pilgrim, J. M., X. Fang, and H. G. Stefan. 1998. Stream temperature correlations with air temperatures in Minnesota: Implicatios for Climate Warming. JAWRA Journal of the American Water Resources Association 34 (5):1109-1121.

Piotrowski, A. P., and J. J. Napiorkowski. 2019. Simple modifications of the nonlinear regression stream temperature model for daily data. Journal of Hydrology 572:308-328.

Poff, N. 1996. A hydrogeography of unregulated streams in the United States and an examination of scale-dependence in some hydrological descriptors. Freshwater Biology 36 (1):71-79.

Poff, N. L., J. D. Allan, M. B. Bain, J. R. Karr, K. L. Prestegaard, B. D. Richter, R. E. Sparks, and J. C. Stromberg. 1997. The Natural Flow Regime. BioScience 47 (11):769-784.

Population Research Center, 2019. 2000 and 2010 Census Profile Portland-VancouverHillsboro MSA.

Pratt, B., and H. Chang. 2012. Effects of land cover, topography, and built structure on seasonal water quality at multiple spatial scales. Journal of Hazardous Materials 209-210:48-58.

Price, K. 2011. Effects of watershed topography, soils, land use, and climate on baseflow hydrology in humid regions: A review. Progress in Physical Geography 35 (4):465-492.

Prudencio, L., and S. E. Null. 2018. Stormwater management and ecosystem services: a review. Environmental Research Letters 13 (3):1-13.

R Core Team. 2018. R: A Language and Environmental for Statistical Computing. Vienna, Austria: R Foundation for Statistical Computing. https://www.Rproject.org/. 
Rana, A., H. Moradkhani, and Y. Qin. 2017. Understanding the joint behavior of temperature and precipitation for climate change impact studies. Theoretical and Applied Climatology 129 (1):321-339.

Razavi, S., and R. Vogel. 2018. Prewhitening of hydroclimatic time series? Implications for inferred change and variability across time scales. Journal of Hydrology 557:109-115.

Sahoo, D., and P. K. Smith. 2009. Hydroclimatic trend detection in a rapidly urbanizing semi-arid and coastal river basin. Journal of Hydrology 367 (3):217-227.

Somers, K. A., E. S. Bernhardt, J. B. Grace, B. A. Hassett, E. B. Sudduth, S. Wang, and D. L. Urban. Streams in the urban heat island: spatial and temporal variability in temperature. Freshwater Science 32 (1):309-326.

Sun, N., J. Yearsley, N. Voisin, and D. P. Lettenmaier. 2015. A spatially distributed model for the assessment of land use impacts on stream temperature in small urban watersheds. Hydrological Processes 29 (10):2331-2345.

Sun, Y., Q. Guo, J. Liu, and R. Wang. 2014. Scale Effects on Spatially Varying Relationships Between Urban Landscape Patterns and Water Quality. Environmental Management 54 (2):272-287.

Taka, M., J. Aalto, and M. Luoto. 2015. Spatial modelling of stream water quality along an urban-rural gradient. Geografiska Annaler: Series A, Physical Geography 97 (4):819-834.

Tu, J. 2011. Spatially varying relationships between land use and water quality across an urbanization gradient explored by geographically weighted regression. Applied Geography 31 (1):376-392.

United Nations. 2014. World Urbanization Prospects: The 2014 Revision, Highlights. https://esa.un.org/unpd/wup/publications/files/wup2014-highlights.pdf.

U.S. Geological Survey. 2012. Water-resources data for the United States, Water Year 2011: U.S. Geological Survey Water-Data Report WDR-US-2011, site 14211550, accessed at http://wdr.water.usgs.gov/wy2011/pdfs/14211550.2011.pdf

U.S. Geological Survey. 2008. Water-resources data for the United States, Water Year 2008: U.S. Geological Survey Water-Data Report WDR-US-2008, site 14207500, accessed at https://wdr.water.usgs.gov/wy2008/pdfs/14207500.2008.pdf

Van Vliet, M. T. H., F. Ludwig, J. J. G. Zwolsman, G. P. Weedon, and P. Kabat. 2011. Global river temperatures and sensitivity to atmospheric warming and changes in river flow. Water Resources Research 47 (2):n/a-n/a. 
Velpuri, N. M., and G. B. Senay. 2013. Analysis of long-term trends (1950-2009) in precipitation, runoff and runoff coefficient in major urban watersheds in the United States. Environmental Research Letters 8 (2).

Walsh, C. J., A. H. Roy, J. W. Feminella, P. D. Cottingham, P. M. Groffman, and R. P. Morgan. 2005. The urban stream syndrome: current knowledge and the search for a cure. Journal of the North American Benthological Society 24 (3):706-723.

Watson, E., and H. Chang. 2018. Relation Between Stream Temperature and Landscape Characteristics Using Distance Weighted Metrics. Water Resources Management 32 (3):1167-1192.

Webb, B. W., P. D. Clack, and D. E. Walling. 2003. Water-air temperature relationships in a Devon river system and the role of flow. Hydrological Processes 17 (15):3069-3084.

Webb, B. W., and F. Nobilis. 2007. Long-term changes in river temperature and the influence of climatic and hydrological factors. Hydrological Sciences Journal 52 (1):74-85.

Western Regional Climate Center. Hillsboro, Oregon NDCD 1981-2010 Normals. https://wrcc.dri.edu/cgi-bin/cliMAIN.pl?or3908 (last accessed 16 May 2019).

Western Regional Climate Center. Portland Intl Ap, Oregon NDCD 1981-2010 Normals. https://wrcc.dri.edu/cgi-bin/cliMAIN.pl?or6751 (last accessed 16 May 2019).

Wilson, N. R., and L. M. Norman. 2018. Analysis of vegetation recovery surrounding a restored wetland using the normalized difference infrared index (NDII) and normalized difference vegetation index (NDVI). International Journal of Remote Sensing 39 (10):3243-3274.

Winfree, M. M., E. Hood, S. L. Stuefer, D. E. Schindler, T. J. Cline, C. D. Arp, and S. Pyare. 2018. Landcover and geomorphology influence streamwater temperature sensitivity in salmon bearing watersheds in Southeast Alaska. Environmental Research Letters 13 (6):064034.

Woltemade, C. J., and T. W. Hawkins. 2016. Stream Temperature Impacts Because of Changes in Air Temperature, Land Cover and Stream Discharge: Navarro River Watershed, California, USA. River Research and Applications 32 (10):20202031.

Woltemade, C. J. 2017. Stream Temperature Spatial Variability Reflects Geomorphology, Hydrology, and Microclimate: Navarro River Watershed, California. The Professional Geographer 69 (2):177-190. 
Wondzell, S. M., M. Diabat, and R. Haggerty. 2019. What Matters Most: Are Future Stream Temperatures More Sensitive to Changing Air Temperatures, Discharge, or Riparian Vegetation? Journal of the American Water Resources Association 55 (1).

Xian, G., C. Homer, J. Demitz, J. Fry, N. Hossain, and J. Wickham. 2011. Change of Impervious Surface Area Between 2001 and 2006 in the Conterminous United States. Photogrammetric Engineering And Remote Sensing 77 (8):758-762.

Yue, S., P. Pilon, and G. Cavadias. 2002. Power of the Mann-Kendall and Spearman's rho tests for detecting monotonic trends in hydrological series. Journal of Hydrology 259 (1):254-271.

Yue, S., P. Pilon, B. Phinney, and G. Cavadias. 2002. The influence of autocorrelation on the ability to detect trend in hydrological series. Hydrological Processes 16 (9):1807-1829.

Zambrano-Bigiarnini, M. 2017. hydroGOF. CRAN. http://hzambran.github.io/hydroGOF/. 


\section{Appendix: Mann-Kendall trend analyses for entire period of record}

A1: Mann-Kendall test results for 7 -day moving average of daily maximum temperature for the entire period of record. $\tau$ values in red indicate a statistically significant increasing trend and values in blue indicate a statistically significant decreasing trend. $\mathrm{p}$ is significance level where values are significant at $* 0.10, * * 0.05$, and $* * * 0.01$, respectively.

\begin{tabular}{lcccccccccccc}
\hline & & Jun & & Jul & & Aug & & \multicolumn{2}{c}{ Sep } & & \multicolumn{2}{c}{ Year } \\
\hline Sites & $\tau$ & & $\mathrm{p}$ & $\mathrm{T}$ & $\mathrm{p}$ & $\tau$ & $\mathrm{p}$ & $\tau$ & $\mathrm{p}$ & $\tau$ & $\mathrm{p}$ \\
\hline 7DADmax & & & & & & & & & & & & \\
\hline
\end{tabular}

Johnson Creek

\begin{tabular}{|c|c|c|c|c|c|c|c|c|c|}
\hline Regner Rd & 0.25 & 0.39 & $* *$ & 0.51 & $* * *$ & 0.54 & $* * *$ & 0.53 & $* * *$ \\
\hline Kelley Cr & 0.22 & 0.22 & & 0.2 & & 0.07 & & 0.21 & \\
\hline Sycamore & $0.36 * *$ & 0.6 & $* * *$ & 0.51 & $* * *$ & 0.57 & $* * *$ & 0.58 & $* * *$ \\
\hline Milwaukie & -0.13 & -0.1 & & -0.22 & & -0.31 & $*$ & -0.15 & \\
\hline \multicolumn{10}{|l|}{ Tualatin River } \\
\hline BronsonCr @ 205 & - & - & & -0.6 & $* * *$ & -0.27 & & - & \\
\hline $\begin{array}{l}\text { Bronson Cr@Bronson } \\
\text { Rd }\end{array}$ & - & - & & 0.03 & & -0.21 & & - & \\
\hline $\begin{array}{l}\text { Bronson Cr@ West } \\
\text { Union }\end{array}$ & - & - & & -0.33 & & -0.29 & & - & \\
\hline BronsonCr@Saltzman & - & - & & -0.2 & & -0.22 & & - & \\
\hline WillowCr@143 & - & - & & 0.11 & & -0.17 & & - & \\
\hline ChickenCr@Scholl’s & - & - & & -0.27 & & -0.49 & $* *$ & - & \\
\hline $\begin{array}{l}\text { Hedges Cr@ Tualatin } \\
\text { PCC }\end{array}$ & - & - & & 0.28 & & 0.28 & & - & \\
\hline AshCr@Hemlock & - & - & & 0.33 & & -0.06 & & - & \\
\hline $\begin{array}{l}\text { Dawson Cr @ } \\
\text { Brookwood }\end{array}$ & - & - & & 0.03 & & -0.1 & & - & \\
\hline Bannister Cr@ $124^{\text {th }}$ & - & - & & 0.13 & & 0.24 & & - & \\
\hline Saum Cr@Borland Rd & - & - & & 0.16 & & -0.02 & & - & \\
\hline Scoggins $\mathrm{Cr}$ & 0.1 & 0.03 & & 0 & & 0.08 & & -0.13 & \\
\hline Fanno Cr Durham & 0.18 & 0.18 & & 0.5 & $* * *$ & 0.33 & $*$ & 0.33 & $*$ \\
\hline Oswego Dam & 0.08 & 0.05 & & 0.03 & & 0.23 & $*$ & 0 & \\
\hline
\end{tabular}


A2: Mann-Kendall test results for 7 -day moving average of daily minimum temperature for the entire period of record. $\tau$ values in red indicate a significant increasing trend and values in blue indicate a significant decreasing trend. $\mathrm{p}$ is significance level where values are significant at $* 0.10, * * 0.05$, $* * * 0.01$

\begin{tabular}{|c|c|c|c|c|c|c|c|c|}
\hline \multirow[b]{2}{*}{ Sites } & Jun & \multicolumn{2}{|c|}{ Jul } & \multicolumn{2}{|c|}{ Aug } & \multicolumn{2}{|c|}{ Sep } & Year \\
\hline & $\mathrm{p}$ & $\tau$ & $\mathrm{p}$ & $\tau$ & $\mathrm{p}$ & $\tau$ & $\mathrm{p}$ & $\tau$ \\
\hline \multicolumn{9}{|l|}{ 7DADmin } \\
\hline \multicolumn{9}{|l|}{ Johnson Creek } \\
\hline Regner Rd & 0.17 & 0.32 & $*$ & 0.33 & $* *$ & 0.31 & $*$ & -0.16 \\
\hline Kelley Cr & -0.03 & 0.23 & & 0.07 & & -0.06 & & -0.07 \\
\hline Sycamore & 0.24 & 0.42 & $* * *$ & 0.51 & $* * *$ & 0.44 & $* * *$ & -0.18 \\
\hline Milwaukie & 0.08 & 0.16 & & 0.15 & & 0.31 & $*$ & -0.19 \\
\hline \multicolumn{9}{|l|}{ Tualatin River } \\
\hline Bronson Cr @ 205th & - & - & & 0.35 & & 0.13 & & - \\
\hline Bronson Cr@ Bronson Rd & - & - & & -0.18 & & 0.23 & & - \\
\hline Bronson Cr @ West Union & - & - & & 0.20 & & 0.07 & & - \\
\hline BronsonCr@Saltzman & - & - & & -0.14 & & -0.12 & & - \\
\hline Willow Cr @ 143rd & - & - & & -0.89 & $* * *$ & 0.17 & & - \\
\hline ChickenCr@Scholl’s & - & - & & -0.45 & $*$ & 0.05 & & - \\
\hline Hedges Cr@ Tualatin PCC & - & - & & -0.61 & $* *$ & 0.11 & & - \\
\hline Ash Cr@ Hemlock & - & - & & 0.22 & & 0.39 & & - \\
\hline DawsonCr@Brookwood & - & - & & 0.36 & $*$ & 0.60 & $* * *$ & - \\
\hline Bannister Cr @ 124th & - & - & & 0.20 & & 0.13 & & - \\
\hline Saum Cr@Borland Rd & - & - & & -0.24 & & 0.16 & & - \\
\hline Scoggins $\mathrm{Cr}$ & 0.20 & 0.20 & & 0.20 & & 0.03 & & 0.03 \\
\hline Fanno Cr@Durham & 0.28 & 0.20 & & 0.20 & & 0.30 & & 0.09 \\
\hline Oswego Dam & 0.11 & 0.32 & $* *$ & 0.49 & $* * *$ & 0.12 & & -0.07 \\
\hline
\end{tabular}


A3: Mann-Kendall test results for the total number of days above $17.8 \mathrm{C}$ for the entire period of record. $\tau$ values in red indicate a significant increasing trend and values in blue indicate a significant decreasing trend. $\mathrm{p}$ is significance level where values are significant at $* 0.10, * * 0.05, * * * 0.01$

\begin{tabular}{lccccccccccccc}
\hline & Jun & & Jul & & Aug & & Sep & & \multicolumn{2}{c}{ Year } \\
\hline Sites & $\tau$ & $\mathrm{p}$ & $\tau$ & $\mathrm{p}$ & $\tau$ & $\mathrm{p}$ & $\tau$ & $\mathrm{p}$ & & $\tau$ & $\mathrm{p}$ \\
\hline \# of Days above 17.8 C & & & & & & & & & & & & \\
\hline
\end{tabular}

Johnson Creek

\begin{tabular}{|c|c|c|c|c|c|c|c|c|}
\hline Regner Rd & 0.20 & 0.15 & 0.43 & $* * *$ & 0.52 & $* * *$ & 0.44 & $* * *$ \\
\hline Kelley Cr & 0.18 & 0.07 & 0.08 & & 0.12 & & 0.05 & \\
\hline Sycamore & $0.28 *$ & 0.13 & 0.22 & & 0.47 & $* * *$ & 0.60 & $* * *$ \\
\hline Milwaukie & 0.03 & 0.14 & 0.03 & & -0.38 & $* *$ & 0 & \\
\hline \multicolumn{9}{|l|}{ Tualatin River } \\
\hline BronsonCr@205th & - & - & 0.33 & & -0.24 & & - & \\
\hline Bronson Cr@ Bronson Rd & - & - & -0.19 & & 0.08 & & - & \\
\hline Bronson Cr@ West Union & - & - & -0.24 & & -0.29 & & - & \\
\hline BronsonCr@Saltzman & - & - & -0.52 & $* * *$ & -0.19 & & - & \\
\hline Willow Cr@143rd & - & - & -0.56 & $*$ & 0.28 & & - & \\
\hline ChickenCr@Scholl’s & - & - & -0.13 & & -0.31 & & - & \\
\hline Hedges Cr@ Tualatin PCC & - & - & 0.11 & & 0.33 & & - & \\
\hline Ash Cr@Hemlock & - & - & 0.28 & & 0.22 & & - & \\
\hline DawsonCr@Brookwood & - & - & 0.02 & & 0.01 & & - & \\
\hline Bannister Cr@124th & - & - & -0.04 & & - & & - & \\
\hline Saum Cr@ Borland Rd & - & - & 0.13 & & - & & - & \\
\hline Scoggins $\mathrm{Cr}$ & - & - & - & & 0.05 & & -0.12 & \\
\hline Fanno Cr @ Durham & 0.28 & 0.06 & 0.36 & $*$ & 0.26 & & 0.41 & $* *$ \\
\hline Oswego Dam & 0.13 & 0.17 & - & & 0.08 & & 0.10 & \\
\hline
\end{tabular}


A3: Mann-Kendall test results for thermal flashiness for the entire period of record. $\tau$ values in red indicate a significant increasing trend and values in blue indicate a significant decreasing trend. $p$ is significance level where values are significant at $* 0.10, * * 0.05, * * * 0.01$

\begin{tabular}{|c|c|c|c|c|c|c|c|c|c|c|}
\hline \multirow[b]{2}{*}{ Sites } & \multicolumn{2}{|c|}{ Jun } & \multicolumn{2}{|c|}{ Jul } & \multicolumn{2}{|c|}{ Aug } & \multicolumn{2}{|c|}{ Sep } & \multicolumn{2}{|c|}{ Year } \\
\hline & $\tau$ & $\mathrm{p}$ & $\tau$ & $\mathrm{p}$ & $\tau$ & $\mathrm{p}$ & $\tau$ & $\mathrm{p}$ & $\tau$ & $\mathrm{p}$ \\
\hline
\end{tabular}

Johnson Creek

\begin{tabular}{cccccc}
\hline Regner Rd. & 0.04 & 0.18 & 0.13 & $-0.32 *$ & -0.10 \\
\hline Kelley Cr. & 0.01 & 0.06 & -0.10 & -0.15 & 0.04 \\
\hline Sycamore & -0.08 & -0.21 & -0.06 & $-0.36 * *$ & -0.17 \\
Milwaukie & $-0.33 * *$ & -0.13 & -0.23 & $-0.54 * * *$ & -0.17 \\
\hline Tualatin River & & & & & \\
\hline Scoggins Cr & -0.27 & -0.02 & -0.05 & -0.02 & -0.30 \\
\hline Fanno Cr @ Durham & 0.12 & -0.07 & -0.16 & -0.03 & -0.09 \\
\hline Oswego Dam & -0.17 & -0.21 & $-0.30 * *$ & -0.11 & -0.07 \\
\hline
\end{tabular}


A4: Mann-Kendall test results for baseflow index for the entire period of record. $\tau$ values in red indicate a significant increasing trend and values in blue indicate a significant decreasing trend. $\mathrm{p}$ is significance level where values are significant at $* 0.10, * * 0.05, * * * 0.01$

\begin{tabular}{|c|c|c|c|c|c|c|c|c|c|c|}
\hline \multirow[b]{2}{*}{ Sites } & \multicolumn{2}{|c|}{ Jun } & \multicolumn{2}{|c|}{ Jul } & \multicolumn{2}{|c|}{ Aug } & \multicolumn{2}{|c|}{ Sep } & \multicolumn{2}{|c|}{ Year } \\
\hline & $\tau$ & $\mathrm{p}$ & $\tau$ & $\mathrm{p}$ & $\tau$ & $\mathrm{p}$ & $\tau$ & $\mathrm{p}$ & $\tau$ & $\mathrm{p}$ \\
\hline
\end{tabular}

Johnson Creek

\begin{tabular}{ccccccc}
\hline Regner Rd & 0.15 & 0.25 & 0.12 & 0.04 & 0.09 \\
\hline Kelley Cr & -0.53 & $* * *$ & $-0.46 * * *$ & 0.23 & 0.18 & $-0.44 * * *$ \\
\hline Sycamore & -0.06 & 0.02 & -0.06 & -0.26 & $* * *$ & $0.14 *$ \\
Milwaukie & 0.08 & $0.32 * *$ & 0.06 & -0.03 & -0.03 \\
\hline
\end{tabular}

\section{Tualatin River}

\begin{tabular}{|c|c|c|c|c|c|c|c|c|c|c|}
\hline Scoggins $\mathrm{Cr}$ & -0.39 & $* * *$ & 0.02 & & -0.08 & & 0.14 & & -0.30 & $* *$ \\
\hline Dilley & 0.14 & $*$ & 0.27 & $* * *$ & 0.23 & $* * *$ & 0.32 & $* * *$ & 0.49 & $* * *$ \\
\hline FannoCr@Durham & -0.28 & & -0.22 & & 0.15 & & -0.07 & & -0.74 & $* * *$ \\
\hline Fanno $\mathrm{Cr}$ at 56th & -0.33 & $* *$ & -0.19 & & -0.36 & $* * *$ & -0.36 & $* * *$ & -0.53 & $* * *$ \\
\hline Oswego Dam & 0.20 & $* * *$ & 0.44 & $* * *$ & 0.28 & $* * *$ & 0.30 & $* * *$ & 0.45 & $* * *$ \\
\hline
\end{tabular}




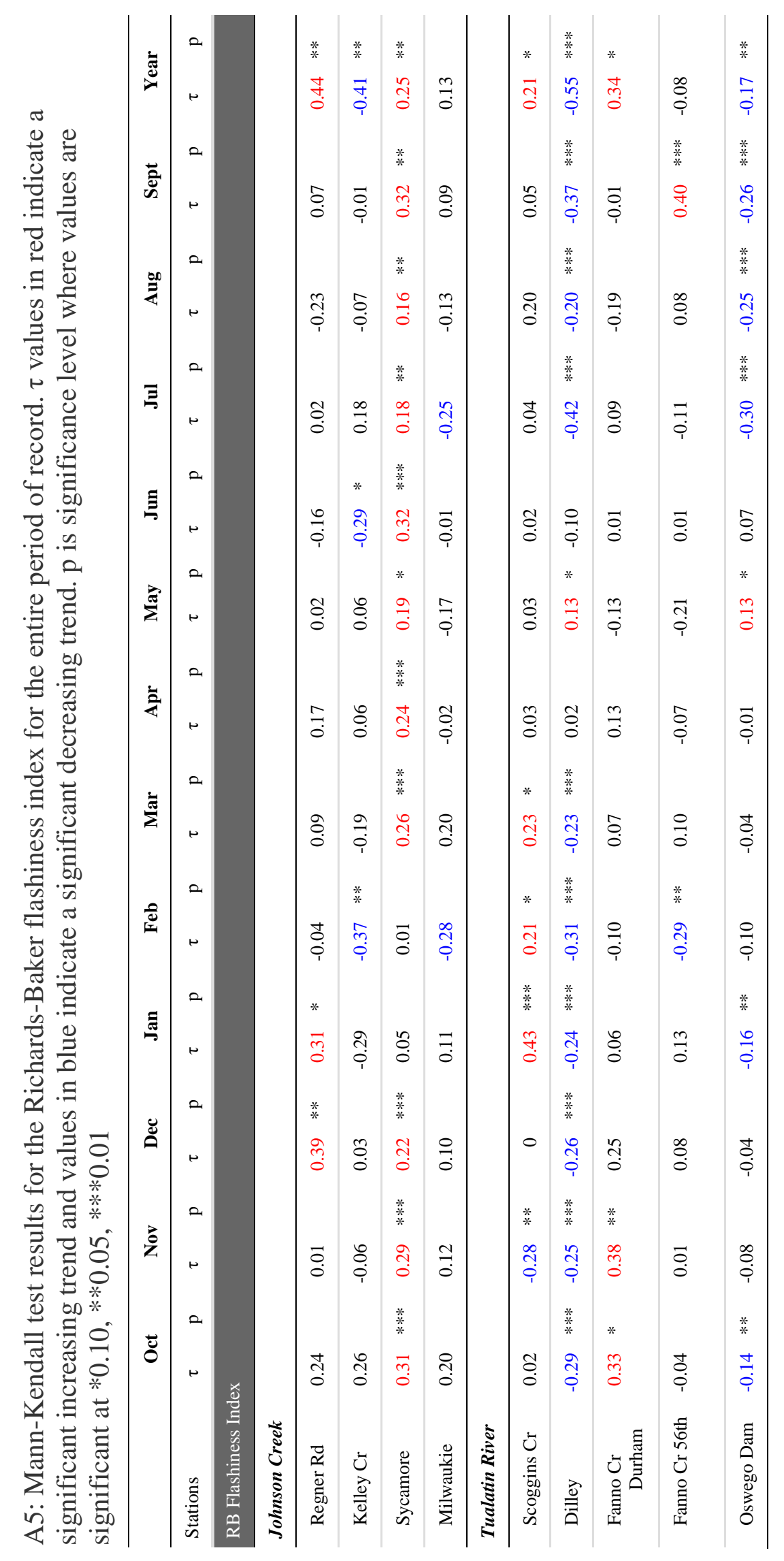




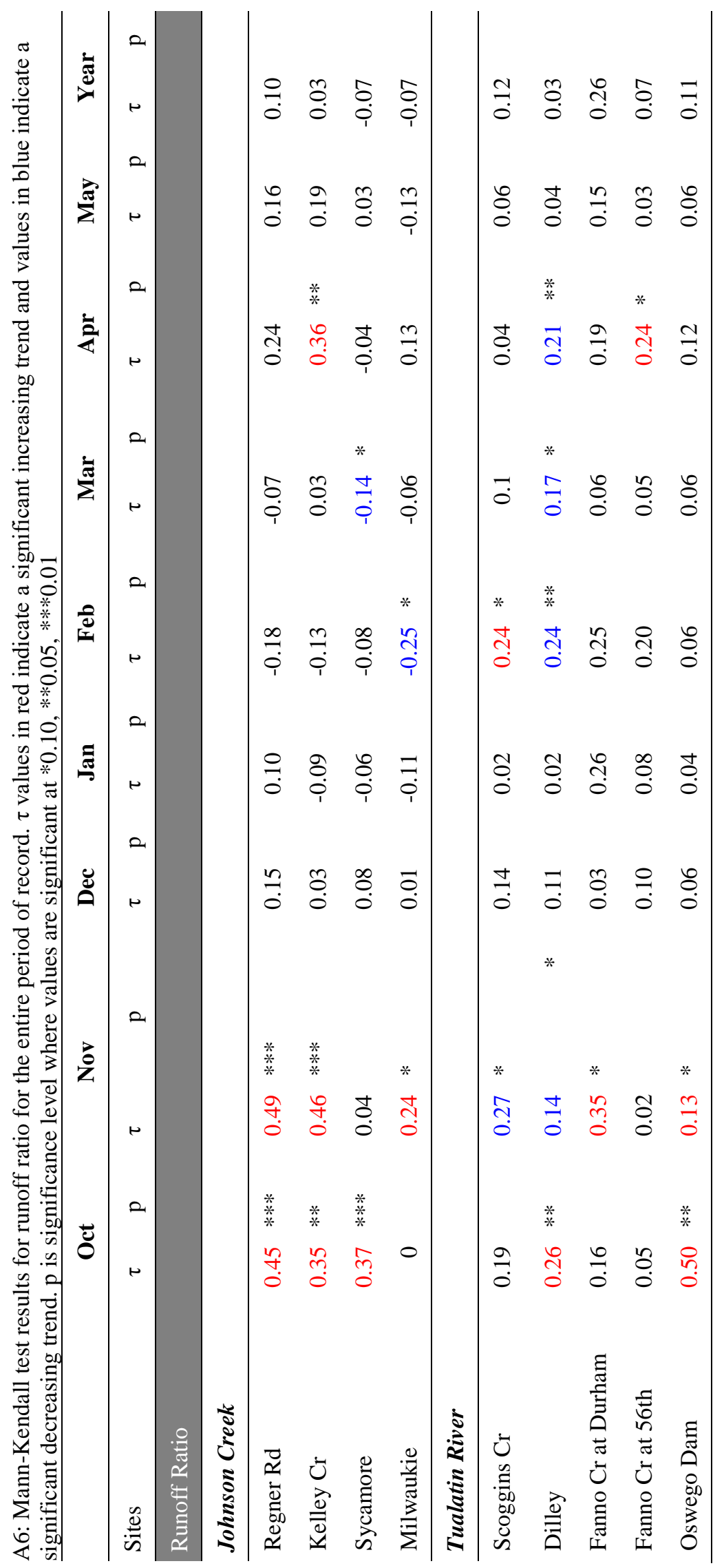




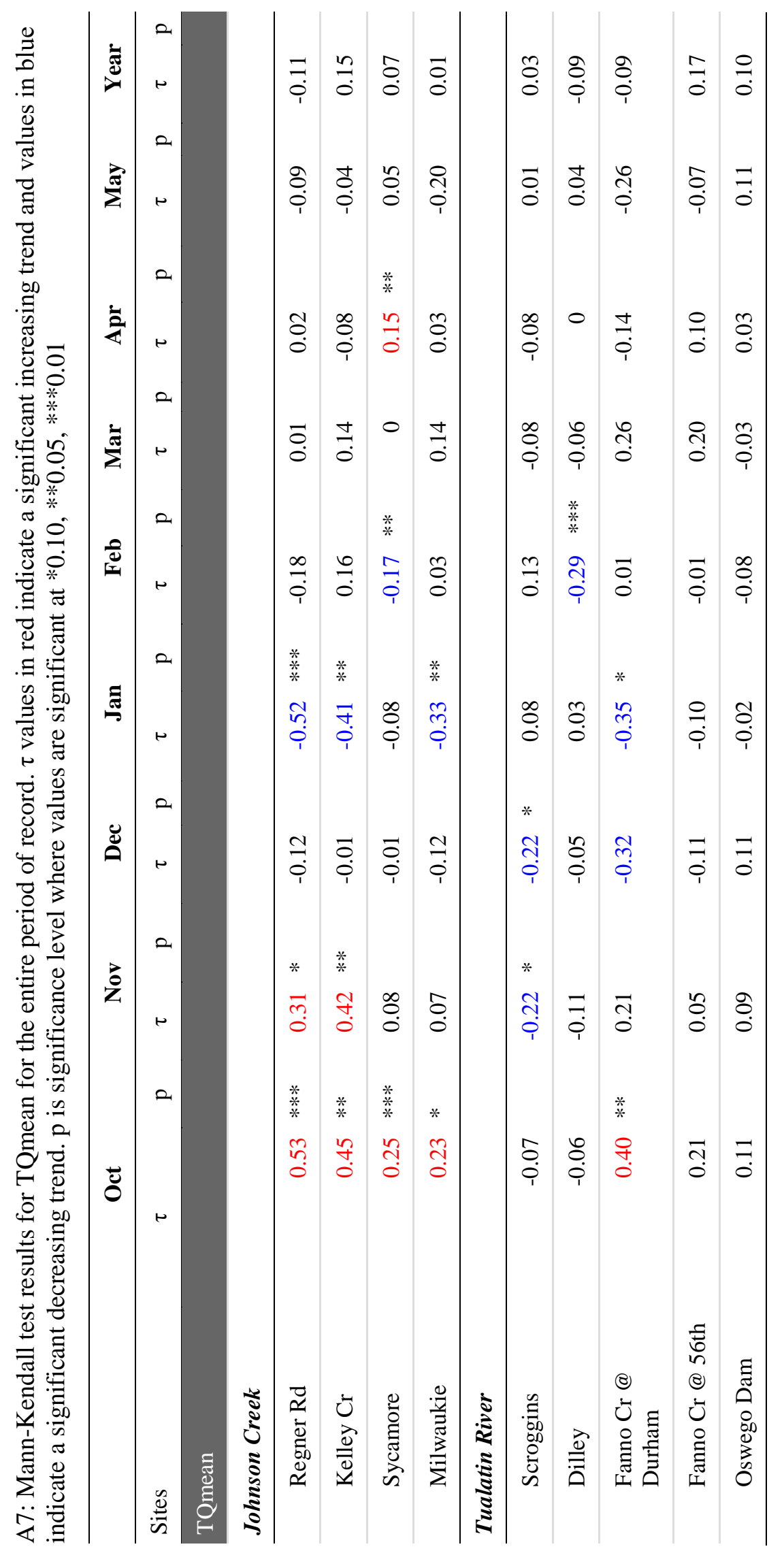




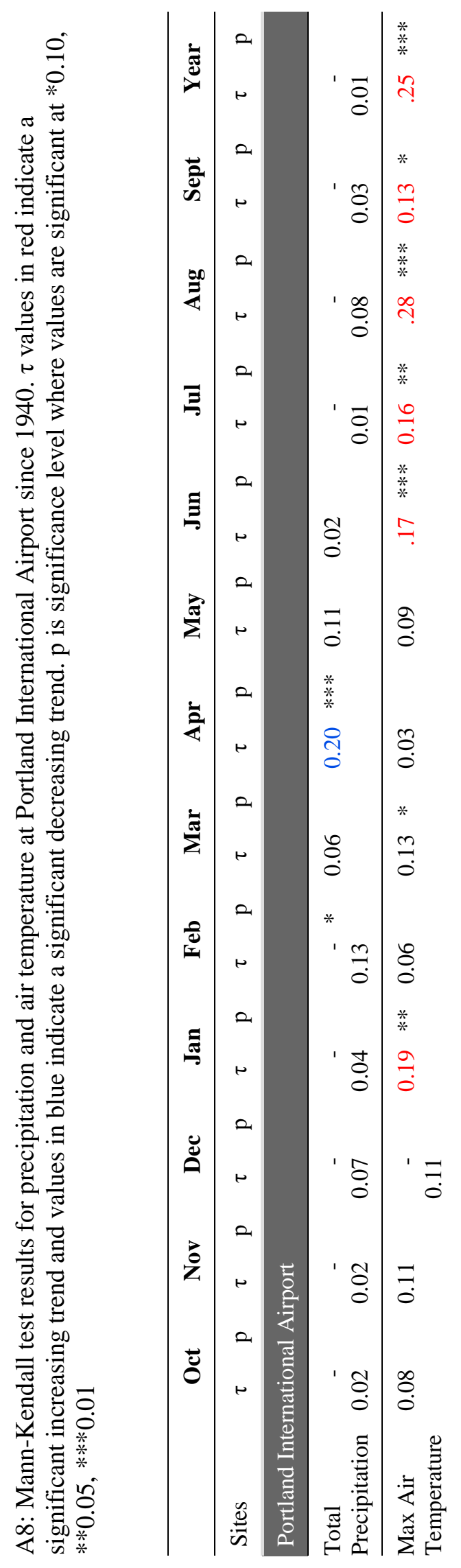

